La Psicología Jurídica como una Fuente Interdisciplinaria del Derecho en Colombia

Trabajo de grado

María Isabel Cuartas Giraldo

Óscar Fernando Acevedo ${ }^{1}$

Universidad Santo Tomás

Maestría en Psicología Jurídica

Bogotá- Febrero de 2016

${ }^{1}$ Director. 
Resumen 6

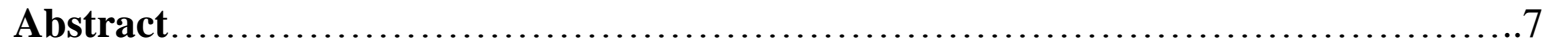

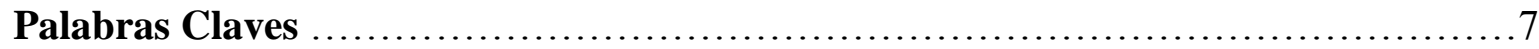

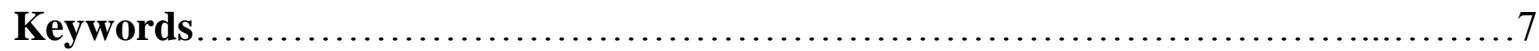

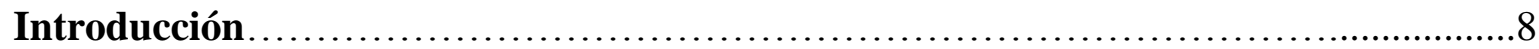

1. Capítulo I. La Psicología jurídica como una Fuente Interdisciplinaria del Derecho en Colombia: Contexto Metodológico, Epistemológico y

Conceptual..........................................................

1.1. Marco metodológico: Método tripartito de indagación iusfilosófica.........11

1.2. Contexto epistemológico. .15

1.2.1. Por un diálogo entre la Psicología Jurídica y el

Derecho 16

1.2.2. Posturas epistemológicas de la indagación iusfilosófica a la psicología jurídica. .24

1.3. Contexto conceptual.........................................28

1.2.3. Derecho.................................................28

1.2.4. Psicología jurídica........................................31 
1.2.5. Fuentes del derecho........................................... 38

2. Capítulo II. Indagación Epistemológica de la Psicología Jurídica.

2.1. Tiempo-espacio del derecho y de la psicología jurídica.

2.1.1. ¿Cuáles espacios pueden ser cohabitados por juristas y psicólogos

jurídicos en Colombia?

2.2. Objeto de estudio de la psicología jurídica.

.56

2.3. Sujeto: el psicólogo jurídico

.58

2.4. Método de la psicología jurídica....

.64

3. Capítulo III. Indagación Fenomenológica de la Psicología Jurídica. 68

3.1. Fenómenos psicojurídicos en el estado colombiano 70

3.1.1. Guía para la realización de pericias psiquiátricas y psicológicas forenses mediante autopsia psicológica en la determinación de la manera de muerte (suicida, homicida o accidental). .70

3.1.2. Guía para la realización de pericias psiquiátricas forenses sobre capacidad de comprensión y autodeterminación.

3.1.3. Guía para la realización de pericias psiquiátricas forenses sobre mantenimiento, cambio o levantamiento de medidas de seguridad en inimputables. .75

3.1.4. Guía para la realización de pericias psiquiátricas y psicológicas forenses sobre perturbación psíquica en presuntas víctimas de lesiones personales y otros. .77

3.1.5. Guía para la realización de pericias psiquiátricas y psicológicas forenses sobre daño psíquico con fines de indemnización, conciliación o reparación..81 
3.1.6. Guía para la realización de pericias psiquiátricas y psicológicas forenses en niños, niñas y adolescentes presuntas víctimas de delitos sexuales.

3.1.7. Guía para la realización de pericias psiquiátricas y psicológicas forenses sobre patria potestad (potestad parental) y custodia. 86

3.1.8. Guía para la realización de pericias psiquiátricas y psicológicas forenses sobre estado de salud mental del privado de la libertad-estado grave por enfermedad o enfermedad muy grave incompatible con la vida en reclusión formal. 81

3.1.9. Guía para la realización de pericias psiquiátricas y psicológicas forenses con fines de reglamentación de visitas y regulación de alimentos .89

3.1.10. Guía para la realización de pericias psiquiátricas y psicológicas forenses en adultos víctimas de delitos sexuales. .92

3.1.11. Guía para la realización de pericias psiquiátricas y psicológicas forenses sobre adicción sustancias

3.2. Fenómenos psicojurídicos en la literatura psicojurídica.

4. Capítulo IV. Indagación Ética o Deontológica de la Psicología Jurídica......115

5. Capítulo V. La Psicología Jurídica como una Fuente Interdisciplinaria del Derecho en Colombia. Una propuesta de Política Pública desde la Academia.128

5.1. Origen de la política pública...................................128

5.2. Propuesta................................................... 130

5.3. Diagnóstica del problema psicojurídico...........................131

5.4.Causas del problema.........................................133

5.5. Política pública: objetivos, escenarios, metas, estrategias, fundamentos

constitucionales............................................... 134

5.5.1. Objetivos............................................. 134

5.5.2. Escenarios................................................. 134 


\section{LA PSICOLOGÍA JURÍDICA COMO UNA FUENTE DEL DERECHO}

5.5.3. Metas........................................................

5.5.4. Estrategias............................................... 135

5.5.6. Fundamentos constitucionales..............................136

5.6. Actores de la política pública y estrategias de inclusión en la agenda

política....................................................... 136

6. Conclusiones....................................................... 141

Referencias.................................................................. 143 


\section{La Psicología Jurídica como una Fuente Interdisciplinaria del Derecho en Colombia Legal psychology as an interdisciplinary source for Colombian law}

\section{Resumen}

Este trabajo de investigación documental y reflexivo presenta una propuesta de inclusión de la Psicología Jurídica en los espacios de creación y aplicación del Derecho en Colombia, a través del planteamiento teórico La Psicología Jurídica como una Fuente Interdisciplinaria del Derecho en Colombia que consiste en la conceptualización del conocimiento interdisciplinario construido por la psicología jurídica acerca de la naturaleza humana, su realidad y los factores que influyen en la formación psíquica, cultural y conductual del individuo en relación con lo otro (individuos, naturaleza, instituciones sociales) y su participación en los ámbitos de la ley, el derecho y la justicia, con el propósito contribuir desde la investigación académica en el fortalecimiento y la dinamización de los procesos de creación de la ley y la jurisprudencia en el sistema jurídico colombiano, por medio de la inclusión Se sugiere adicionalmente la utilización del método tripartito de indagación iusfilosófica diseñado por Icilio Vanni (2008) como método integral que permite indagar a la Psicología Jurídica desde tres ramas de la filosofía como son la epistemología, la fenomenología y la ética, para identificar el lugar que debe ocupar esta área del 


\title{
LA PSICOLOGÍA JURÍDICA COMO UNA FUENTE DEL DERECHO
}

conocimiento en el espacio del derecho colombiano y comprobar la coherencia del planteamiento teórico de esta investigación, es decir, la posibilidad real y lógica de situar a la psicología jurídica como una fuente del derecho en Colombia.

\begin{abstract}
This research suggests the iusphilosophical way to improve the process of making law and jurisprudence in Colombia. It discusses how to incorporate a contemporary contextual, situational, or legal-psychological model of human behavior in the Colombian legal system. From an ius philosophy-based tripartite inquiry method proposes by Icilio Vanni (2008), it inquiries into psychology and law fields to ask for its epistemological, phenomenological and deontological basis with the purpose to achieve a place as a scientific source in making law in the Republic of Colombia.
\end{abstract}

Palabras Claves: Psicología Jurídica, Fuentes del Derecho, Pragmatismo, Método Iusfilosófico Tripartito.

Keywords: Psychology and Law, The Sources of The Law, Pragmatism, The tripartite Iusphilosophical Method. 


\section{LA PSICOLOGÍA JURÍDICA COMO UNA FUENTE DEL DERECHO}

\section{Introducción}

El objetivo de este trabajo consiste en encontrar las razones epistemológicas, fenomenológicas y éticas que justifiquen la ubicación de la Psicología Jurídica como una fuente interdisciplinaria del Derecho en el sistema jurídico colombiano.

Para ello se realiza una indagación iusfilosófica tripartita que cuestiona a la Psicología Jurídica a propósito de su estructura epistemológica, de los fenómenos que estudia, comprende, analiza y explica ${ }^{2}$; y finalmente acerca de los fundamentos, principios y límites éticos de su función social y científica.

Los resultados de esta indagación me permitirán acreditar desde una perspectiva conceptual la conveniencia social, contextual, jurídica, política y ética de proponer formalmente la ubicación de la Psicología Jurídica como una fuente interdisciplinaria del derecho en Colombia para los procesos de creación, aplicación, e interpretación normativa y jurisprudencial del Derecho, a través de la construcción teórica y la presentación de un proyecto de política pública constitutiva o de infraestructura, a los actores políticos competentes, para su posible implementación.

En el capítulo I se contextualiza al lector a propósito del marco metodológico, epistemológico y conceptual que orienta este trabajo, con el propósito de definir los parámetros cognoscitivos desde los cuales se propone a la Psicología Jurídica como una fuente interdisciplinaria del Derecho en Colombia.

\footnotetext{
${ }^{2}$ Díaz, F (2008, febrero). Entrevista a Fernando Díaz Colorado-Psicología Jurídica. Revista Psicología Científica.com. Tomada de: http://www.psicologiacientifica.com/fernando-diaz-colorado-entrevista/
} 


\section{LA PSICOLOGÍA JURÍDICA COMO UNA FUENTE DEL DERECHO}

El marco metodológico hace referencia al método Iusfilosófico que orienta la indagación de la Psicología Jurídica, este es, el método tripartito de indagación iusfilosófica propuesta por Vanni (2008) para la construcción o reconstrucción del concepto de Derecho, a partir del diálogo con otras ciencias afines a éste. En este caso, el diálogo se establece con la Psicología Jurídica, a fin de identificar los aportes que este campo del conocimiento psicológico puede compartir con el Derecho para su transformación.

El contexto epistemológico plantea las posturas epistemológicas desde las cuales se puede pensar y proponer la creación de una relación causal entre el Derecho y la Psicología Jurídica, en la que esta última puede convertirse en fuente del Derecho, con el propósito de mejorar la utilización de éste en la solución y prevención de los conflictos humanos. Las posturas epistemológicas que orientan esta propuesta son el pragmatismo y el intelectualismo, como se verá en el capítulo I.

En el contexto o marco conceptual, se presenta la definición de los conceptos claves de la investigación, para orientar al lector y plantear el punto de vista conceptual desde el que se realiza la propuesta de este texto. Estos conceptos están definidos desde la óptica de las posturas epistemológicas pragmática e intelectualista, las cuales garantizan la posibilidad de justificar la necesidad que tiene el Derecho de esta nueva fuente interdisciplinaria, como es, la Psicología Jurídica, para la transformación social, a través de la creación de normas jurídicas basadas en los datos científicos de esta área psicológica.

En el capítulo II se inicia la aplicación del método Iusfilosófico tripartito, a partir del primer paso de éste método, el cual consiste la indagación epistemológica de la Psicología Jurídica, con la intención de identificar el espacio, el tiempo, el objeto de 


\section{LA PSICOLOGÍA JURÍDICA COMO UNA FUENTE DEL DERECHO}

estudio, los sujetos y el método de la Psicología Jurídica y la relación con el Derecho en el plano epistemológico.

El capítulo III, contiene el segundo momento de la indagación Iusfilosófica, éste es, la indagación fenomenológica, la cual presenta los fenómenos psicojurídicos que han sido objeto de estudio de la psicología jurídica en diferentes contextos geográficos y jurídicos, y propone el lugar que pueden ocupar estos fenómenos con respecto a las ramas y momentos del Derecho.

Por su parte, el capítulo IV presenta el tercer momento de la Indagación Iusfilosófica tripartita, que corresponde a la indagación ética o deontológica de la Psicología Jurídica, la cual indaga acerca de los límites éticos que plantea el Derecho a la Psicología Jurídica y el rol del psicólogo jurídico en el ámbito del Derecho.

Finalmente, el capítulo V plantea desde la información obtenida a través de la indagación iusfilosófica de la Psicología Jurídica una propuesta de política pública, la cual materializa la propuesta teórica de este trabajo. 


\section{LA PSICOLOGÍA JURÍDICA COMO UNA FUENTE DEL DERECHO}

\section{Capítulo I. La Psicología jurídica como una Fuente Interdisciplinaria del}

Derecho en Colombia: Contexto Metodológico, Epistemológico y Conceptual

En este capítulo se realiza la contextualización epistemológica, conceptual y metodológica del planteamiento teórico: La Psicología Jurídica como una Fuente Interdisciplinaria del Derecho en Colombia. En primer lugar, se describe el método que se utiliza para la indagación de la Psicología Jurídica y el ámbito del conocimiento desde donde se plantea esta indagación. En segundo lugar, se presentan las posturas epistemológicas desde las cuales se abordan a la Psicología Jurídica y el Derecho, en esta investigación. Finalmente, se definen los conceptos que son objeto de estudio del presente trabajo, de acuerdo con las posturas epistemológicas que lo orientan. Estos conceptos son: Psicología Jurídica, Derecho, Fuentes del Derecho, derecho colombiano.

\subsection{Marco metodológico: Método tripartito de indagación iusfilosófica}

El método que orienta este diálogo de la Iusfilosofía o Filosofía del Derecho con la Psicología Jurídica es el método de indagación tripartita propuesta por el jurista italiano Icilio Vanni (2008), el cual consiste en conocer a partir del diálogo con las ciencias y disciplinas afines al derecho, los fundamentos epistemológicos de estas ciencias, los fenómenos de los que éstas se ocupan y los postulados éticos de estas áreas del conocimiento humano, para poner en relación dichos conocimientos y prácticas con el Derecho.

En tal indagación, la Iusfilosofía o filosofía del derecho "clasifica y ordena y reúne en una unidad el saber jurídico, disperso por la natural limitación de la mente" (Vanni, 2008, p. 23), con la intención de facilitar el diálogo y trabajo entre estas ciencias y/o disciplinas y 


\section{LA PSICOLOGÍA JURÍDICA COMO UNA FUENTE DEL DERECHO}

el Derecho, con el fin de promover la transformación y la intervención positiva de las sociedades humanas.

La indagación tripartita está adscrita al ámbito de la Filosofía del Derecho o ciencia filosófica, ciencia que de acuerdo con Vanni (2008, p. 18) es la "scientia alterior" que estudia los principios del Derecho, coordina las ideas madres de las ciencias jurídicas y de las ciencias y disciplinas afines al Derecho, y tiene como telos o finalidad comprender, explicar e integrar el Derecho en el sistema de todas las cosas.

Vanni (2008) describe esta indagación iusfilosófica como "una investigación relativa al saber jurídico. Por ella debemos indagar cuál es el fundamento y las condiciones que debe cumplir la ciencia jurídica para estar seguros de la validez y legitimidad de sus resultados" (p. 21). Se trata entonces de conocer por medio de esta indagación, el valor científico de la ciencia o disciplina indagada, sus fundamentos epistemológicos, los paradigmas que la orientan, los fenómenos jurídicos de los que se ocupa y la concepción de la naturaleza y la conducta humana que éstas plantean.

Este método Iusfilosófico está compuesto de tres partes o procesos: la indagación epistemológica o crítica, la indagación fenomenológica o sintética y la indagación ética o deontológica.

La indagación epistemológica o crítica cuestiona a las ciencias o disciplinas que se ocupan del fenómeno jurídico aplicándoles la teoría del conocimiento o gnoseología, para identificar la constitución epistemológica de estas ramas del saber, su relación con el Derecho y la validez de sus planteamientos y resultados (Vanni, 2008).

En la primera etapa de la indagación tripartita se trata de encontrar los elementos epistemológicos que constituye a la ciencia o disciplina y que le permiten entrar en diálogo 


\section{LA PSICOLOGÍA JURÍDICA COMO UNA FUENTE DEL DERECHO}

y colaboración con el derecho, éstos son: 1) el espacio o los espacios en los que la ciencia o disciplina se aplica, se desarrolla, se construye e investiga; 2) el tiempo o los tiempos en los que interviene; 3) los objetos de estudio; 4) los sujetos que se ocupan de estudiarla, los sujetos a los que benefician con sus resultados y los sujetos a los que pretenden intervenir; 5) los métodos de investigación que se utilizan para conocer sus objetos de estudio y su coherencia con el Derecho.

Así, en el primer momento de la indagación tripartita, esta es, la indagación epistemológica, se propone identificar los espacios y tiempos jurídicos en los que interviene la Psicología Jurídica; los espacios y tiempos propios de la Psicología Jurídica; el objeto de estudio de ésta; el sujeto estudiado por la psicología jurídica, es decir, el hombre, y el sujeto que estudia la psicología jurídica, o sea, el psicólogo jurídico y su rol en el ámbito jurídico; y los métodos que utiliza la Psicología Jurídica para conocer su objeto de estudio.

El segundo momento de la indagación tripartita propone realizar un cuestionamiento fenomenológico a las ciencias o disciplinas afines al derecho, con el objetivo de "poner en relación el fenómeno jurídico con los demás fenómenos que se dan con él juntamente en la realidad" (Vanni, 2008. p. 21), y obtener así, un conocimiento más amplio del fenómeno social y humano que es regulado e intervenido por el Derecho, ya que como lo afirma Vanni, "la vida humana es parte de un sistema más vasto, que es todo el sistema cósmico; la vida es parte del mundo, y por esto hay que indagar las relaciones del Derecho con el sistema de todas las cosas" (Vanni, 2008. p. 24).

En el caso de esta investigación, la indagación fenomenológica de la Psicología Jurídica pregunta por los fenómenos ${ }^{3}$ psicológicos humanos con trascendencia jurídica, a

\footnotetext{
${ }^{3}$ De acuerdo con la Edición del Tricentenario del Diccionario de la lengua española de la Real Academia de la Lengua española, un Fenómeno es: 1. "Toda manifestación que se hace presente a
} 


\section{LA PSICOLOGÍA JURÍDICA COMO UNA FUENTE DEL DERECHO}

fin de ponerlos en relación con el Derecho, facilitar el diálogo entre el Derecho y la Psicología Jurídica, y contribuir a una intervención positiva de los individuos y las sociedades humanas.

La tercera parte de la indagación iusfilosófica, corresponde a la indagación deontológica o ética. Esta es una indagación de carácter práctico o valorativo, puesto que "lo que debe ser, la valuación y la transformación progresiva de los hechos, pertenece a la ética" (Vanni, 2008. p. 26). Por ello, con esta indagación, la filosofía del derecho pretende informar al derecho acerca de los avances y conocimientos que otras ciencias van adquiriendo al respecto de la naturaleza del hombre, la conducta humana (sus causas y sus fines), la evolución cultural, etc., los cuales le pueden permitir al Derecho transformarse y evolucionar en beneficio de la sociedad.

La indagación ética de la Psicología Jurídica, nos permite de otro lado, identificar los límites y retos éticos del Psicólogo Jurídico en el ámbito del Derecho, en relación con las personas con las que interactúa en este ámbito, entre quienes están los acusados, las víctimas, las familias de éstas, los jueces, los abogados, los fiscales, los magistrados; en relación con la norma jurídica; en relación con la rama o ámbito del Derecho en que aparece; y finalmente en relación con su responsabilidad ética en éstas relaciones.

Luego, el propósito de utilizar este método Iusfilosófico es lograr la integración de las tres indagaciones y justificar desde la filosofía del derecho, la necesidad real de incluir a la Psicología Jurídica como una fuente interdisciplinaria para el derecho en Colombia.

\subsection{Contexto epistemológico}

la consciencia de un sujeto y aparece como objeto de su percepción”. Tomado de: http://dle.rae.es/?id=HlH0iLR 


\section{LA PSICOLOGÍA JURÍDICA COMO UNA FUENTE DEL DERECHO}

El contexto epistemológico de este trabajo de investigación, hace referencia en primer lugar, a los límites virtuales que se han establecido en el proceso de construcción del conocimiento humano entre las diferentes ciencias y disciplinas existentes, a propósito de los objetos de estudio de cada una de ellas, los métodos que utilizan para estudiar dichos objetos, las características de los estudiosos éstas y los ámbitos de aplicación de sus conocimientos. En segundo lugar, se refiere a las posturas epistemológicas que adoptan los estudiosos y pensadores en lo que respecta a la posibilidad y al origen del conocimiento de las diversas ciencias y disciplinas.

En el caso de esta investigación, se propone abordar la relación epistemológica, fenomenológica y ética entre el Derecho y la Psicología Jurídica, para facilitar el diálogo y la colaboración entre estas ciencias y/o disciplinas. Y de otro lado, se propone la mirada de la relación entre el Derecho y la Psicología Jurídica desde las posturas epistemológicas del pragmatismo y el intelectualismo (Hessen,1981) a fin de mostrar el beneficio que puede causar la relación epistemológica y práctica entre la Psicología Jurídica y el Derecho (Kapardis, 2010) a la transformación positiva de las normas jurídicas, las instituciones jurídicas y sociales; y al contexto en el que se construyen las relaciones humanas que transcienden al ámbito jurídico. 


\section{LA PSICOLOGÍA JURÍDICA COMO UNA FUENTE DEL DERECHO}

\subsubsection{Por un diálogo epistemológico entre la psicología jurídica y el derecho.}

Para propiciar un diálogo entre la Psicología Jurídica y el Derecho, es necesario, en primer lugar, identificar las diferencias entre la Psicología y el Derecho, sus principales desencuentros y el modelo del hombre con el que éstas funcionan. En segundo lugar, con el objetivo de facilitar el diálogo entre éstas ciencias, se presentan las postura de algunos estudiosos que afirman, tanto desde el ámbito del Derecho como desde el ámbito de la Psicología, que a pesar de las diferencias epistemológicas entre la Psicología y el Derecho, éstas deben abrirse al diálogo para la investigación y el estudio interdisciplinario, a fin de realizar un trabajo eficiente en el estudio, comprensión y explicación del comportamiento humano en el ámbito jurídico.

Para mencionar algunas de las diferencias más relevantes entre la Psicología y el Derecho, Andreas Kapardis (2010), cita a Haney (1980), quien menciona ocho fuentes de los problemas y desencuentros entre ambas disciplinas. Éstos son:

- El Derecho recalca el conservadurismo; la Psicología la creatividad

- El Derecho es autoritario; la Psicología es empírica

- El Derecho confía en el proceso adversario; la Psicología confía en la experimentación

- El Derecho es prescriptivo; la Psicología es descriptiva

- El Derecho es ideográfico; la Psicología es nomotética

- El Derecho hace énfasis en la certeza; la Psicología es probabilística

- El Derecho es reactivo; la Psicología es proactiva

- El Derecho es operacional; la Psicología es académica (Kapardis, 2010, p. 8). 


\section{LA PSICOLOGÍA JURÍDICA COMO UNA FUENTE DEL DERECHO}

Al respecto de estas diferencias, menciona Kapardis (2010) que éstas provienen de los modelos del hombre con los que trabajan estas disciplinas, afirma el autor que ambas funcionan con dos modelos diferentes del hombre. "El Derecho sea en el área civil o criminal, generalmente supone, el libre albedrío y hace énfasis en la responsabilidad individual, en contraste con la tendencia de diversas teorías psicológicas que destacan las fuerzas inconscientes e incontrolables como aspectos determinantes de la conducta de los individuos". (Kapardis, 2010, p. 8).

Así, el modelo de naturaleza humana que prevalece en la Psicología contemporánea es el modelo social contextual, mientras que el Derecho está basado en una teoría de la naturaleza humana más individualista, voluntarista y clásica. De acuerdo con Haney (2002) el Derecho y la ley deberían tener como fundamento un modelo de la conducta y naturaleza humana con sustento empírico, ya que las teorías y supuestos que respaldan su modelo de naturaleza humana han sido cuestionadas por la ciencia, pero aún así, y el Derecho las mantiene para conservar su status quo.

Este individualismo psicológico con el que opera el que opera el Derecho (Haney 2002) estaba basado en la creencia de que el individuo y su interioridad son el único lugar donde se encuentra la causa de su conducta, por tanto la problemática social y las conductas ilegales son atribuidas desde esta perspectiva, a algún defecto del individuo, así dichas conductas pueden ser modificadas a través de los cambios en la naturaleza o características de las problemáticas personales del individuo infractor. Según Haney $(2002$, p. 6) la ley en su proceso de formación se caracterizó por concebir la conducta enfocada exclusivamente en el individuo, ignorando la influencia del contexto social en ella. 


\section{LA PSICOLOGÍA JURÍDICA COMO UNA FUENTE DEL DERECHO}

Entonces, afirma Haney (2002), que la coincidencia entre el individualismo psicológico y la formación de la Ley norteamericana demuestra que la concepción legal del modelo de conducta individualista fue literalmente institucionalizada en el sistema jurídico. Haney (2002) denuncia que esta concepción que proviene del siglo XIX y que ha sido conservada por el sistema jurídico, a pesar de que la academia y las investigaciones sociales hayan demostrado las implicaciones del contexto social en la conducta humana en general y aquella con trascendencia jurídica.

Las doctrinas legales y las instituciones han sido creadas y transformadas bajo la teoría legal de la conducta, según la cual la autonomía individual es la causa universal y se ha relegado la influencia del contexto social en el comportamiento humano. Haney (2002) critica esta postura teórica y egocéntrica del individualismo psicológico.

Para generar el encuentro entre la Psicología y Derecho, Haney (2002, p. 10) propone un nuevo realismo jurídico que armonice el Derecho y la Psicología con el fin de que el sistema jurídico pueda contener lo que es y debe ser entendido por los ciudadanos por naturaleza humana. La propuesta de Haney (2002) es que la Psicología y la información de otras Ciencias Sociales sean usadas para cerrar la brecha entre los hechos psicológicos y las ficciones legales en nombre de la equidad y la imparcialidad.

Según Haney (2002, p. 147) la Psicología debe ocupa un lugar importante en el proceso de mejoramiento de la ley, acercamiento de ésta a la realidad y el mejoramiento de la calidad de la justicia, ya que los datos de la Psicología pueden contribuir al cambio social. Por ello sostiene Haney (2002, p.173) que el sistema legal debe ser dirigido 


\section{LA PSICOLOGÍA JURÍDICA COMO UNA FUENTE DEL DERECHO}

"forzosamente" y necesariamente al uso de la información y los datos de la ciencia y dejar de lado la ideología que orienta la decisión de los jueces y los legisladores.

De acuerdo con Haney (2002), los datos de la Psicología deben ser usados para la creación de las presunciones legales, caso en el cual éstas sólo podrían ser refutadas por los hechos y las circunstancias en un caso específico. Esto permitiría el movimiento o el dinamismo del Derecho, en tanto que los hechos que contradigan las presunciones basadas en evidencias permite la nueva investigación de la Psicología y las demás ciencias para "la construcción de un mejor Derecho” (Díaz, 2009).

En este mismo sentido, el psicólogo jurídico Andreas Kapardis (2010) apuesta por ejemplo, por superar las diferencias estrictamente formales e ideológicas entre la Psicología y el Derecho, puesto que el objetivo fundamental de éstas consiste en contribuir al buen funcionamiento de las relaciones humanas, y no simplemente en mantener un estatus científico con la sobreproducción de artículos académicos o normas jurídicas. Por ello Kapardis afirma que:

Más allá de las diferencias entre la Psicología y el Derecho, las dos disciplinas están intrínsecamente ligadas por virtud de su papel como reguladores del comportamiento humano y sus responsabilidades para mantener el tejido social en una sociedad civilizada, así como también, la forma como son utilizados los conceptos psicojurídicos. (Kapardis, 2010. págs. 15-16).

De manera que, desde la perspectiva de Kapardis (2010), la relación entre la Psicología Jurídica y el Derecho tiene dos objetivos fundamentales, estos son, contribuir con sus datos o conocimientos adquiridos a preservar y reconstruir el tejido social y a definir y acordar la 


\section{LA PSICOLOGÍA JURÍDICA COMO UNA FUENTE DEL DERECHO}

manera como se deben utilizar los conceptos que surgen de la relación entre la Psicología y el Derecho, la Psicología Jurídica y el Derecho, es decir, los conceptos psicojurídicos.

Por ello, el encuentro entre la Psicología Jurídica y el Derecho va más allá de cumplir con el objetivo de estudiar, comprender y regular el comportamiento humano antijurídico puesto que desde la óptica de Kapardis (2010), este encuentro entre la Psicología y el Derecho tiene además la misión epistemológica de crear los conceptos psicojurídicos a través de los cuales se proponen ejercer los objetivos mencionados anteriormente, y el deber ético de preservar el tejido social de las sociedades humanas.

David Carson (2011), plantea una postura crítica a propósito de la manera cómo perciben el Derecho otras disciplinas, y afirma que los combates epistemológicos entre la Psicología, otras ciencias y el Derecho están basados en la falsa premisa de que el Derecho se reduce a lo que ocurre o sucede en las cortes o en el foro, limitando así el espectro de acción del derecho al ámbito judicial. Por lo tanto, de acuerdo con Carson (2011) estas premisas que muestran como diferentes al Derecho y a la Psicología son falsas, ya que entienden y reducen el Derecho a aquello a lo que ocurre exclusivamente en las cortes o en el foro.

Esta percepción limitada o reduccionista que del Derecho tienen otras ciencias y/o disciplinas como la Psicología, ignora el hecho de que el Derecho cuenta con tres momentos y/o funciones fundamentales, éstas son: el momento de la creación de la ley y las instituciones jurídicas, el momento de la aplicación de la ley en el ámbito jurisdiccional, y el momento de la recepción de la ley y el sistema jurídico por parte de los destinatarios de éstos. 


\section{LA PSICOLOGÍA JURÍDICA COMO UNA FUENTE DEL DERECHO}

Siguiendo la propuesta de Carson (2011), es necesario que tanto los psicólogos como los abogados comprendan que el Derecho no se reduce a la aplicación de la ley, y se procure la participación de la Psicología Jurídica en los tres momentos del Derecho, ya que ésta tiene mucho que aportar en ellos, a partir, por ejemplo, de la orientación a los juristas en estos procesos jurídicos que afectan directa e indirectamente a los individuos y a la sociedad que hacen parte de un sistema político y jurídico específico.

Entonces, desde la perspectiva de Carson (2011), el reto de la Psicología Jurídica consiste en encontrar métodos y focos comunes de estudio e intervención para la Psicología y el Derecho que permitan comprender la realidad de la conducta humana y que tenga en cuenta las necesidades pragmáticas de la creación de las leyes y el litigio, para el cambio social.

Según Carson, (2011.p. 87) “existen muchas oportunidades para la colaboración interdisciplinar entre la Psicología y el Derecho para la reforma de las leyes, los procedimientos jurídicos y el mejoramiento de la investigación como prerrequisito para cualquier procedimiento jurídico", y en este contexto, el rol de las universidades o la academia es fundamental, porque es la institución social responsable de la formación de los profesionales flexibles y abiertos al trabajo interdisciplinario.

¿Cómo hacer eficaz y útil el encuentro entre la Psicología Jurídica y el Derecho?

Para hacer efectivo el encuentro con la Psicología desde lo jurídico, Sullivan (2002) propone tres caminos posibles para hacerlo. El primero de ellos, se refiere a la aplicación de las herramientas de otras disciplinas para el conocimiento del Derecho y las Instituciones gobernadas por éste; el segundo camino posible consiste en la utilización de las 


\section{LA PSICOLOGÍA JURÍDICA COMO UNA FUENTE DEL DERECHO}

herramientas de otras disciplinas para mejorar la práctica del Derecho, la calidad de las reglas y normas y las instituciones jurídicas; y el tercer camino radica en aceptar la idea de que la visión del Derecho a través de las lentes de otras disciplinas incorporará comprensión y conocimiento a otras disciplinas que estudian fenómenos comunes a los estudiados y regulados por el derecho.

De acuerdo con Sullivan (2002) "el derecho como disciplina no es y nunca ha sido una disciplina autónoma. La regulación del orden social a través de la variedad de textos autoritarios necesariamente interactúa de una forma dialéctica y compleja con el contenido y técnicas de las ciencias sociales y las humanidades”. (Sullivan, 2002, p. 1219).

La relación causal entre el Derecho y la Psicología Jurídica que propone esta investigación elige el segundo camino expuesto por Sullivan (2002), es decir, el uso de los conocimientos adquiridos por la Psicología Jurídica acerca de la naturaleza y el comportamiento humanos, a fin de mejorar la creación de las normas jurídicas, las instituciones jurídicas y la práctica del Derecho. Para ello, se realiza a continuación la indagación epistemológica, fenomenológica y ética de la Psicología Jurídica, a fin de identificar los conceptos, los datos y las herramientas teóricas y prácticas que esta ciencia y/o disciplina contiene, con la intención de justificar la propuesta de incluir a la Psicología Jurídica como una fuente interdisciplinaria válida del Derecho en Colombia.

No obstante, es necesario advertir que esta relación causal entre el Derecho y la Psicología Jurídica no debe limitarse a un cálculo utilitarista, pues de acuerdo con el jurista y filósofo italiano Francesco Carnelutti (1962), la relación entre el Derecho y las demás ciencias debe ser el de un recambio: 


\section{LA PSICOLOGÍA JURÍDICA COMO UNA FUENTE DEL DERECHO}

“ No tanto una relación, cuanto un recambio, se da no sólo entre la ciencia y la práctica, entre la ciencia y la técnica, entre la ciencia y la metodología, sino también entre la ciencia y la ciencia, esto es, entre las varias especies o familias de la ciencia. Las divisiones que entre ellas, por modo empírico o también por modo científico solemos trazar, no valen más que los confines dibujados con varios colores por el geógrafo en el mapa. Ocurre que alguno habiendo traspasado en realidad uno de esos confines, se sorprende de no estar en otro mundo; o también cuando al llegar al confín no encuentra la red o el guardián, no se da cuenta de haberlo traspasado. Ahí también, los doctos pretender montar la guardia en el límite; pero no hay esfuerzo tan vano como ése" (Carnelutti, 1962. p. 15).

Esta profunda reflexión de Carnelutti (1962), hace parte de uno de los grandes principios propuestos por este autor en su visión holística del Derecho, este es, el principio de la Unidad de las Ciencias o principio de la Interdependencia de las Ciencias, según el cual, las diversas ciencias no son más que un punto de vista específico y delimitado del único mundo que existe, por lo tanto si queremos tener un visión integral de éste y habitarlo de la manera más armónica, debemos, según Carnelutti, apostar por fortalecer la relación entre las ciencias y sus practicantes.

Por ello, en este trabajo se busca no solo la utilización de las herramientas de la Psicología Jurídica en el ejercicio y mejoramiento del Derecho, sino también pretende promover un recambio de conocimientos y experticia entre éstas, a fin de crear unas normas jurídicas y unas instituciones jurídicas acordes al contexto colombiano y a la vida de las relaciones humanas y el comportamiento humano. 


\section{LA PSICOLOGÍA JURÍDICA COMO UNA FUENTE DEL DERECHO}

\subsubsection{Posturas epistemológicas de la indagación iusfilosófica a la psicología jurídica.}

La postura epistemológica en el contexto de la teoría del conocimiento, hace referencia a la posición que adquiere el sujeto cognoscente en relación con el objeto (Hesse, 1981), a propósito de las siguientes cuestiones: 1. La posibilidad de que el sujeto aprehenda realmente el objeto de conocimiento; 2. La forma como tiene lugar el conocimiento en el sujeto pensante.

De acuerdo con Johannes Hessen (1981), la primera cuestión responde a la pregunta por la posibilidad del conocimiento humano, es decir, si en el acto de conocimiento el sujeto puede aprehender realmente al objeto. La segunda cuestión responde al interrogante acerca del lugar en el que se origina o produce el conocimiento en el sujeto pensante o la aprehensión psicológica del objeto, esto es en la razón, en los sentidos o en ambos.

Para estas dos cuestiones podemos encontrar como lo afirma Hessen (1981) diferentes respuestas históricas, las cuales se conocen en el ámbito de la epistemología o teoría del conocimiento como posturas epistemológicas. Estas son, el dogmatismo, el

escepticismo, el subjetivismo y el relativismo, el pragmatismo, el criticismo, el racionalismo, el empirismo, el intelectualismo y el apriorismo.

A propósito de la primera cuestión, existen diferentes posturas epistemológicas que han elaborado una respuesta a la pregunta por la posibilidad que tiene el sujeto cognoscente de aprehender el objeto de conocimiento. El dogmatismo, por ejemplo, ofrece una respuesta afirmativa a dicha pregunta y sostiene que el sujeto cognoscente si puede aprehender al 


\section{LA PSICOLOGÍA JURÍDICA COMO UNA FUENTE DEL DERECHO}

objeto de conocimiento y el medio efectivo para hacerlo es a través de la fe o el dogma (Hessen, 1981).

El escepticismo, es otra de las posturas epistemológicas que surge históricamente como respuesta a la postura dogmática, según la cual el sujeto cognoscente no puede aprehender realmente al objeto, y a diferencia del dogmatismo que se apoya en la fe para mantener su postura, el escepticismo se apoya en la duda.

La tercera postura epistemológica, según Hessen (1981) corresponde al subjetivismo y al relativismo, posturas de acuerdo con las cuales, la posibilidad de que el sujeto cognoscente aprehende realmente al objeto de conocimiento depende, en el caso del subjetivismo de las cualidades del sujeto que conoce y juzga, las cuales están limitadas por la calidad de los sentidos y la razón humanas. En el caso del relativismo, la posibilidad del conocimiento humano es relativo y depende de los factores externos o del contexto, tales como el tiempo, el espacio, el entorno cultural y político, etc.

El pragmatismo, es otra de las posturas epistemológicas que responden al primer interrogante. De acuerdo con éste, la posibilidad de que el sujeto cognoscente aprehenda al objeto, depende de la utilidad que ofrezca este nuevo conocimiento para fomentar la vida.

La última respuesta a la primera cuestión epistemológica es, según Hessen (1981), el criticismo. Para el criticismo, la aprehensión real del objeto por el sujeto depende del filtro reflexivo y crítico que haga el sujeto del proceso de conocimiento.

En lo relativo a la segunda cuestión que pregunta por la manera en que se da el conocimiento y por el origen del mismo, emergen diferentes posturas epistemológicas que intentan dar respuesta a esta cuestión. Según Hessen (1981), se trata del racionalismo, el empirismo, el intelectualismo, el apriorismo, y la crítica o posición propia. 


\section{LA PSICOLOGÍA JURÍDICA COMO UNA FUENTE DEL DERECHO}

Para el racionalismo, la fuente primordial del conocimiento humano es la razón o el pensamiento (Hessen, 1981). De acuerdo con esta postura epistemológica, el ser humano puede conocer los objetos de la naturaleza y el mundo porque posee a priori la capacidad de nombrar y conceptualizar la información que viene de los sentidos y emitir juicios sobre los objetos que conceptualiza.

De otro lado, afirma Hessen (1981) que desde la óptica del empirismo, el único origen posible del conocimiento humano es la experiencia, ya que para esta postura epistemológica no existen tales facultades a priori de la razón que nos permiten conocer el mundo, sino que el conocimiento de éste depende de las vivencias y del encuentro del sujeto cognoscente con el mundo.

El intelectualismo surge como postura mediadora entre el racionalismo y el empirismo, puesto que para el intelectualismo el origen del conocimiento humano depende tanto de la intervención de la razón como de la experiencia en el proceso de producción del conocimiento humano, aunque el intelectualismo le da cierta prioridad a la experiencia, ya que de acuerdo con esta postura sólo es posible crear los conceptos de las cosas a través de lo que se lee en la experiencia.

Finalmente, el apriorismo es otra postura epistemológica que intenta mediar entre el racionalismo y el empirismo a través de la afirmación de que el origen del conocimiento humano depende tanto de la razón como de la experiencia, pero a diferencia del intelectualismo, el apriorismo sostiene que en el proceso del conocimiento humano los elementos a priori que posee la razón humana, hacen que ésta prevalezca sobre la experiencia (Hessen, 1981).

Después de hacer este breve recorrido por las diferentes posturas epistemológicas que plantea la epistemología de Johannes Hessen, es necesario presentar las posturas que 


\section{LA PSICOLOGÍA JURÍDICA COMO UNA FUENTE DEL DERECHO}

orientan este trabajo de indagación iusfilosófica a la psicología jurídica, a saber, el pragmatismo y el intelectualismo.

Como lo estudiaremos en el siguiente apartado, uno de los propósitos de la relación entre la Psicología Jurídica y el Derecho consiste en contribuir al cambio social, a través del estudio y trabajo conjunto acerca del comportamiento humano con trascendencia jurídica como los conflictos en las relaciones humanas y la violencia, y las mecanismos eficaces para conocerlo, prevenirlo, explicarlo e intervenirlo.

Por ello, y teniendo presente que la disputa por los límites epistemológicos y científicos entre las ciencias debe hacerse a un lado a la hora de buscar el bienestar en el mundo de los individuos y los grupos humanos, la postura epistemológica desde la que se indaga a la Psicología Jurídica en este trabajo, a fin de proponerla como fuente del Derecho en Colombia es el pragmatismo, ya que desde esta postura la búsqueda del conocimiento y la verdad está dirigida por la utilidad, teniendo por lo útil, aquello que resulta beneficioso para la vida y particularmente para la vida social (Hessen, 1981) orientada por éste,

Por esta razón, la viabilidad de la propuesta de esta trabajo está condicionada por la necesidad de que los conocimientos de la Psicología Jurídica oxigenen al Derecho en Colombia y fomenten la vida, objetivos propios de una postura pragmática, en sentido epistemológico.

El intelectualismo es la segunda postura epistemológica que orienta la indagación iusfilosófica de la Psicología Jurídica, por ello, se considera que el origen y la validez del conocimiento de la psicología jurídica proceden tanto de la experiencia o la experimentación como de la razón y la creación de conceptos que realizan los estudiosos de esta área del conocimiento. Pero es necesario advertir que aunque la Psicología Jurídica obtiene los datos para construir sus conocimientos tanto de la experimentación como de las 


\section{LA PSICOLOGÍA JURÍDICA COMO UNA FUENTE DEL DERECHO}

teorías que la sustentan, la Psicología Jurídica privilegia los datos de la experimentación, teniendo en cuenta que es una disciplina en construcción y está formando su corpus a partir de la investigación.

Ahora, después de definir las posturas epistemológicas que orientan la indagación tripartita de la Psicología Jurídica, se delimitarán algunos conceptos fundamentales en esta indagación.

\subsection{Contexto conceptual}

Cada uno de los objetos de la naturaleza y los objetos creados por los humanos, adquieren diferentes nombres y conceptos de acuerdo con la postura epistemológica y el contexto cultural que posean los humanos que los nombran, crean y conceptualizan.

En este apartado se presentan los conceptos centrales con los que se trabaja en esta investigación, desde las posturas epistemológicas del pragmatismo y el intelectualismo. Esto quiere decir, que aunque existen muchas definiciones de cada uno de los conceptos aquí abordados, se han elegido aquellas definiciones que se ajustan a las posturas pragmática e intelectualista que orientan esta tesis. Estos conceptos son: la Psicología Jurídica, el Derecho y las Fuentes del Derecho, ya que el título o nombre de este trabajo, $L a$ Psicología Jurídica como una Fuente Interdisciplinaria del Derecho en Colombia, contiene la esencia de esta investigación y está integrada por los conceptos que a continuación se definen:

\subsubsection{Derecho.}

El nombre derecho tiene diferentes acepciones y construcciones teóricas e ideológicas en torno suyo, pero para los efectos de este trabajo de indagación iusfilosófica 


\section{LA PSICOLOGÍA JURÍDICA COMO UNA FUENTE DEL DERECHO}

se acoge la visión holística que el jurista italiano Francesco Carnelutti (2015) tiene del derecho.

De acuerdo con el análisis que hace este pensador en su texto Como nace el Derecho, podemos definir al Derecho como un conjunto de normas, mandatos e instituciones construidas y administradas por un grupo de seres humanos calificados y elegidos como representantes de los grupos a los que ellos pertenecen, que imponen un modelo de acción específico, el cual está permeado por los intereses morales y económicos de conservar la paz, de proteger la propiedad privada y de controlar y castigar las acciones egoístas e impulsivas de los individuos y grupos humanos que llevan a la guerra y a la vulneración de la esfera íntima, familiar y corporal entre congéneres. Cumplir con este fin, le implica a la ciencia del derecho construir todo un artificio lingüístico de imperativos y un sistema lógico, coherente, pleno y único de normas e instituciones que le permita administrar el ejercicio de la fuerza y la violencia para la imposición de los castigos a los receptores y transgresores de este sistema.

De acuerdo con mi apreciación y reflexión del Derecho, desde el ámbito académico y práctico, el Derecho como práctica cuenta con tres momentos: el momento de la creación, el de la recepción, y el de la aplicación. El primer momento hace referencia a la creación y reforma de las normas jurídicas y las instituciones jurídicas que integran un sistema jurídico y a la creación de teorías y doctrinas que explican el funcionamiento del Derecho como ciencia o disciplina.

El segundo momento del Derecho coincide con la recepción de las normas, las instituciones y las doctrinas jurídicas por parte de los destinatarios de las mismas, es decir, 


\section{LA PSICOLOGÍA JURÍDICA COMO UNA FUENTE DEL DERECHO}

por parte de aquéllos que integran el sistema que emite el Derecho. En el caso de las sociedades postmodernas estos sistemas reciben el nombre de Estados.

Y el tercer momento del Derecho es el momento de la aplicación de las normas jurídicas y la activación de las instituciones jurídicas por parte de los funcionarios competentes para hacerlo. La figura que representa este momento del Derecho es la figura del juez, aquél individuo o grupo de individuos que interpretan la ley y el Derecho, a fin de premiar a los cumplidores de la ley en una sociedad o de castigar a sus transgresores.

Una de las corrientes que defiende la visión pragmática del Derecho es la corriente norteamericana Social Science in Law (SSL), que en castellano traduce las Ciencias Sociales en el Derecho. Según Melton (1990) "las Ciencias Sociales en el Derecho aparecen para que compartir un compromiso con el bienestar social y creencias de que la ley es un medio útil para lograr este fin, que la ley es reformable y que las ciencias sociales pueden asistir en el logro de esta misión" (Melton, 1990. p. 321).

De acuerdo con esta corriente, el objetivo principal del Derecho es el bienestar social y para lograrlo debe contar con la participación de las ciencias sociales en los procesos de creación, reforma y aplicación del derecho. Es así como afirma Melton (1990) que "las ciencias sociales en el Derecho está enfocada en la aplicación de las ciencias sociales, no sólo de la psicología, a las presunciones sociales y comportamentales del Derecho. (Melton, 1990. p. 321)

Esta perspectiva pragmática del Derecho abre el espectro para justificar la necesidad de la relación no sólo entre la Psicología Jurídica y el Derecho, sino también entre el Derecho y las ciencias sociales con el objetivo de buscar el bienestar social, que es 


\section{LA PSICOLOGÍA JURÍDICA COMO UNA FUENTE DEL DERECHO}

precisamente uno de los aportes que pretende realizar este trabajo, a saber, las posturas teóricas y conceptuales para promover la relación causal y de recambio entre el Derecho, la Psicología Jurídica y las ciencias sociales.

\subsubsection{Psicología jurídica.}

Existen diferentes definiciones acerca de la Psicología Jurídica, algunas de ellas fueron exploradas de manera detallada por Gutiérrez (2010). En esta exploración la autora llega a la conclusión de que aún no existe un acuerdo a propósito de lo que la Psicología Jurídica sea, porque existen diferentes posturas a propósito de ésta. A este respecto concluye la autora:

Autores como Brown (1926), citado por Kapardis (2003), Mira y López (1932); Muñoz (1980); Hoyos (2002), Lugo y Rivas (s.f), Colegio Oficial de Psicólogos de España (s.f), la entendieron e intentaron definirla como área, especialización, campo o aplicación de la Psicología. Radbruch (2002) como un área del Derecho; Ogloff (2001), Nin (2002), Garrido y Herrero (2006), Garrido (1982), Díaz (s.f;), y Rodríguez (s.f), la entendieron desde una perspectiva interdisciplinaria y la definieron como una intersección entre dos o más disciplinas, como la Psicología, el Derecho o la ley, la Criminología y la Sociología; Toch (1961); Garzón (1989), citado por Rico (1997), Carson (2003), citado por Garrido y Herrero (2006) como otra Psicología; Munné (1980) y Kool \& Arawal (2006) como un área de la Psicología Social; y Fox \& Prilleltensky (1997), como una corriente de la Psicología Política. 


\section{LA PSICOLOGÍA JURÍDICA COMO UNA FUENTE DEL DERECHO}

Gutiérrez (2010), apuesta por la definición del grupo de profesores de la Universidad Santo Tomás, Seccional Bogotá, definición, que según Gutiérrez cumple con los requerimientos formales de una definición y reúne los elementos necesarios para delimitar el campo epistemológico de la Psicología Jurídica. A continuación se transcribe dicha definición citada por Gutiérrez (2010, p. 233):

“La Psicología Jurídica es un área especializada, básica y aplicada de la Psicología Científica, que investiga e interviene sobre el comportamiento humano que alcanza implicaciones Jurídicas. Esta área propende por la defensa de los Derechos Humanos, la salud mental y el impacto de éstas en la sociedad, con el fin de alcanzar y humanizar la justicia". Grupo de Profesores de los Posgrados en Psicología Jurídica de la Universidad Santo Tomás. (2009).

Aunque esta definición cumple con los propósitos formales de una definición, existen otros conceptos que amplían el espectro epistemológico y práctico de la Psicología Jurídica y superan las distinciones y los límites estrictos que se han marcado en la Psicología y el Derecho.

Por ejemplo, Mira y López (1961, págs. 17-18), uno de los pensadores tradicionales de la Psicología Jurídica, propuso concebir a este ámbito del conocimiento de la psicología como "la psicología aplicada al mejor ejercicio del Derecho". Aunque esta definición presenta la perspectiva pragmática de la Psicología Jurídica es demasiado amplia y reduce el papel de la Psicología Jurídica al ejercicio del Derecho, dejando por fuera el ámbito de creación de éste que es el que más nos interesa en este trabajo. 


\section{LA PSICOLOGÍA JURÍDICA COMO UNA FUENTE DEL DERECHO}

Fernando Díaz Colorado (2008) propone una definición de Psicología Jurídica en una entrevista que le realizan en la Revista Psicología Cientfica.com. Según Díaz (2008):

La Psicología Jurídica es el campo del conocimiento psicológico que intenta estudiar, comprender, y analizar, explicar las relaciones que se dan entre el sujeto, entre el hombre, entre el individuo y el escenario, digamos que de ahí caben múltiples relaciones, digamos que la psicología jurídica tenga diferentes áreas, por ejemplo para muchos autores hay psicología penitenciaria, psicología criminológica, psicología del menor y la familia, es decir, hay muchos espacios de relación que la psicología podría abordar y que son resultado de la interacción entre el sujeto, entre el hombre, entre el individuo y el campo legal. Digamos que esa relación, amplia, macro, contextualizada es en términos generales la psicología jurídica.

Un año más tarde, Díaz (2009) da un paso más allá, y afirma que "la Psicología Jurídica, antes que un campo del conocimiento psicológico que aporta sus hallazgos y conocimientos a la Ley, debe estar al servicio de la construcción de un mejor derecho, de un derecho más cercano al anhelo de alcanzar unas condiciones de existencia que posibiliten materializar una auténtica dignidad humana. La postura ética está fundamentada en que todo conocimiento debe estar al servicio del mejoramiento de las condiciones de existencia del ser humano y principalmente de los más necesitados”. (Díaz, 2009, p. 18).

El llamado ético que hace Díaz (2009) a la Psicología Jurídica, impone el deber a esta ciencia de mejorar a través de su ejercicio, práctica e investigación las 


\section{LA PSICOLOGÍA JURÍDICA COMO UNA FUENTE DEL DERECHO}

condiciones de existencia de todas personas, pero principalmente de aquellos que más lo necesitan, ya sea por su condición económica, cultural, social, de salud, sexo, género, raza, etc.

Otra de las acepciones de la Psicología Jurídica que se discute en diversos textos sobre esta área del conocimiento amplía es la lectura integrativa que hace Kapardis (2010) de la Psicología Jurídica desde tres de los ámbitos de aplicación de ésta:

La plétora o abundancia de aplicaciones de la Psicología al Derecho pueden ser diferenciadas en los términos en que éstas han sido definidas como: a) Psicología en el derecho, b) Psicología y Derecho; y c) Psicología del Derecho. De acuerdo con Blackburn (1996:6) la Psicología en el Derecho se refiere a las aplicaciones específicas de la Psicología dentro del Derecho: como la fiabilidad del testigo presencial, el estado mental del acusado, la idoneidad de un padre para la custodia de los hijos en caso de divorcio. La Psicología en el Derecho ha sido la más común de las tres diferenciaciones antes mencionadas y la fuente de muchas preocupaciones en la Psicología Jurídica. Psicología y Derecho es usada por Blackburn (1996), para indicar, por ejemplo, la investigación psicojurídica en infractores, abogados, magistrados, jueces y jurados. Finalmente, la Psicología del Derecho es usada para referirse a la investigación psicológica en asuntos como porque la gente obedece o desobedece las normas, el desarrollo moral y las percepciones públicas y actitudes hacia las sanciones penales (Kapardis, 2010, p.2). 


\section{LA PSICOLOGÍA JURÍDICA COMO UNA FUENTE DEL DERECHO}

Esta lectura que Kapardis (2010) hace de Blackburn (1996), amplía el espectro epistemológico y práctico de lo que puede ser la Psicología Jurídica en relación con el Derecho.

De otro lado, la Profesora Consuelo Hoyos (2013), en su trabajo Dilemas Psicojurídicos en Materia de Derecho Penal Juvenil propone que:

La psicología Jurídica que entrelaza las disciplinas jurídica y psicológica, ofrece un campo de acción más amplio en tanto que se ocupa de los principios jurídicos básicos de los problemas jurídicos fundamentales en los diferentes campos del Derecho y su relación con la subjetividad, de aquí que se pretenda otra cosa: la conjugación de los elementos jurídicos y psicológicos para comprender al sujeto (su mundo interno, sus relaciones, sus vivencias, sus comportamientos) en asocio al deber ser que se explicita en el acatamiento o no, y en el cumplimiento, o no, de normas impuestas por la ley (Hoyos, 2013, págs. 17-18).

Aunque esta definición invita a que la relación entre la Psicología y el Derecho enfoque sus esfuerzos en el estudio de los principios jurídicos y problemas jurídicos fundamentales que intentan comprender y regular la relación entre el Derecho y la subjetividad, ejercicio necesario de la Psicología Jurídica, deja por fuera una de las funciones urgentes y necesarias que debe emprender la Psicología Jurídica, éste es su participación en la creación y modificación del Derecho, o de la construcción de un mejor Derecho como lo menciona Díaz (2009). 


\section{LA PSICOLOGÍA JURÍDICA COMO UNA FUENTE DEL DERECHO}

Miguel Clemente (2012) propone una innovadora y realista definición de la psicología jurídica en su trabajo titulado El Papel de las Ciencias Sociales y del Comportamiento en la Ley. Una definición de la Psicología Jurídica.

Para Clemente, la Psicología Jurídica es una ciencia sincrética que surge o nace del derecho, la medicina y la psiquiatría (Clemente, 2012, p.102), pero que debe movilizarse y construir una auténtica disciplina bien definida.

Clemente parte de la idea de que el Derecho es una ciencia que necesita fundamentos teóricos acerca del comportamiento humano social y las relaciones humanas, y de acuerdo con este autor, este fundamento puede brindárselo la Psicología Social y la Psicología Política, por eso apuesta por una definición de la Psicología Jurídica como la unión de estas dos áreas de la psicología (Clemente, 2012), y la define de la siguiente manera:

Es el estudio del comportamiento de las personas y de los grupos de cara a crear normas y formas de convivencia social que permitan la convivencia y consiguientemente el desarrollo de las personas en sociedad, normas que al tomar cuerpo jurídico conforman el denominado Derecho Positivo, y que se basan en los principios científicos verificados por la Psicología Social. La creación de dichas normas se guiará especialmente por la teoría de los valores y la motivación, y verificará la posibilidad de que la futura norma cree conducencia, basándose para ello en las teorías de la Persuasión, y en el Comportamiento Colectivo. Asimismo, instaurada la norma, la Psicología Jurídica estudia el comportamiento en cuanto que se desenvuelve dentro de los 


\section{LA PSICOLOGÍA JURÍDICA COMO UNA FUENTE DEL DERECHO}

ambientes jurídicos y respetando normas jurídicas, y de la evolución de las sociedades, que implica el cambio a su vez de la normas (Clemente, 2012, p. 106).

El autor no solo propone esta amplia definición de la Psicología Jurídica sino también los principios orientados de esta ciencia sincrética, lo cuales se transcriben a continuación:

1. Aplicar los principios psicosociales a la regulación de la vida social.

2. Ayudar al sistema de justicia en la determinación de la verdad de los hechos, de cara a conseguir tanto la justicia individual como la social en su conjunto.

3. Contribuir al funcionamiento adecuado de las organizaciones jurídicas, aplicando los principios de la Psicología del Trabajo y de las Organizaciones.

4. Diagnosticar y evaluar la existencia de características psicológicas importantes para el sistema jurídico. Así la inimputabilidad, la enfermedad mental transitoria o no, la posibilidad de recordar un hecho, la comprobación de la veracidad de una declaración, la detección de una patología.

5. Rehabilitar y reinsertar socialmente.

6. Atender a la salud psicosocial de las personas que por la razón que sea (víctimas, agresores, reclusos, detenidos, etc.) sufren cualquier tipo de desequilibrio psicológico, y por lo tanto requieren de una intervención psicológico para restablecer su equilibrio como personas. 


\section{LA PSICOLOGÍA JURÍDICA COMO UNA FUENTE DEL DERECHO}

7. Atender a los sistemas de creencias de la sociedad.

8. Velar por el estado del pacto social y socializar en valores democráticos y de respeto a la sociedad. (Clemente, 2012, págs. 100-101).

Como se puede leer en las anteriores definiciones de Psicología Jurídica, dos de ellas coinciden con la postura epistemológica pragmática que orienta esta indagación, estas son las definiciones de Díaz (2009) y la de Clemente (2012), aunque para por para los efectos de la indagación epistemológica, la indagación fenomenológica y la indagación ética de la Psicología Jurídica se utilizará la definición de Clemente (2012) teniendo en cuenta su amplitud y especificidad.

Esta definición (Clemente,2012), aportará las respuestas fundamentales que realiza la indagación tripartita Iusfilosófica a la Psicología Jurídica, puesto que ésta abren el campo de acción de la Psicología Jurídica y le otorgan unas funciones y principios en los diferentes momentos del Derecho, con el propósito de contribuir a la evolución de las sociedad y el respeto de las normas jurídicas válidos, justas y conducentes que han sido creadas con base en las teorías y la realidad del comportamiento humano social.

Entonces, en uno de los apartados del siguiente capítulo se realizaré un análisis detallado del objeto de estudio de la psicología con base en la definición antes mencionadas.

\subsubsection{Fuentes del derecho.}




\section{LA PSICOLOGÍA JURÍDICA COMO UNA FUENTE DEL DERECHO}

Las fuentes del derecho son todos aquellos hechos, teorías y principios que tienen la posibilidad de determinar la creación de una ley, de una constitución, una decisión judicial o de una institución jurídica. Históricamente dentro de la doctrina jurídica se ha dividido en dos la exposición de las fuentes del derecho. De acuerdo con Jácome (2006):

Se ha dicho que hay unas fuentes materiales del derecho y unas formales. Las primeras responden a la pregunta por qué razón nace el derecho. Dentro de esta perspectiva se dice que la economía, la política, la sociología, la presión de la comunidad internacional, la moral y los ideales de justicia de una sociedad pueden ser razones para que se profiera el derecho. Por otra parte, se habla de las fuentes formales del derecho como aquellas que hacen referencia a los procedimientos que conducen a que ciertos hechos jurídicos sean reconocidos como normas jurídicas dentro de un sistema; se trata de las formas legitimas a través de las cuales se profiere el derecho (2006, p. 286).

En nuestro país, influenciados por el modelo europeo, la exposición de las fuentes formales del Derecho está dominada por la imagen del esquema piramidal en donde se establece una jerarquía entre las normas que integran el sistema jurídico.

Esto significa que el Derecho colombiano ha estado determinado por la estructura jerárquica y normativa de los sistemas jurídicos europeos, que funcionan de acuerdo con la propuesta del jurista germánico Hans Kelsen. La teoría kelseniana del derecho propone una organización sistemática del derecho en forma piramidal. Sistema que tiene en la cúspide a la Constitución o Norma Fundamental del sistema jurídico, pasando por las leyes orgánicas, reglamentarias y generales, hasta las decisiones jurídicas concretas y los acuerdos unilaterales y bilaterales de la voluntad. 


\section{LA PSICOLOGÍA JURÍDICA COMO UNA FUENTE DEL DERECHO}

Esta estructura limita y determina la creación, modificación y derogación del sistema jurídico positivo, el cual en muchos casos desconoce o ignora los fenómenos reales de los individuos y la sociedad, situación que genera profundos problemas sociales teniendo en cuenta que dichos fenómenos se evalúan de acuerdo al parámetro normativo y sólo en casos excepcionales se acude a los conocimientos, conceptos, constructos, prácticas y experimentos científicos de otras ciencias para la creación, modificación a aplicación del Derecho en Colombia.

En este trabajo se propone y crea una lectura más amplia de las fuentes del derecho, la cual permita la inclusión de los conocimientos, prácticas y teorías de otras ciencias como fuentes del derecho. Además se plantea la visión de estas fuentes desde tres perspectivas, estas son, la perspectiva histórica, la perspectiva teórico-jurídica y la perspectiva filosófica.

La perspectiva tríadica que se presenta a continuación de las fuentes del Derecho, es decir, la mirada histórica, filosófica y teórica de éstas, y la propuesta de inclusión de la ciencia como una fuente del Derecho, es producto de mi valor-acción del contacto que he tenido con el Derecho, con la Filosofía del Derecho a la largo de cinco años y recientemente con la Psicología Jurídica en el ámbito académico, como docente e investigadora de las primeras, y estudiante de Psicología Jurídica. Esta propuesta se presenta en tablas para su mayor comprensión:

\begin{tabular}{|c|c|c|}
\hline $\begin{array}{l}\text { Perspectiva Histórica } \\
\text { de las Fuentes del } \\
\text { Derecho de acuerdo } \\
\text { con } \\
\text { Carnelutti }(2015)\end{array}$ & $\begin{array}{l}\text { Perspectiva Teórica del } \\
\text { Derecho, de acuerdo } \\
\text { con la Teoría Jurídica. }\end{array}$ & 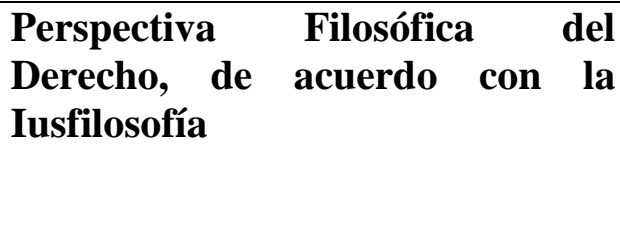 \\
\hline $\begin{array}{l}\text { La Propiedad Privada: } \\
\text { Separación entre lo que }\end{array}$ & $\begin{array}{l}\text { 1. El Acuerdo de } \\
\text { voluntades como fuente }\end{array}$ & $\begin{array}{l}\text { Desde la perspectiva filosófica la } \\
\text { propiedad de sí mismo y de lo }\end{array}$ \\
\hline
\end{tabular}




\begin{tabular}{|c|c|c|}
\hline $\begin{array}{l}\text { es mío y lo que es de } \\
\text { otro. } \\
\text { De acuerdo con } \\
\text { Carnelutti (2015), la } \\
\text { propiedad privada es } \\
\text { creada por los seres } \\
\text { humanos con el objetivo } \\
\text { de satisfacer las } \\
\text { necesidades básicas } \\
\text { (alimentación, crianza y } \\
\text { reproducción, crianza la } \\
\text { educación de los hijos, } \\
\text { conservación de le la } \\
\text { especie, techo, higiene, } \\
\text { desarrollo de empatía) en } \\
\text { un espacio seguro que } \\
\text { les permita protegerse de } \\
\text { los depredadores; y de } \\
\text { otro lado para ocupar un } \\
\text { lugar con respecto a sus } \\
\text { congéneres y establecer } \\
\text { relaciones regladas. } \\
\text { Entre las necesidades } \\
\text { mundanas creadas por } \\
\text { los hombres con el } \\
\text { propósito anteriormente } \\
\text { descrito están, el vestido, } \\
\text { el dinero, el arte, la } \\
\text { religión la tecnología, la } \\
\text { escuela, las clases } \\
\text { sociales, el poder, los } \\
\text { sistemas económicos, } \\
\text { políticos y jurídicos, } \\
\text { dando así origen al } \\
\text { Estado y al Derecho. } \\
\text { etc. }\end{array}$ & $\begin{array}{l}\text { del derecho consiste en } \\
\text { los pactos o contratos } \\
\text { que realizan las personas } \\
\text { sobre su propiedad. Esta } \\
\text { fuente del Derecho } \\
\text { origina la dicotomía } \\
\text { entre Derechos y } \\
\text { Obligaciones, Acreedor y } \\
\text { Deudor, Propietario e } \\
\text { Inquilino, Título y Modo } \\
\text { de adquirir el dominio. } \\
\text { 2. Doctrina: Esta es la } \\
\text { segunda fuente del } \\
\text { derecho que se } \\
\text { corresponde con la } \\
\text { fuente histórica de la } \\
\text { propiedad, puesto que la } \\
\text { doctrina es el } \\
\text { pensamiento subjetivo o } \\
\text { colectivo particular, } \\
\text { teórico-científico sobre el } \\
\text { deber ser del Derecho y } \\
\text { los creadores de dichas } \\
\text { teorías ejercen los } \\
\text { derechos de propiedad } \\
\text { intelectual sobre éstos. }\end{array}$ & $\begin{array}{l}\text { OTRO implica o impone como } \\
\text { límite la Responsabilidad, en el } \\
\text { sentido de que al ser dueño de mis } \\
\text { acciones debo responder } \\
\text { necesariamente por las } \\
\text { consecuencias de éstas. Así lo } \\
\text { postula el pensamiento kantiano } \\
\text { sobre el que está estructurado el } \\
\text { derecho moderno, este el Principio } \\
\text { de Imputación según el cual toda } \\
\text { acción tiene un ejecutor. }\end{array}$ \\
\hline $\begin{array}{l}\text { La Guerra: Como } \\
\text { fuente del derecho, la } \\
\text { guerra origina acuerdos o } \\
\text { pactos entre los grupos } \\
\text { humanos en conflicto } \\
\text { con el objetivo de } \\
\text { encontrar la paz, volver } \\
\text { al orden anterior, } \\
\text { conservar un orden o }\end{array}$ & $\begin{array}{l}\text { 3. Costumbre: como } \\
\text { fuente de derecho la } \\
\text { costumbre se refiere a los } \\
\text { hábitos humanos que se } \\
\text { practican dentro de una } \\
\text { comunidad, y que son } \\
\text { adquiridas y transmitidas } \\
\text { por dicha comunidad a } \\
\text { los miembros de la }\end{array}$ & $\begin{array}{l}\text { La perspectiva filosófica explica } \\
\text { desde esta fuente el surgimiento del } \\
\text { Estado como la institución que } \\
\text { organiza la sociedad y en la que los } \\
\text { individuos, las familias, las clases } \\
\text { sociales, la iglesia, la escuela, los } \\
\text { oficios, etc. se articulan de manera } \\
\text { armónica para otorgar a cada uno } \\
\text { de los integrantes sus derechos y }\end{array}$ \\
\hline
\end{tabular}




\begin{tabular}{|c|c|c|}
\hline n. & $\begin{array}{l}\text { misma. Las costumbres } \\
\text { se codifican en normas y } \\
\text { responden al poder } \\
\text { organizador del lenguaje } \\
\text { humano. La costumbre } \\
\text { determina a los grupos } \\
\text { sociales humanos a la } \\
\text { búsqueda del poder, la } \\
\text { paz y el orden, todos } \\
\text { estos elementos presentes } \\
\text { en la guerra. } \\
\text { 4. Derecho } \\
\text { Internacional: Se refiere } \\
\text { a los acuerdos o tratados } \\
\text { entre diferentes Estados a } \\
\text { propósito de sus } \\
\text { relaciones soberanas, los } \\
\text { derechos humanos, los } \\
\text { ciudadanos y el estado, la } \\
\text { guerra y la paz, el } \\
\text { intercambio de bienes y } \\
\text { servicios entre estados y } \\
\text { entre ciudadanos de } \\
\text { diferentes estados, la } \\
\text { migración, etc. }\end{array}$ & $\begin{array}{l}\text { vigilar con la «fuerza legítima» las } \\
\text { relaciones de los individuos entre sí } \\
\text { y la de éstos con el Estado. }\end{array}$ \\
\hline $\begin{array}{l}\text { La Moral: De acuerdo } \\
\text { con Carnelutti (2015) la } \\
\text { moral como fuente del } \\
\text { derecho hace referencia a } \\
\text { la determinación de la } \\
\text { voluntad que tiene lugar } \\
\text { por amor a las leyes } \\
\text { universales del amor, el } \\
\text { bien, la verdad, la } \\
\text { justicia. Se refiere o se } \\
\text { predica de las acciones } \\
\text { conformes al deber. } \\
\text { Se presume por tanto } \\
\text { desde esta perspectiva } \\
\text { que los hombres que } \\
\text { aman el bien ejercen sus } \\
\text { derechos y respetan los } \\
\text { límites de éstos que son } \\
\text { impuestos por los } \\
\text { derechos de los demás. }\end{array}$ & $\begin{array}{l}\text { 6. Principios Generales } \\
\text { del Derecho: } \\
\text { Son conceptos o } \\
\text { proposiciones de } \\
\text { naturaleza axiológica que } \\
\text { informan acerca del } \\
\text { contenido y la estructura } \\
\text { de las normas y del } \\
\text { propio Derecho } \\
\text { Estos son: } \\
\text {-Buenafe } \\
\text {-Pacta sunt Servanda } \\
\text { Prohibición } \\
\text { aprovechamiento por el } \\
\text { dolo propio. } \\
\text {-Protección de los } \\
\text { derechos adquiridos } \\
\text { conforme a la ley. } \\
\text { Prohibición de } \\
\text { Simulación y Fraude a la }\end{array}$ & $\begin{array}{l}\text { El sentido moral hace referencia } \\
\text { según Kant a la conciencia acerca } \\
\text { de la existencia del Bien. Este } \\
\text { puede concebirse como: } \\
\text { Como de origen divino o de origen } \\
\text { natural. } \\
\text { Como innato o como adquirido. } \\
\text { Como objetivo o como subjetivo. } \\
\text { Como personal o como impersonal. } \\
\text { Como individual o como social. } \\
\text { Como natural o como histórico. } \\
\text { Como racional o como irracional. } \\
\text { Como determinado por el amor o } \\
\text { como determinado por la voluntad. } \\
\text { Como auténtico o como ficticio. } \\
\text { (Ferrater, 2004, p. } 347 \text { ) } \\
\text {. }\end{array}$ \\
\hline
\end{tabular}




\begin{tabular}{|c|c|c|c|}
\hline & $\begin{array}{l}\text { ley } \\
\text { Abuso del Derecho } \\
\text { Enriquecimiento } \\
\text { causa. } \\
\text { El bien común como } \\
\text { límite de la propiedad } \\
\text { privada. } \\
7 . \text { La Constitución: Es } \\
\text { la fuente del derecho } \\
\text { suprema en los estados } \\
\text { modernos y } \\
\text { postmodernos, la cual } \\
\text { implica una declaración } \\
\text { de derechos y una } \\
\text { organización inspirada en } \\
\text { cierta interpretación del } \\
\text { principio de separación } \\
\text { de poderes. unidad del } \\
\text { sistema jurídico. }\end{array}$ & & \\
\hline \multirow{5}{*}{$\begin{array}{l}\text { La Norma: Es toda } \\
\text { proposición descriptiva, } \\
\text { prescriptiva, hipotética o } \\
\text { categórica que enuncia el } \\
\text { funcionamiento de la } \\
\text { naturaleza o impone un } \\
\text { modelo de } \\
\text { comportamiento o acción } \\
\text { a los seres humanos. Su } \\
\text { origen histórico proviene } \\
\text { del Nómos de los griegos } \\
\text { que se traduce como uso, } \\
\text { costumbre, mandato y } \\
\text { con ello da un cierto } \\
\text { orden LINGÜÍSTICO a } \\
\text { la naturaleza, los } \\
\text { hombres y el mundo. }\end{array}$} & \multirow{5}{*}{$\begin{array}{l}\text { 8. Ley: Es una norma } \\
\text { jurídica dictada por el } \\
\text { legislador, es decir, un } \\
\text { por la autoridad } \\
\text { competente, en que se } \\
\text { manda o prohíbe algo de } \\
\text { acuerdo con la costumbre } \\
\text { y la justicia. Su } \\
\text { incumplimiento implica } \\
\text { una sanción. } \\
\text { 9. Jurisprudencia: es la } \\
\text { decisión del más alto } \\
\text { tribunal de un país que al } \\
\text { resolver un caso concreto } \\
\text { establece un principio o } \\
\text { doctrina jurídica } \\
\text { vinculante para el mismo } \\
\text { tribunal y para todos los } \\
\text { órganos inferiores que } \\
\text { dicen el derecho. }\end{array}$} & \multicolumn{2}{|c|}{$\begin{array}{l}\text { Desde la perspectiva filosófica se } \\
\text { presenta la diferencia entre las leyes } \\
\text { de la naturaleza y las leyes de la } \\
\text { libertad. }\end{array}$} \\
\hline & & $\begin{array}{l}\text { Leyes de la } \\
\text { naturaleza }\end{array}$ & $\begin{array}{ll}\text { Leyes de la } \\
\text { libertad }\end{array}$ \\
\hline & & $\begin{array}{l}\text { 1. Describe los } \\
\text { HECHOS de la } \\
\text { naturaleza. }\end{array}$ & $\begin{array}{l}\text { 1. Prescribe y } \\
\text { proscribe } \\
\text { ACCIONES } \\
\text { humanas. }\end{array}$ \\
\hline & & $\begin{array}{lr}2 . & \text { Están } \\
\text { regidas por } & \text { el } \\
\text { principio } & \text { de } \\
\text { causalidad: } & \\
\text { TODA } & \\
\text { CAUSA } & \\
\text { TIENE } & \\
\text { EFECTO } & \\
\end{array}$ & $\begin{array}{lr}2 . & \text { Están } \\
\text { regidas por el } \\
\text { principio de } \\
\text { Imputación: } \\
\text { TODA } \\
\text { ACCIÓN } \\
\text { TIENEN UN } \\
\text { EJECUTOR }\end{array}$ \\
\hline & & $\begin{array}{l}3 . \quad \mathrm{Su} \\
\text { incumplimiento } \\
\text { no implica una } \\
\text { sanción. }\end{array}$ & $\begin{array}{lr}3 . \quad \mathrm{Su} \\
\text { incumplimiento } \\
\text { implica una } \\
\text { sanción. }\end{array}$ \\
\hline
\end{tabular}




\begin{tabular}{|c|c|c|}
\hline & & 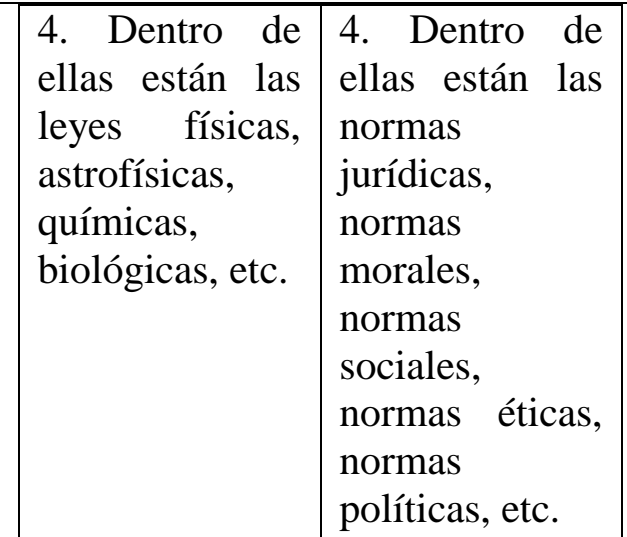 \\
\hline $\begin{array}{l}\text { La Ciencia } r \\
\text { construcción } \\
\text { epistemológica de los } \\
\text { seres humanos que } \\
\text { describe, explica } \\
\text { conceptualiza } \\
\text { naturaleza y el mundo } \\
\text { con el fin de permitir la } \\
\text { adaptación de los seres } \\
\text { humanos en la naturaleza } \\
\text { y la evolución cultural de } \\
\text { la especie. }\end{array}$ & $\begin{array}{l}\text { 10. Los Datos de las } \\
\text { Ciencias como Fuente } \\
\text { de Derecho } \\
\text { La inclusión de los datos } \\
\text { de las ciencias en los } \\
\text { procesos creativos del } \\
\text { Derecho puede brindarle } \\
\text { a éste, un conocimiento } \\
\text { holístico de la vida, el } \\
\text { mundo, la sociedad, el } \\
\text { hombre, y las relaciones } \\
\text { entre éstos, con el fin de } \\
\text { resolver los conflictos } \\
\text { humanos y propiciar la } \\
\text { convivencia armónica y } \\
\text { la equidad social. }\end{array}$ & $\begin{array}{l}\text { Principio de Unidad de las } \\
\text { Ciencias: «Una primera verdad que } \\
\text { puede brotar de estas reflexiones, es } \\
\text { aquella que puede llamarse de la } \\
\text { Unidad de las Ciencia o también, } \\
\text { en otros términos, de la } \\
\text { Interdependencia de las ciencias. } \\
\text { Como la materia de las diversas } \\
\text { ciencias no son un diverso mundo, } \\
\text { sino un diverso aspecto del único } \\
\text { mundo al cual debemos limitar } \\
\text { nuestro trabajo, porque somos } \\
\text { pequeños, y el mundo es inmenso, } \\
\text { así los resultados de este trabajo no } \\
\text { son diversos sino porque son las } \\
\text { diversas caras de un prisma único". } \\
\text { (Carnelutti, 1962.p 15) }\end{array}$ \\
\hline
\end{tabular}

Después de definir el horizonte epistemológico, el marco metodológico y los conceptos que orientan la indagación epistemológica, fenomenológica y ética de la Psicología Jurídica, se presenta en el capítulo que sigue, el primer momento de la Indagación Iusfilosófica Tripartita, ésta es la Indagación Epistemológica de la Psicología Jurídica. 


\section{Capítulo II. Indagación Epistemológica de la Psicología Jurídica}

La indagación epistemológica de la psicología jurídica consiste en cuestionar los problemas epistemológicos fundamentales de esta ciencia desde las tres cuestiones básicas del conocimiento humano abordadas en el capítulo anterior, estas son: los presupuestos epistemológicos de la psicología jurídica, la posibilidad del conocimiento (Hessen, 1981) real de los objetos que esta ciencia estudia y el origen del conocimiento psicojurídico.

Los presupuestos epistemológicos hacen referencia a los elementos necesarios que deben concurrir para conocer un fenómeno. El espacio y el tiempo en los que aparece el fenómeno son los presupuestos a priori, es decir, necesarios e independientes a la voluntad

del hombre que conoce. Éstos determinan el contexto del fenómeno, el cuál puede consistir en un objeto físico, virtual, imaginario, fantástico o ideal como en el caso de las teorías, las leyes de las ciencias y los conceptos.

El objeto de conocimiento es el tercer presupuesto epistemológico, y hace referencia a aquello que va a ser conocido y que se encuentra no sólo en la naturaleza sino también en el ámbito de las creaciones humanas, por ello existen diferentes clases de objetos de conocimiento. Éstos pueden consistir en una cosa, una persona, un fenómeno de la naturaleza, un comportamiento animal y/o humano, una idea, una teoría, una ciencia, un planeta, una galaxia, un animal, una planta, una roca, una idea, un concepto, etc. 


\section{LA PSICOLOGÍA JURÍDICA COMO UNA FUENTE DEL DERECHO}

El sujeto que conoce, es el cuarto presupuesto, requerido por la epistemología filosófica de occidente para que se dé el fenómeno del conocimiento. Este sujeto es un presupuesto epistemológico cualificado, pues debe contar con unas características específicas para poder relacionarse con el objeto de conocimiento. Estas características varían de acuerdo al epistemólogo que las propone. Descartes por ejemplo, exige que el sujeto cognoscente sea autoconsciente, es decir, capaz de reconocer su existencia y la de lo otro. Kant, el alemán de la ilustración, describe dos elementos más, y ellos son las facultades humanas que le permiten al hombre conocer los objetos del universo: el entendimiento, facultad que organiza la información que viene de los sentidos, y la imaginación, característica que le permite al hombre jugar libremente con la información del entendimiento y crear objetos fantásticos.

Johannes Hessen (1981) agrega la importancia que tiene el sujeto en el acto del conocimiento, la cual consiste en la capacidad que debe tener el sujeto para crear la imagen del objeto y que ésta corresponda al objeto real.

Filósofos como Nietzsche y Michel Foucault critican este sujeto epistemológico, ya que según ellos, teorizar sobre el sujeto cognoscente no es más que un ejercicio de poder y control sobre la naturaleza humana, con múltiples finalidades.

El método es el quinto presupuesto epistemológico y consiste en seguir un camino, para alcanzar un fin específico propuesto de antemano, es por ello que todo método implica seguir unas reglas lógicas sean inductivas o deductivas para conocer el objeto de estudio.

Después de ubicar los elementos o presupuestos epistemológicos básicos de la psicología jurídica a partir de la definición de esta ciencia planteada por Clemente (2012) 


\section{LA PSICOLOGÍA JURÍDICA COMO UNA FUENTE DEL DERECHO}

que se hace a continuación, se discutirá desde varios autores, las otras dos cuestiones epistemológicas a propósito de la psicología jurídica, es decir, la posibilidad del conocimiento de los objetos psicojurídicos y el origen del conocimiento de esta ciencia.

\subsection{Tiempo-espacio del derecho y de la psicología jurídica.}

Del mismo modo que existe diferentes clases de objetos que los seres humanos podemos conocer, tales como los objetos físicos, los objetos virtuales, los objetos imaginarios, los objetos fantásticos, lo objetos ideales, etc., es indispensable que exista un tiempo-espacio a priori para éstos.

Entonces, cuando se habla de espacio no solo se hace referencia al vacío físico que es ocupado por objetos físicos, sino también al espacio-tiempo psíquico o lugar en el que suceden los fenómenos de la psique, tales como el pensamiento, la atención, la memoria, el deseo, etc.; al espacio-tiempo virtual, que de un lado hace referencia al "ambiente conceptual, abstracto e intangible... que pertenece al mundo digital...y hace posible la interacción en tiempo real sin necesidad de que exista la proximidad física" (Rodríguez, 2007, p. 94); y al espacio-tiempo ideal o lugar en el que se ordenan las ideas y conceptos humanos que determinan el rumbo de las sociedades, tales como las teorías, las leyes del conocimiento objetivo de las ciencias, las normas morales, las normas religiosas, las normas jurídicas, las normas políticas, las normas económicas, etc. (Zizek, 2002).

A propósito de la definición de la Psicología Jurídica planteada por Clemente (2012), es necesario advertir que esta definición propone entender a la psicología jurídica como una ciencia sincrética, que congrega los conocimientos de la Psicología Social y la Psicología Política, con la intención de comprender "el comportamiento de las personas y 


\section{LA PSICOLOGÍA JURÍDICA COMO UNA FUENTE DEL DERECHO}

de los grupos de cara a crear normas y formas de convivencia social que permitan la convivencia y consiguientemente el desarrollo de las personas en sociedad" (Clemente, 2012, p. 106).

Por lo tanto, antes de pasar a identificar el espacio-tiempo de esta ciencia que integra los conocimientos de la Psicología Social y la Psicología Política, se deben revisar las definiciones éstas, con el objetivo de identificar los aportes que le hacen estas ciencias a la Psicología Jurídica y comprender con mayor detalle la propuesta de Clemente (2012) que se describió en el capítulo I, apartado 1.3.2.

De acuerdo con Schneider, Gruman, y Coutts (2012, p. 4), la psicología social "debe ser definida como la ciencia que busca entender como la gente piensa, siente, se relaciona y es influenciada por otros". Afirman los autores, que el propósito científico de esta ciencia consiste en describir el fenómeno psicosocial, determinar su causalidad, predecir su desarrollo y explicar su funcionamiento.

La descripción de los fenómenos psicosociales se refiere a la identificación de los detalles de los fenómenos que estudia, su clasificación y el reporte de su frecuencia y ocurrencia. La predicción de estos fenómenos requiere del conocimiento de la correlación entre los factores descritos. Determinar la causalidad de los fenómenos psicosociales implica determinar los cambios que un factor produce en otros factores. Y la explicación consiste en establecer porque ocurre un fenómeno o una relación entre fenómenos. (Schneider, Gruman, y Coutts, 2012).

Para Schneider, Gruman, y Coutts (2012, p. 15), el núcleo de las hipótesis de la psicología social consiste en que la conducta de los individuos está fuertemente 


\section{LA PSICOLOGÍA JURÍDICA COMO UNA FUENTE DEL DERECHO}

influenciada por la situación social o el contexto, en el que los seres humanos nacemos, crecemos, construimos, interpretamos y morimos. Por ello la teoría y la investigación psicosocial se concentran en comprender la influencia de los factores personales y los factores sociales en las personas.

Finalmente, afirman los autores, que el telos o la meta de la psicología social es "generar un cambio positivo y mejorar el funcionamiento de las personas en la sociedad". (Schneider, Gruman, y Coutts (2012, p. 8).

Entonces, se puede concluir que el gran aporte que le hace la Psicología Social a la Psicología Jurídica consiste en la comprensión y la explicación detallada del comportamiento social de las personas y los grupos, los factores contextuales que la determinan y las alternativas de intervención.

Estos conocimientos de la Psicología Social también le permiten a la Psicología Jurídica comprender la influencia del contexto en los comportamientos sociales y personales jurídicos y antijurídicos, la influencia de las normas sociales y de las normas jurídicas en el comportamiento humano, etc., datos que le permiten a la psicología jurídica proponer desde la ciencia la creación de normas jurídicas conducentes, la prevención de los comportamientos transgresores de los congéneres, el entendimiento del comportamiento violento, la evaluación de los individuos transgresores, el funcionamiento de las instituciones jurídicas, la intervención especializada en el foro, etc.

De otro lado, de acuerdo con Sears, Huddy \& Jervis (2004) citado por Erişen (2012, p. 9), la psicología política "a nivel general es la aplicación de lo que se conoce acerca de la psicología humana al estudio de la política”. Por ello Erișen afirma que la psicología 


\section{LA PSICOLOGÍA JURÍDICA COMO UNA FUENTE DEL DERECHO}

política reúne los conocimientos de todas las ciencias y disciplinas que estudian desde diferentes perspectivas la psicología humana con el objetivo de explicar "el fenómeno político a nivel individual y con énfasis en el proceso" (Erişen, 2012, p. 9).

Algunos de los objetos de estudio de la Psicología Política que menciona la autora son: "el liderazgo, el comportamiento político de las masas, las relaciones entre grupos, la toma de decisiones, los efectos de la comunicación masiva, los movimiento políticos y la movilización política”. Erișen (2012, p. 9)

Según Houghton, (2009) el principal objeto de estudio de la Psicología Política es el comportamiento político y afirma que éste "se refiere a cualquier tipo de actividad diseñada para encontrar algún fin político" (Houghton, 2009, p. 6).De acuerdo con el autor, el comportamiento político de los seres humanos va desde el simple acto del voto hasta las acciones calificadas como terroristas, los comportamientos racistas, el genocidio, la guerra, etc.

La Psicología Política ofrece los conocimientos necesarios acerca de la influencia que tienen el poder político y las relaciones políticas emanadas del Estado en el sistema jurídico y las instituciones jurídicas que pertenecen a éste. Por ello la psicología jurídica requiere de estos conocimientos, con la intención de comprender la influencia de las relaciones políticas, las decisiones políticas y el comportamiento político de los agentes del Estado y de los ciudadanos pertenecientes a éste en el campo jurídico.

En palabras de Clemente, la Psicología Jurídica requiere de estos saberes políticos, “dado que el Derecho debe enmarcarse dentro del denominado Estado de Derecho y, por 


\section{LA PSICOLOGÍA JURÍDICA COMO UNA FUENTE DEL DERECHO}

tanto, supeditado al poder político, la Psicología Política supone un aporte fundamental” (2012, p. 105).

Esta propuesta integrativa de Clemente abre el espectro de acción de la Psicología Jurídica como ciencia sincrética que integra los conocimientos de la Psicología Social y la Psicología Política, lo cual permite ubicarla en diferentes espacios en relación con el derecho como se propone en las siguientes tablas ${ }^{4}$ :

\begin{tabular}{|c|c|c|}
\hline Clase de Espacio-tiempo & $\begin{array}{l}\text { Espacio-tiempo de la } \\
\text { Psicología Jurídica }\end{array}$ & $\begin{array}{l}\text { Espacio-tiempo del } \\
\text { Derecho }\end{array}$ \\
\hline Real & $\begin{array}{l}\text { - Presente, pasado y posible } \\
\text { futuro de las relaciones } \\
\text { entre las personas y los } \\
\text { grupos con trascendencia } \\
\text { jurídica, es decir, aquellos } \\
\text { comportamientos humanos } \\
\text { sociales que tienen que ver } \\
\text { con los tres momentos del } \\
\text { derecho: creación del } \\
\text { derecho (creadores de las } \\
\text { normas jurídicas y de las } \\
\text { teorías jurídicas); aplicación } \\
\text { (jueces, funcionarios } \\
\text { públicos y privados que } \\
\text { tiene dentro sus funciones } \\
\text { la aplicación de normas } \\
\text { jurídicas y la verificación }\end{array}$ & $\begin{array}{l}\text {-El Derecho a través de sus } \\
\text { enunciados normativos y la } \\
\text { aplicación de sanciones } \\
\text { afecta el cuerpo y la psique } \\
\text { de los seres humanos que } \\
\text { intervienen en los procesos } \\
\text { jurídicos: Receptores de las } \\
\text { normas jurídicas, creadores } \\
\text { de las normas jurídicas y } \\
\text { aplicadores e intérpretes de } \\
\text { éstas. } \\
\text {-Las Instituciones Jurídicas } \\
\text { y Políticas creadas por las } \\
\text { normas jurídicas. } \\
\text {-Los bienes, objeto de } \\
\text { propiedad privada. } \\
\text {-Los bienes públicos. }\end{array}$ \\
\hline
\end{tabular}

${ }^{4}$ Fuente de las tablas, la autora del documento. 


\begin{tabular}{|c|c|c|}
\hline & $\begin{array}{l}\text { del cumplimiento de las } \\
\text { mismas); recepción del } \\
\text { derecho políticos y } \\
\text { funcionarios distadanos, } \\
\text { actores delicos, } \\
\text { destinatarios del sociales, } \\
\text { jurídico en general). } \\
\text {-los contextos } \\
\text { jurídicos y políticos donde } \\
\text { surgen y se desarrollan las } \\
\text { relaciones entre } \\
\text { personas y los grupos con } \\
\text { trascendencia jurídica. }\end{array}$ & \\
\hline Virtual & $\begin{array}{l}\text { Los mensajes de los } \\
\text { discursos que circulan por } \\
\text { el espacio de la red de } \\
\text { información INTERNET y } \\
\text { la influencia de éstos en las } \\
\text { relaciones entre personas y } \\
\text { grupos con transcendencia } \\
\text { jurídica; y la influencia en } \\
\text { el comportamiento humano } \\
\text { transgresor y/o respetuoso } \\
\text { de las normas del sistema } \\
\text { jurídico y social. }\end{array}$ & $\begin{array}{l}\text { La Información que circula } \\
\text { por la Red de información } \\
\text { INTERNET, con la } \\
\text { intención de controlar la } \\
\text { legalidad de dicha } \\
\text { información. }\end{array}$ \\
\hline Ideal & $\begin{array}{l}\text { Las ideas y teorías de la } \\
\text { psicología, la psicología } \\
\text { social, la psicología } \\
\text { política, la conducencia de } \\
\text { la norma, las teorías sobre } \\
\text { la personalidad y el }\end{array}$ & $\begin{array}{l}\text {-Las ideas y teorías que } \\
\text { explican e informan acerca } \\
\text { del funcionamiento del } \\
\text { Derecho y la creación y } \\
\text { aplicación de las normas } \\
\text { jurídicas, las teorías a }\end{array}$ \\
\hline
\end{tabular}




\begin{tabular}{|l|l|l|}
\hline & $\begin{array}{l}\text { comportamiento humano, la } \\
\text { teorías de la persuasión, y } \\
\text { demás teorías que explican }\end{array}$ & $\begin{array}{l}\text { propósito del deber ser del } \\
\text { político de los seres } \\
\text { el comportamiento humano } \\
\text { humanos. } \\
\text { en los contextos jurídicos. }\end{array}$ \\
\hline Psíquico & $\begin{array}{l}\text { Estudia la psique para } \\
\text { encontrar las causas y y } \\
\text { motivos delico y } \\
\text { comportamiento humano } \\
\text { con trascendencia jurídica y } \\
\text { así poder intervenirlo. }\end{array}$ & $\begin{array}{l}\text { Es el espacio al que llega la } \\
\text { surídicas, a través de los }\end{array}$ \\
\hline
\end{tabular}

\subsection{1. ¿Cuáles espacios pueden ser cohabitados por el derecho y la psicología jurídica en Colombia?}

Con la intención de identificar los espacios que pueden ser cohabitados por el derecho y la Psicología Jurídica en Colombia, se presenta a continuación una tabla en la que se trata de ubicar los escenarios jurídicos en los que pueden interactuar ambas ciencias y/o disciplinas en los tres momentos del derecho ${ }^{5}$.

\begin{tabular}{|c|c|c|}
\hline $\begin{array}{l}\text { Momentos o } \\
\text { Tiempos del } \\
\text { Derecho }\end{array}$ & $\begin{array}{l}\text { Espacios del Derecho en Colombia de acuerdo } \\
\text { con la Constitución Política de Colombia de } \\
1991\end{array}$ & $\begin{array}{l}\text { Intervención de la } \\
\text { Psicología Jurídica } \\
\text { en escenarios } \\
\text { jurídico-políticos }\end{array}$ \\
\hline $\begin{array}{l}\text { Creación del } \\
\text { Derecho }\end{array}$ & $\begin{array}{l}\text {-Congreso de la República de Colombia (Arts. } \\
\text { 114, 132, 133, 134, 135, 136,137, 150, 151, 152, } \\
\text { 153,155 C.P.) } \\
\text {-La Presidente de la República (Arts. 115, 189, } \\
\text { C.P.) } \\
\text {-La Corte Constitucional (Arts. 156, } 243 \text { C.P.) } \\
\text {-La Corte Suprema de Justicia (Art. 156 C.P.) } \\
\text {-El Consejo de Estado (Art. 156 C.P.) } \\
\text { - Las Asambleas Departamentales (Arts. } 300\end{array}$ & $\begin{array}{l}\text { Asesoría, diálogo, } \\
\text { capacitación y } \\
\text { mediación para el } \\
\text { trabajo } \\
\text { interdisciplinario y } \\
\text { transdisciplinario } \\
\text { entre juristas y } \\
\text { psicólogos } \\
\text { jurídicos, }\end{array}$ \\
\hline
\end{tabular}

${ }^{5}$ Ver Definición de los tres momentos del Derecho en el apartado 1.3.1 del presente texto. De otro lado, el criterio de selección de las normas constitucionales está determinado por el momento del Derecho a que se refieren, es decir, a la creación, recepción y/o aplicación del Derecho. 


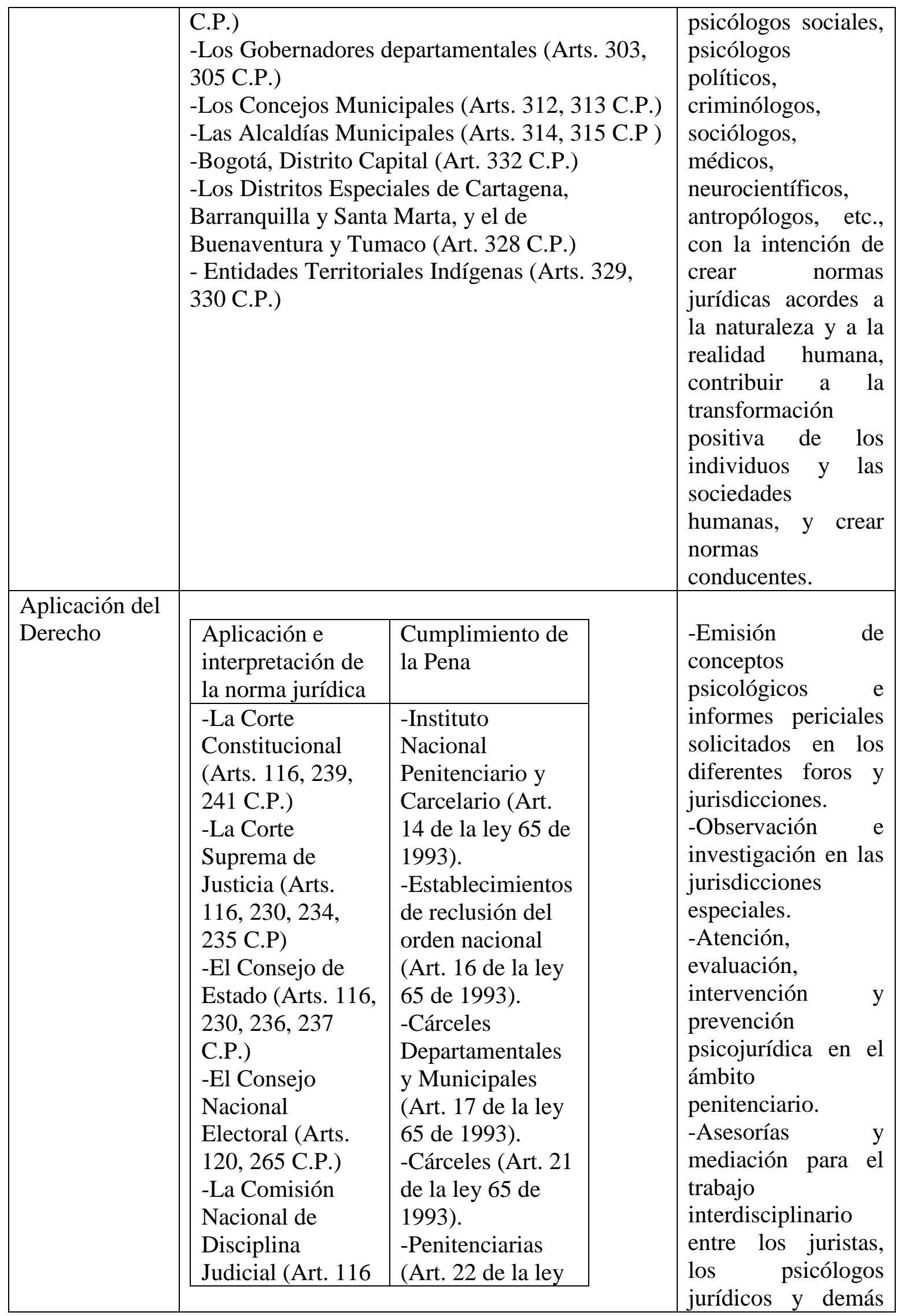




\begin{tabular}{|c|c|c|c|}
\hline & $\begin{array}{l}\text { C.P.- Acto } \\
\text { Legislativo 02 de } \\
\text { 2015. Arts. 26, } \\
\text { Arts. 254, 255, } \\
\text { 256, 257 C.P.) } \\
\text {-La Fiscalía } \\
\text { General de la } \\
\text { Nación (Arts. } \\
\text { 116, 249, 250,251 } \\
\text { C.P.) } \\
\text {-Los Tribunales y } \\
\text { los Jueces (Arts. } \\
\text { 116, 230 C.P.) } \\
\text {-Los Tribuales y } \\
\text { los jueces de la } \\
\text { jurisdicción penal } \\
\text { militar (Arts. 116, } \\
\text { 230 C.P) } \\
\text {-Jurisdicciones } \\
\text { Especiales: } \\
\text { Jurisdicción } \\
\text { Indígena y } \\
\text { Jurisdicción de } \\
\text { Paz (Arts. 246, } \\
\text { 247, 248 C.P) } \\
\text {-El Ministerio } \\
\text { Público integrado } \\
\text { por el Procurador } \\
\text { general de la } \\
\text { Nación y El } \\
\text { Defensor del } \\
\text { Pueblo (Arts. } \\
\text { 117,118, 275,277, } \\
\text { 278, 282 C.P.) } \\
\text {-La Contraloría } \\
\text { General de la } \\
\text { República (Arts. } \\
\text { 119, 267,268 C.P) }\end{array}$ & $\begin{array}{l}65 \text { de 1993). } \\
\text {-Penitenciarias } \\
\text { Especiales (Art. } \\
22 \text { de la ley } 65 \text { de } \\
\text { 1993). } \\
\text {-Reclusiones de } \\
\text { Mujeres (Art. } 26 \\
\text { de la ley } 65 \text { de } \\
\text { 1993). } \\
\text {-Cárceles para } \\
\text { miembros de la } \\
\text { Fuerza Pública } \\
\text { (Art. 27 de la ley } \\
\text { 65 de 1993). } \\
\text { - Colonias } \\
\text { Agrícolas (Art. } 28 \\
\text { de la ley 65 de } \\
\text { 1993). } \\
\text { - Casa-cárceles } \\
\text { (Art. 23 de la ley } \\
\text { 65 de 1993). } \\
\text {-Establecimientos } \\
\text { de rehabilitación } \\
\text { y pabellones } \\
\text { psiquiátricos (Art. } \\
\text { 24 de la ley 65 de } \\
\text { 1993). }\end{array}$ & $\begin{array}{l}\text { profesionales que } \\
\text { ejerzan funciones } \\
\text { en el Ministerio } \\
\text { Público y en la } \\
\text { Fiscalía General de } \\
\text { la Nación. } \\
\text { - Atención, } \\
\text { evaluación e } \\
\text { intervención en el } \\
\text { Instituto Nacional } \\
\text { de Medicina Legal } \\
\text { y Ciencias } \\
\text { Forenses. Asesoría } \\
\text { - y } \\
\text { psicojurídica } \\
\text { psicopolítica en la } \\
\text { Contraloría General } \\
\text { de la República. }\end{array}$ \\
\hline $\begin{array}{l}\text { Recepción del } \\
\text { Derecho }\end{array}$ & \multicolumn{2}{|c|}{$\begin{array}{l}\text {-El cuerpo y la psique de los nacionales } \\
\text { colombianos por nacimiento y por adopción, } \\
\text { según el Artículo } 96 \text { de la C.P. } \\
\text { - El cuerpo y la psique de los extranjeros que } \\
\text { estén en territorio colombiano. (Art. } 100 \text { C.P.) } \\
\text { - El cuerpo y la psique de los integrantes de las } \\
\text { Fuerzas Militares y la Policía Nacional (Arts. }\end{array}$} & $\begin{array}{l}\text { - Educación, } \\
\text { observación, } \\
\text { investigación e } \\
\text { intervención } \\
\text { positiva de los } \\
\text { receptores del } \\
\text { sistema jurídico a }\end{array}$ \\
\hline
\end{tabular}




\begin{tabular}{|l|l|l|}
\hline 216, 217, 218, 219, 221 C.P.). & propósito de su \\
- El cuerpo y la psique de los servidores públicos & propio \\
(Arts. 122, 123, 124,125 C.P). & $\begin{array}{l}\text { dejportamiento, el } \\
\text { tejido de sus } \\
\text { relaciones con los } \\
\text { congéneres, las } \\
\text { instituciones } \\
\text { sociales, las } \\
\text { instituciones } \\
\text { políticas, las } \\
\text { instituciones } \\
\text { jurídicas, etc., y su } \\
\text { relación con las } \\
\text { normas, el sistema } \\
\text { jurídico y el Estado. }\end{array}$
\end{tabular}

Así, el llamado de esta propuesta consiste en la apertura de los escenarios jurídicos y de las mentes de los juristas para la participación activa de los psicólogos jurídicos y de la evidencia psicojurídica en los tres momentos del derecho, es decir, que la evidencia y los conocimientos de esta ciencia sean tenidos en cuenta como fuente del derecho en Colombia, lo cual permitirá el dinamismo del derecho y su coherencia con la realidad de la naturaleza humana.

\subsection{Objeto de estudio de la psicología jurídica.}

Después de hacer una búsqueda amplia acerca del objeto de estudio de la Psicología Jurídica, sólo se encontró un texto que aborda los objetos de estudio de la Psicología Jurídica desde la perspectiva de las áreas de aplicación de ésta.

Se trata de la tesis doctoral de la psicóloga chilena Isabel Salinas Chaud titulado Teoría y Práctica Psicológica en el Ámbito Jurídico. Según Salinas (2009) cada área de aplicación de la Psicología Jurídica tiene un objeto de estudio específico, por ejemplo, afirma Salinas (2009) que los objetos de estudio de la Psicología Jurídica Penitenciaria son 


\section{LA PSICOLOGÍA JURÍDICA COMO UNA FUENTE DEL DERECHO}

la evaluación y el tratamiento psicológico de los internos en centros penitenciarios. Así, para cada una de las áreas de aplicación de la Psicología Jurídica Salinas (2009) señala uno o varios objetos de estudio, pero no define específicamente el objeto de estudio general de la Psicología Jurídica.

Así las cosas, se procede a identificar el objeto de estudio de la Psicología Jurídica en las algunas de las definiciones que de ésta fueron propuestas en el capítulo anterior.

Por ejemplo, de acuerdo con la definición propuesta por el Grupo de Profesores de Posgrados en Psicología Jurídica de la Universidad Santo Tomás (2009), el objeto de estudio de la Psicología Jurídica es el comportamiento humano que alcanza implicaciones jurídicas.

En la definición de Díaz (2008), se puede encontrar que el objeto de estudio de la Psicología es la relación del hombre, individuo o sujeto con el campo legal o el escenario jurídico y todos los escenarios que éste implica.

De otro lado, en la definición de Hoyos (2013) se puede identificar que el objeto de estudio de la Psicología Jurídica son "los principios jurídicos básicos de los problemas jurídicos fundamentales en los diferentes campos del Derecho y su relación con la subjetividad" (Hoyos, 2013, p. 17).

De acuerdo con la definición de la Psicología Jurídica propuesta por Clemente (2012) que el objeto de estudio de ésta es el comportamiento con trascendencia jurídica de las personas y de los grupos y la manera como el contexto condiciona el obrar del individuo, especialmente de aquellas conductas lesivas de otros individuos y prohibidas por el sistema jurídico, con el fin de exhortar al sistema político y a sus dirigentes para la 


\section{LA PSICOLOGÍA JURÍDICA COMO UNA FUENTE DEL DERECHO}

transformación preventiva de estos contextos a través de la educación, la creación de leyes y políticas públicas conducentes, y la aplicación correcta del Derecho

Finalmente, es posible afirmar que el objeto de estudio de la Psicología Jurídica no ha sido unificado hasta el momento y que depende de la definición de Psicología Jurídica que se acoja, aunque algunas de ellas coinciden por lado, en que el objeto de estudio es de la comportamiento humano con trascendencia jurídica en los diversos escenarios del derecho (Grupo de Profesores USTA, 2009 y Clemente 2012), por otro lado Hoyos (2013) y Díaz (2008) coinciden en que el objeto de estudio es la relación entre el sujeto y el campo legal.

\subsection{Sujeto: Hombre/Persona}

De acuerdo con Hoyos (1999), el sujeto de intervención de la Psicología Jurídica es hombre, y en su Manual de Psicología Jurídica lo aborda desde cuatro perspectivas: la perspectiva filosófica, la perspectiva antropológica, la perspectiva cultural y la perspectiva latinoamericana.

En el punto de vista filosófico, la autora se refiere a las definiciones o concepciones que del hombre han ofrecido importantes filósofos en la historia de la filosofía, tales como Sócrates, Platón, Aristóteles, Marx, Nietzsche, etc. Y que deben ser reconocidas por los psicólogos jurídicos. Éstas se presentan a continuación en un tabla para sintetizar lo expuesto por Hoyos (1999):

\begin{tabular}{|l|l|}
\hline Autor & Concepción del Hombre \\
\hline Sócrates & "El hombre es la medida de todas las \\
\hline
\end{tabular}


LA PSICOLOGÍA JURÍDICA COMO UNA FUENTE DEL DERECHO

\begin{tabular}{|c|c|}
\hline & cosas" Citado por Hoyos (1999, p. 32). \\
\hline Platón & $\begin{array}{l}\text { "Una alma que se sirve de un cuerpo" } \\
\text { Citado por Hoyos (1999, p. 32). }\end{array}$ \\
\hline Aristóteles & $\begin{array}{l}\text { "Animal racional", lo concibe de una parte, } \\
\text { con tendencias e instintos y de otra, como } \\
\text { ser pensante y racional" Citado por Hoyos } \\
(1999, \text { p. } 33)\end{array}$ \\
\hline Maquiavelo & $\begin{array}{l}\text { "el hombre es malo por naturaleza" Citado } \\
\text { por Hoyos }(1999, \text { p. } 33)\end{array}$ \\
\hline Feuerbach & $\begin{array}{l}\text { "El Hombre es el Dios del hombre" Citado } \\
\text { por Hoyos }(1999, \text { p. } 33) \text {. }\end{array}$ \\
\hline Marx & $\begin{array}{l}\text { "Hombre Nuevo, fruto de las relaciones de } \\
\text { producción" Citado por Hoyos (1999, p. } \\
\text { 33). }\end{array}$ \\
\hline Nietzsche & $\begin{array}{l}\text { "Conoce al hombre como como un ser } \\
\text { cuya voluntad de poder lo "empuja a } \\
\text { permanecer fiel al sentido de la tierra, el } \\
\text { que supera la moral antivida, enfermiza y } \\
\text { alienante" Citado por Hoyos }(1999, \text { p. } 33) \text {. }\end{array}$ \\
\hline Kant & $\begin{array}{l}\text { El hombre moral que atiende a su } \\
\text { imperativo categórico "Obra siempre de tal }\end{array}$ \\
\hline
\end{tabular}




\section{LA PSICOLOGÍA JURÍDICA COMO UNA FUENTE DEL DERECHO}

\begin{tabular}{|c|c|}
\hline & $\begin{array}{l}\text { manera que la máxima de tu voluntad } \\
\text { pueda valer como principio de legislación } \\
\text { universal" Citado por Hoyos }(1999, \text { p. } 34) \text {. }\end{array}$ \\
\hline Freud & $\begin{array}{l}\text { Lo que hace Freud en cambiar el centro del } \\
\text { hombre, ya no es la conciencia sino el } \\
\text { inconsciente (Hoyos, 1999). }\end{array}$ \\
\hline Ortega y Gasset (1966) & $\begin{array}{l}\text { "El Hombre no es su naturaleza, sino que } \\
\text { él es su historia” Citado por Hoyos (1999, } \\
\text { págs.34-35) }\end{array}$ \\
\hline Heidegger & $\begin{array}{l}\text { "Resalta el valor humano de la existencia } \\
\text { en su afirmación “estar-siendo-en-el } \\
\text { mundo" Citado por Hoyos (1999.p. 35). }\end{array}$ \\
\hline Zubirí & $\begin{array}{l}\text { "Reconoce la corporeidad en la acciones } \\
\text { humanas y "habla de la animicidad } \\
\text { corpórea" o "corporeidad anímica como } \\
\text { dos realidades intrínsecamente } \\
\text { conjugadas". Citado por Hoyos (1999, p. } \\
\text { 35) }\end{array}$ \\
\hline
\end{tabular}

De otro lado, el enfoque antropológico que presenta Hoyos (1999) del hombre, plantea una postura crítica muy interesante y crítica, de acuerdo con la cual el hombre de 


\section{LA PSICOLOGÍA JURÍDICA COMO UNA FUENTE DEL DERECHO}

hoy "vive extrañado en su propio mundo" ya que su vida gira en torno al consumo, la posesión y la producción, es un hombre que sobrevive y olvida las maravillas de la vida.

Desde el punto de vista ético y cultural, Hoyos (1999) afirma que de acuerdo con la época se construye y/o modifica el concepto de hombre, por ejemplo, afirma Hoyos (1999, p. 37) citando a (Hortal, 1990) que en la modernidad la ética es "ante todo la ética de los individuos que confían en la razón exigen el ejercicio de la libertad.

La postmodernidad, en cambio, la época del imperio tecnológico está marcada por la idea del hombre como individuo, solitario, donde impera la oferta de la demanda y la competencia.

Comenta Hoyos (1999, p.37) a propósito de la contemporaneidad que "para Hortal (1990), la involución ética plantea por el nuevo tipo de hombre, describe el aspecto sociocultural actual: La ley del consumo, el fenómeno de la industrialización, el hombre masa, la desintegración de las relaciones humanas, la función manipuladora de la palabra, el utilitarismo afectivo y la violencia, debida en buena parte a esa crisis que caracteriza al hombre contemporáneo".

Finalmente, Hoyos (1999) plantea la necesidad que tiene los psicólogos de reconocer al hombre latinoamericano como un ser marcado por el proceso de aculturación vivido durante la colonia y las repercusiones que éste tiene a todo nivel, lo cual genera confusiones identitarias que afectan profundamente a los seres humanos que habitan las tierras latinoamericanas.

De otro lado, en el Manual de Psicología Jurídica de Mira y López (1961), se propone que la Psicología Jurídica debe comprender al hombre desde la categoría de 


\section{LA PSICOLOGÍA JURÍDICA COMO UNA FUENTE DEL DERECHO}

persona, ya que desde esta perspectiva, el hombre es considerado como "unidad humana considerándola en sus relaciones con el medio natural y social en que vive" (Mira y López, 1961, p. 21).

Afirma Mira y López, (1961, p. 21) que "la persona es una, entera e indivisa, y como tal debe ser estudiada y comprendida por la ciencia. Ha desaparecido la barrera entre lo físico y lo psíquico desde el punto de vista funcional: ante un estímulo físico no es el cuerpo quien reacciona, y ante un estímulo psíquico no es el alma quien responde, sino que en ambos casos es el organismo en su totalidad, o sea la persona, quien crea la respuesta.

Para explicar esta idea del hombre como unidad o persona, Mira y López (1961) presenta los factores que determinan la reacción personal en un momento dado y que finalmente integran lo que la persona es.

Tabla transcrita del texto de Mira y López (1961, p. 22)

\begin{tabular}{|c|c|c|}
\hline ores generales & Heredados - & $\begin{array}{l}\text { a) Constitución corporal. } \\
\text { b) Temperamento. } \\
\text { b) Inteligencia. }\end{array}$ \\
\hline Responsables de la & Mixtos & d) Carácter. \\
\hline Reacción personal & & e) Previa experiencia de situaciones análogas. \\
\hline En un momento & Adquiridos & f) Constelación. \\
\hline Dado & & $\begin{array}{l}\text { g) Situación externa actual. } \\
\text { h) Tipo medio de la reacción social colectiva. } \\
\text { i) Modo de percepción de la situación. }\end{array}$ \\
\hline
\end{tabular}

De acuerdo con Mira y López, la constitución corporal es "el conjunto de propiedades morfológicas y bioquímicas transmitidas al individuo por herencia”. (Mira y López, 1961, p. 24) y hace referencia al aspecto morfológico de la persona, lo que "condiciona en gran medida el estilo de movimientos, haciéndolos más o menos rápidos, 


\section{LA PSICOLOGÍA JURÍDICA COMO UNA FUENTE DEL DERECHO}

gráciles, enérgicos, etc. Pero como hemos dicho antes, su importancia principal radica en la correlación que guarda con el temperamento, es decir, con "el modo de ser" del sujeto (Mira y López, 1961, p. 23)

En segundo lugar, el temperamento es definido por Mira y López como "la resultante funcional directa de la constitución, que marca en todo momento la especial modalidad de la primitiva tendencia de reacción frente a los estímulos ambientales” (Mira y López, 1961 p. 24).

A propósito de la inteligencia, afirma Mira y López que ésta es un factor endógeno y que tiene que ver con la capacidad de juicio abstracto y el juicio moral" (Mira y López, 1961 p. 25).

El factor mixto, es decir, endógeno y exógeno que determina la reacción de la persona en un momento dado es el carácter, que según Mira y López (1961, p. 26) “el término de transición entre los factores endógenos y los factores exógenos integrantes de la personalidad y representa en definitiva el resultado de su lucha. Los factores endógenos impulsarían al hombre a una conducta puramente animal, basada en la satisfacción de sus instintos y tendencias apetitivas o repulsivas. Los factores exógenos, por el contrario, le conducirían a la completa sumisión al medio externo; es la clásica oposición entre el hombre y el mundo (la lucha por la vida) la que se simboliza en la pugna entre el elemento endógeno y el exógeno y da, como producto final, el tipo de conducta externa, esto es, el carácter".

La previa experiencia de situaciones anteriores es el primero de los factores exógenos que determinan la reacción de la persona en un momento dado y hace referencia 


\section{LA PSICOLOGÍA JURÍDICA COMO UNA FUENTE DEL DERECHO}

hace referencia al elemento exógeno de la vivencia análoga previa que influye decisivamente la reacción actual.

La constelación, por su parte, como otro de los factores exógenos que determinan a la persona, "designa la influencia que la vivencia o experiencia inmediatamente antecedente ejerce en la determinación de la respuesta a la situación actual (Mira y López, 1961, p. 26).

La situación externa actual como factor exógeno es "el estímulo desencadenante de la reacción personal” (Mira y López, 1961, p. 27), su causa eficiente.

De otro lado, el tipo medio de la reacción colectiva en vigencia, se refiere a la influencia que tiene la conducta social en la conducta individual, porque existe "una influencia recíproca entre el sujeto y el medio social” (Mira y López, 1961, p. 28).

Finalmente, el modo de percepción subjetiva de la situación, hace referencia al modo como el sujeto asimila su situación y de acuerdo con esta asimilación reacciona en un momento dado.

Las concepciones de hombre y persona que plantean estos dos psicólogos jurídicos Mira y López (1961) y Hoyos (1999), señalan diferentes perspectivas históricas, teóricas y científicas que han intentado explicar lo que el hombre es y que deben ser tenidas en cuenta por la Psicología Jurídica al momento de estudiar, explicar, comprender y analizar el comportamiento del hombre y/o la persona en el ámbito jurídico y la relación de éste con el campo legal.

\subsection{Método de la psicología jurídica.}




\section{LA PSICOLOGÍA JURÍDICA COMO UNA FUENTE DEL DERECHO}

Después de revisar bastante literatura en el campo de la Psicología Jurídica y rastrear lo referente al método de estudio de ésta, sólo se encontró una referencia directa a propósito de los medios y métodos que puede utilizar Psicología Jurídica en el estudio, comprensión y la solución de los problemas que se plantean en el ámbito jurídico y que son de su incumbencia. Éste es el Manual de Psicología Jurídica de Mira y López (1961).

El autor, presenta una tabla en la que resume los diferentes medios que tiene la Psicología Jurídica para identificar la naturaleza de los fenómenos estudiados, las condiciones de investigación, los modos de recolectar los hechos, la clase de sujeto estudiado y el propósito y técnica de investigación.

Según Mira y López (1961), los métodos que pueden ser utilizados por la Psicología Jurídica, son: Los métodos de enfoque cuantitativo, de un lado, y los métodos de enfoque cualitativo, de otro lado.

Los métodos de enfoque cuantitativos se sirven de la psicometría, y se utilizan De acuerdo con Mira y López (1961, p. 19) “como medio inmediato para la medida o el análisis de un procesos de recepción, juicio, ejecución, expresión”. De otro lado, los métodos cualitativos utilizan las técnicas psicoléxicas como medio para la medida o análisis de procesos de recepción, juicio, ejecución, expresión.

Ambos métodos intentan evaluar según los casos: 1) los grados del excitante (método psicofísico); 2) la duración del proceso (método psicocronométrico); 3) el trabajo realizado (método psicodinámico): 4) el número de sujetos (método Psicoestadístico).

El cuadro siguiente fue tomado de Mira y López (1961, págs. 18-19). 


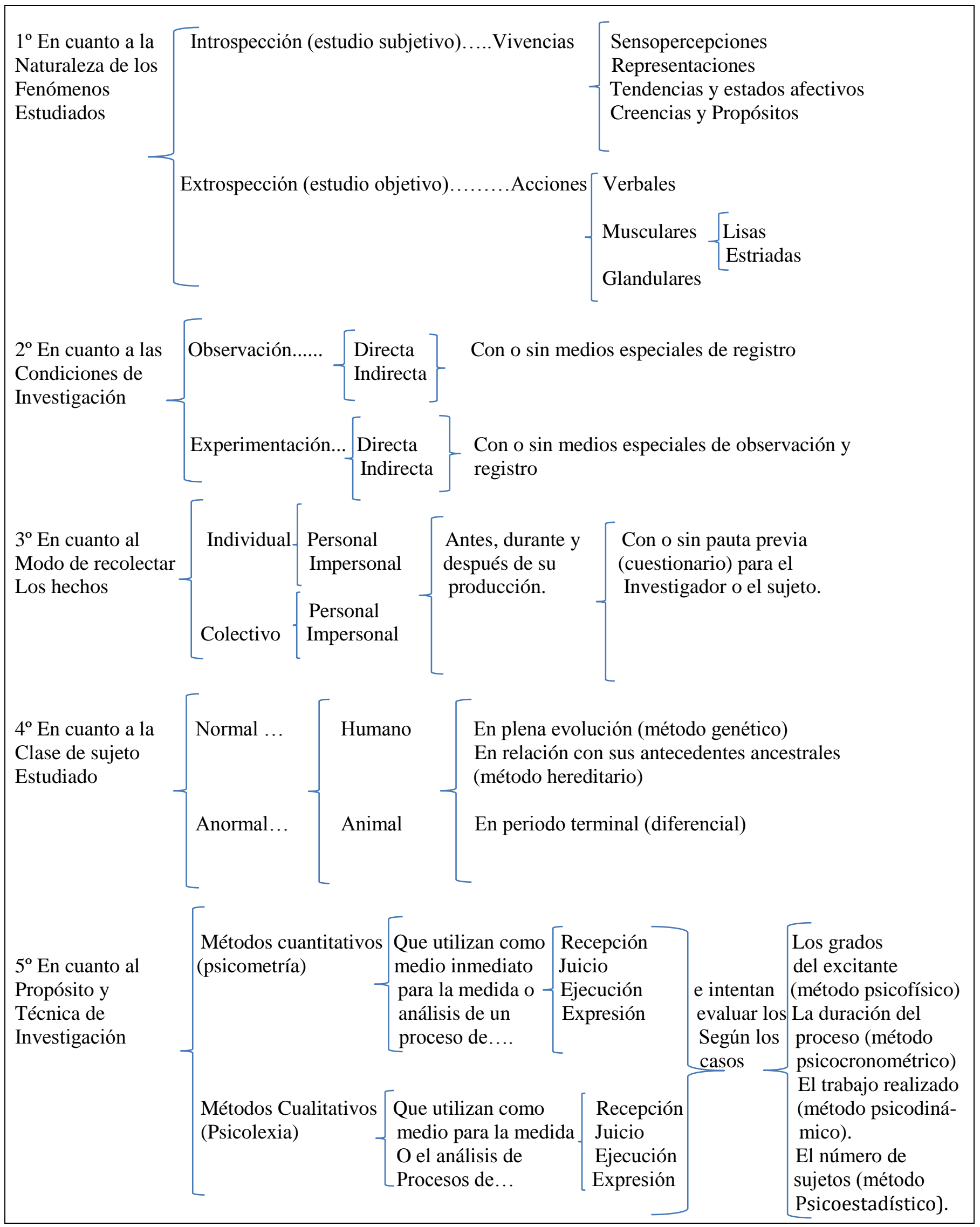




\section{LA PSICOLOGÍA JURÍDICA COMO UNA FUENTE DEL DERECHO}

A pesar de que la presentación de Mira y López (1961) es amplia y detallada, aún hace falta realizar un estudio desde la Psicología Jurídica, que permita precisar los métodos que se deben utilizar en cada uno de los áreas de aplicación de la Psicología Jurídica, para resolver los problemas que se presentan en el ámbito jurídico con trascendencia psicojurídica y diseñar por ejemplo, un método, a partir de la Teoría de la Conducencia de la Norma Jurídica propuesta por (Oceja y Fernandez-Dols 2006), la Técnica Legislativa el Análisis de Discursos para el análisis crítico psicojurídico de las normas jurídicas, con el fin de que la Psicología Jurídica pueda participar en la reconstrucción del Derecho y aparecer en la práctica como una fuente eficaz del Derecho. 


\section{LA PSICOLOGÍA JURÍDICA COMO UNA FUENTE DEL DERECHO}

\section{Capítulo III. Indagación Fenomenológica de la Psicología Jurídica}

Como se mencionó en el Capítulo I de este trabajo, el objetivo de la indagación fenomenológica $^{6}$ de la Psicología Jurídica consiste en identificar los fenómenos ${ }^{7}$ psicológicos humanos con trascendencia jurídica que han sido propuestos por algunos estudiosos de esta área del conocimiento humano en diferentes contextos geográficos y por algunas instituciones jurídicas, para ponerlos en relación con el Derecho, facilitar la relación entre el Derecho y la Psicología Jurídica, y contribuir a una intervención y transformación positiva de las sociedades humanas.

${ }^{6}$ De acuerdo con Ferrater, J (1994, p. 1240) La fenomenología es pura descripción de lo que se muestra por sí mismo, de acuerdo con "el principio de los principios": reconocer que "el principio de los principios": reconocer que "toda intuición primordial es una fuente legítima de conocimiento, que todo lo que se presenta por sí mismo en la intuición (y, por así decirlo, en persona) debe ser aceptado simplemente como lo que se ofrece, aunque solamente dentro de los límites en los cuales se presenta(Ideen, § 24)". La fenomenología "se coloca "antes" de toda creencia y de todo juicio para explorar simplemente y pulcramente lo dado. Es como ha declarado Husserl, un "positivismo absoluto"(Ferrater, 1994, p. 1240)

${ }^{7}$ En el Diccionario de Filosofía de Ferrater, J (1994, p. 1235) “El término 'fenómeno' proviene del

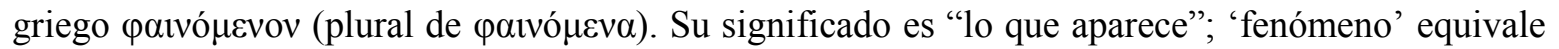
pues a 'apariencia'".

Mira y López (1961, p.18) utiliza la palabra "fenómeno" para referirse a aquello que puede ser estudiado por la Psicología Jurídica, esto es las vivencias y las acciones. Ver Manual de Psicología Jurídica de Mira y López. 


\section{LA PSICOLOGÍA JURÍDICA COMO UNA FUENTE DEL DERECHO}

En este capítulo se hará un recuento, en primer lugar, de los fenómenos psicojurídicos u objetos ${ }^{8}$ estudiados desde la Psicología Jurídica que aparecen en los textos, manuales, guías y protocolos institucionales, y artículos científicos consultados para la realización de este trabajo y que en ciertos casos se han institucionalizado en el sistema jurídico colombiano a través de las guías para la realización de pericias psiquiátricas y psicológicas forenses creadas por el Instituto Nacional de Medicina Legal y Ciencias Forenses para la práctica judicial.

Y en segundo lugar, se presentará a grosso modo la denominación de los fenómenos psicojurídicos planteados por diferentes autores, ya que la descripción y estudio de cada uno de estos fenómenos implica un trabajo investigativo independiente.

Es necesario advertir, que por razones prácticas y teniendo en cuenta el diálogo con el lector, la presentación de los fenómenos se realiza a través de unas tablas que permiten comprender la estrecha relación que existe y que debe fortalecerse entre el derecho y la psicología jurídica.

A propósito de las guías del Instituto Nacional de Medicina Legal y Ciencias Forenses de Colombia, se debe hacer la salvedad y proponer para la reflexión el hecho de que para la evaluación de la capacidad de autodeterminación y comprensión de una persona, la evaluación para el mantenimiento, cambio o levantamiento de las medidas de seguridad de los inimputables, y para la evaluación sobre el estado de salud mental de la persona privada de la libertad, el Instituto señala que sólo pueden ser realizada por médicos psiquiatras forenses y se excluye tácitamente la posibilidad de que un psicólogo forense

\footnotetext{
${ }^{8}$ Fenómeno como objeto de la percepción según el Diccionario de la Real Academia de la Lengua Española: "Toda manifestación que se hace presente a la consciencia de un sujeto y aparece como objeto de su percepción". Tomada de: http://dle.rae.es/?id=HIH0iLR
} 


\section{LA PSICOLOGÍA JURÍDICA COMO UNA FUENTE DEL DERECHO}

realiza este tipo de evaluación. En la guía no se expresan claramente los motivos de esta decisión, pero queda abierta la pregunta: ¿Es posible que un psicólogo jurídico forense realice este tipo de evaluaciones y peritajes y que sean admitidas por el juez como elemento material probatorio en Colombia?

De otro lado cabe mencionar que las guías del Instituto Nacional de Medicina Legal y Ciencias Forenses de Colombia se limita al estudio y evaluación de fenómenos psicojurídicos forenses, es decir, de aquellos fenómenos que son requeridos en los diferentes foros o tribunales por los jueces o magistrados que los dirigen para el momento de la aplicación del derecho y esto se debe a que dicho Instituto está adscrito a la rama judicial del poder público, encargada por regla general de la aplicación del derecho, pero habrá que pensar en la posibilidad de participación desde la perspectiva psicojurídicos del Instituto Nacional de Medicina Legal y Ciencias Forenses en los momentos en que los altos tribunales y cortes de nuestro país crean derecho a través de la jurisprudencia, al respecto pregunto ¿podrá este organismo a través de sus expertos, asesorar e investigar fenómenos psicojurídicos propios del momento creativo del derecho?.

A continuación se presentan de manera sintética las guías para la evaluación y realización de pericias psiquiátricas y psicológicas forenses del Instituto Nacional de Medicina Legal y Ciencias Forenses de Colombia:

\subsection{Fenómenos psicojurídicos en el estado colombiano.}

\subsubsection{Guía para la realización de pericias psiquiátricas y psicológicas forenses mediante autopsia psicológica en la determinación de la manera de muerte (suicida, homicida o accidental).}




\section{LA PSICOLOGÍA JURÍDICA COMO UNA FUENTE DEL DERECHO}

\begin{tabular}{|c|c|}
\hline $\begin{array}{l}\text { Nombre del Fenómeno } \\
\text { Psicojurídico }\end{array}$ & $\begin{array}{l}\text { Autopsia psicológica para determinar la manera de muerte } \\
\text { (suicida, homicida o accidental). }\end{array}$ \\
\hline Entidad creadora & $\begin{array}{l}\text { - Instituto Nacional de Medicina Legal y Ciencias Forenses } \\
\text { de Colombia }\end{array}$ \\
\hline $\begin{array}{l}\text { Definición del fenómeno } \\
\text { psicojurídico. }\end{array}$ & $\begin{array}{l}\text { - "Se trata de un procedimiento científico que, después de la } \\
\text { muerte, nos posibilita describir cómo era la víctima en } \\
\text { vida; es una reconstrucción psicológica de la personalidad } \\
\text { de un fallecido. Se reconstruye la historia de vida de la } \\
\text { persona fallecida, haciendo énfasis en el estilo de vida, } \\
\text { rasgos de personalidad, nivel de estrés, historia de } \\
\text { enfermedad mental, y en algunos casos se toman } \\
\text { referencias de expresión de ideación o intención suicida y } \\
\text { se da especial atención a las circunstancias previas } \\
\text { ocurridas los días antes de la muerte". (Instituto Nacional } \\
\text { de Medicina Legal y Ciencias Forenses, 2010, p. 8) } \\
\text { "Como método de investigación la autopsia psicológica es } \\
\text { un proceso sistemático de recolección de datos, que se } \\
\text { desarrolla por etapas, las cuales pueden variar, } \\
\text { dependiendo de las características del evento en estudio" } \\
\text { (Instituto Nacional de Medicina Legal y Ciencias } \\
\text { Forenses, 2010, p. 8) }\end{array}$ \\
\hline $\begin{array}{l}\text { Aspectos Psicológicos del } \\
\text { Fenómeno o teorías y } \\
\text { conceptos psicológicos } \\
\text { que explican el fenómeno. }\end{array}$ & $\begin{array}{l}\text { Pautas recomendadas para la entrevista psiquiátrica o } \\
\text { psicológica Forense con Fines de autopsia psicológica } \\
\text { - Planeación Se recomienda realizar una meticulosa } \\
\text { selección de por lo menos } 4 \text { personas para entrevistar. } \\
\text { - Criterios deseables en los entrevistados son: } \\
\text {-Tener alguna relación con el fallecido, ya sea a nivel familiar, } \\
\text { social, laboral, estudiantil o terapéutico. } \\
\text {-Haber conocido al fallecido de manera cercana. } \\
\text { - No estar en la lista de sospechoso en el caso que se investiga. } \\
\text {-Que la entrevista se realiza entre los seis primeros meses al } \\
\text { fallecimiento para que el recuerdo no esté limitado por asuntos } \\
\text { como el duelo. } \\
\text { - Ejecución } \\
\text { Se recomienda realizar una entrevista de entrevista }\end{array}$ \\
\hline
\end{tabular}


Semiestructurada similar a la planteada en la versión vigente del "Protocolo de Evaluación Básica de Psiquiatría y Psicología Forenses" del Instituto Colombiano de Medicina Legal y Ciencias Forenses.

- Utilización de test psicométricos u otros exámenes

No se recomienda el uso de este tipo de herramientas, es preferible el uso de las entrevistas semiestructuradas.

- Elaboración del informe pericial o

dictamen

Se sigue el modelo establecido para el informe pericial o dictamen sobre una persona viva, descrito en el "Protocolo de

Evaluación Básica en Psiquiatría y Psicología Forense” del

Instituto Nacional de Medicina Legal y Ciencias Forenses.

- Análisis y conclusión en pericias psiquiátricas o psicológicas forenses mediante la técnica de autopsia psicológica

-Usar terminología comprensible para el solicitante de la valoración.

- "El análisis y la conclusión en la autopsia psicológica se rinden en términos de posibilidad o de probabilidad, dependiendo de la calidad y cantidad de información disponible. En ningún caso se expresarán en términos de certeza, sino que el análisis y la conclusión podrán fluctuar entre lo simplemente posible (cuando un fenómeno o hecho pudo haber o no haber ocurrido), y lo probable (cuando se suman argumentos a favor de la hipótesis confiriéndole mayor solidez). En todos los casos se debe hacer esta advertencia en el informe pericial". (Instituto Nacional de Medicina Legal y Ciencias Forenses, 2010, p. 13)

- Análisis

para ofrecer información útil a la autoridad, el análisis del caso se divide en tres partes: personalidad básica, psicopatología (si la hubiere) y consideraciones respecto al funcionamiento mental para la época y el día de la ocurrencia de los hechos. 


\section{LA PSICOLOGÍA JURÍDICA COMO UNA FUENTE DEL DERECHO}

\begin{tabular}{|c|c|}
\hline $\begin{array}{l}\text { Rama o área del Derecho } \\
\text { para la que trasciende este } \\
\text { fenómeno }\end{array}$ & Derecho Penal, Derecho Civil. \\
\hline $\begin{array}{l}\text { Normatividad que regula } \\
\text { el fenómeno psicojurídico }\end{array}$ & $\begin{array}{l}\text {-Constitución Política de Colombia (1991) Artículos } 1 \text { y } 13 . \\
\text {-Código de Procedimiento Penal (Ley } 906 \text { de 2004) Título } \\
\text { Preliminar "Principios Rectores y garantías procesales", } \\
\text { artículo 1. Libro II, Título I "La indagación y la investigación": } \\
\text { Capítulo I "Órganos de indagación e investigación", } \\
\text { Artículo 204. Capítulo V "Cadena de custodia", artículos 254, } \\
\text { 255, } 257 \text { a 265. Libro II, Título II "Medios cognoscitivos en la } \\
\text { indagación e investigación", Capítulo Único, artículos } 275,276 \\
\text { y } 277 . \text { Libro III "El juicio", Título IV "Juicio Oral", Capítulo } \\
\text { III "Práctica de la prueba": Parte I "Disposiciones generales"; } \\
\text { artículos } 372 \text { "Fines", } 373 \text { "Libertad" y } 375 \text { "Pertinencia". } \\
\text { Parte III "Prueba pericial"; artículos } 405 \text { "Procedencia" y } 422 \\
\text { "Admisibilidad de publicaciones científicas y de prueba novel". }\end{array}$ \\
\hline Responsables & $\begin{array}{l}\text { "Son responsables de seguir los lineamientos contemplados en } \\
\text { esta guía los peritos psiquiatras o psicólogos forenses del } \\
\text { Instituto Nacional de Medicina Legal y Ciencias Forenses, o } \\
\text { cualquier psiquiatra, psicólogo o psicoanalista debidamente } \\
\text { entrenado y capacitado, que deba realizar una pericia } \\
\text { psiquiátrica o psicológica forense mediante autopsia } \\
\text { psicológica como técnica complementaria para el } \\
\text { esclarecimiento de la manera de muerte y rendir el respectivo } \\
\text { informe pericial o dictamen en el marco de la legislación } \\
\text { colombiana pertinente, en todo el territorio nacional". (Instituto } \\
\text { Nacional de Medicina Legal y Ciencias Forenses, 2010, p. 15) }\end{array}$ \\
\hline
\end{tabular}

\subsubsection{Guía para la realización de pericias psiquiátricas sobre capacidad de comprensión y autodeterminación.}




\begin{tabular}{|c|c|}
\hline $\begin{array}{l}\text { Nombre del Fenómeno } \\
\text { psicojurídico }\end{array}$ & $\begin{array}{l}\text { Capacidad de comprensión y autodeterminación de una } \\
\text { persona. }\end{array}$ \\
\hline Entidad creadora & $\begin{array}{l}\text { Instituto Nacional de Medicina Legal y Ciencias Forenses de } \\
\text { Colombia }\end{array}$ \\
\hline $\begin{array}{l}\text { Definición del fenómeno } \\
\text { psicojurídico. }\end{array}$ & $\begin{array}{l}\text { COMPRENSIÓN } \\
\text { "La capacidad de comprensión en el marco de este tipo de } \\
\text { pericia en psiquiatría forense se entiende como la facultad para } \\
\text { entender, conocer y diferenciar si un comportamiento es un } \\
\text { comportamiento es lícito o ilícito" ". (Instituto Nacional de } \\
\text { Medicina Legal y Ciencias Forenses, 2009, p.11-12) } \\
\text { AUTODETERMINACIÓN } \\
\text { "Autosuficiencia y autodirección individual, a la motivación, } \\
\text { voluntariedad y capacidad de autorregulación, es la habilidad } \\
\text { para desempeñar una conducta con libertad, autonomía, } \\
\text { conocimiento y comprensión". (Instituto Nacional de Medicina } \\
\text { Legal y Ciencias Forenses, 2009, p.12) }\end{array}$ \\
\hline $\begin{array}{l}\text { Aspectos Psicológicos del } \\
\text { Fenómeno o teorías y } \\
\text { conceptos psicológicos } \\
\text { que explican el fenómeno. }\end{array}$ & $\begin{array}{l}\text { - Inmadurez psicológica: se refiere a la "falta de maduración } \\
\text { global, severa y perfectamente instaurada. Esto impidió } \\
\text { que obrara con pleno conocimiento y libre capacidad de } \\
\text { autodeterminación". (Instituto Nacional de Medicina Legal } \\
\text { y Ciencias Forenses, 2009, p.13) } \\
\text { - Trastorno mental: Este puede ser: } \\
\text { - Trastorno mental permanente: "afectaciones mentales } \\
\text { graves, perfectamente instauradas, de evolución crónica } \\
\text { y difícil recuperación". (Instituto Nacional de Medicina } \\
\text { Legal y Ciencias Forenses, 2009, p.13). } \\
\text { - Trastorno mental transitorio con base patológica: hace } \\
\text { referencia a la "alteración mental severa que se genera } \\
\text { en una disfunción biológica o de personalidad, de } \\
\text { presentación aguda o crónica episódica". (Instituto } \\
\text { Nacional de Medicina Legal y Ciencias Forenses, 2009, } \\
\text { p.14). } \\
\text { Trastorno mental transitorio sin base patológica: } \\
\text { alteración mental de corta duración } \\
\text { Diversidad sociocultural o estados similares: "no asimilación }\end{array}$ \\
\hline
\end{tabular}




\begin{tabular}{|c|c|}
\hline & $\begin{array}{l}\text { de la escala de valores y patrones de conducta que maneja el } \\
\text { Código Penal colombiano" (Instituto Nacional de Medicina } \\
\text { Legal y Ciencias Forenses, 2009, p.14). } \\
\text { Discapacidad psíquica o mental: "alteración mental que haya } \\
\text { afectado la cognición o volición al momento de los hechos" } \\
\text { (Instituto Nacional de Medicina Legal y Ciencias Forenses, } \\
\text { 2009, p.15). }\end{array}$ \\
\hline $\begin{array}{l}\text { Rama o área del Derecho } \\
\text { para la que trasciende este } \\
\text { fenómeno }\end{array}$ & Derecho Penal. \\
\hline $\begin{array}{l}\text { Normatividad que regula } \\
\text { el fenómeno psicojurídico }\end{array}$ & $\begin{array}{l}\text { Discapacidad psíquica o mental: artículo } 142 \text { del Código de } \\
\text { Infancia y Adolescencia. } \\
\text { Sentencia: C-370/02 } \\
\text { Artículo } 33 \text { del Código Penal, Ley } 599 \text { de } 2000 \\
\text { Constitución Política de Colombia: Artículos 1, 2, 5, } 13 \text { y } 47 . \\
\text { Código Penal, Ley } 599 \text { del } 2000 \\
\text { Código de Procedimiento Penal, Ley } 600 \text { de } 2000 . \\
\text { Código de Procedimiento Penal, Ley } 609 \text { de } 2004 \\
\text { Código Penal Militar, Ley } 522 \text { de } 19995\end{array}$ \\
\hline Responsables & $\begin{array}{l}\text { Peritos psiquiatras forenses del Instituto Nacional de Medicina } \\
\text { Legal y Ciencias Forenses o peritos médicos psiquiatras } \\
\text { oficiales. }\end{array}$ \\
\hline
\end{tabular}

\subsubsection{Guía para la realización de pericias psiquiátricas sobre mantenimiento, cambio o levantamiento de medida de seguridad en inimputables.}

\begin{tabular}{|l|l|}
\hline $\begin{array}{l}\text { Nombre del Fenómeno } \\
\text { psicojurídico }\end{array}$ & $\begin{array}{l}\text { Mantenimiento, Cambio o Levantamiento de Medidas de } \\
\text { Seguridad en Inimputables. }\end{array}$ \\
\hline $\begin{array}{l}\text { Entidad creadora de la } \\
\text { guía y Participantes }\end{array}$ & $\begin{array}{l}\text { Instituto Nacional de Medicina Legal y Ciencias Forenses de } \\
\text { Colombia }\end{array}$ \\
\hline
\end{tabular}




\begin{tabular}{|c|c|}
\hline $\begin{array}{l}\text { Definición del fenómeno } \\
\text { psicojurídico. }\end{array}$ & $\begin{array}{l}\text { INIMPUTABLE: "Persona cuyos procesos intelectivos y } \\
\text { volitivos se encuentran afectados hasta el punto de impedirle } \\
\text { comprender el contenido y el alcance social de su conducta y } \\
\text { en consecuencia determinarla hacia un fin". (Instituto Nacional } \\
\text { de Medicina Legal y Ciencias Forenses, 2010, p.6). } \\
\text { DISCAPACIDAD PSÍQUICA O MENTAL: Terminología } \\
\text { utilizada en el artículo Art. } 142 \text { del Código de Infancia y } \\
\text { Adolescencia. Al menor no puede ser declarado inimputable, } \\
\text { por ello se hace la claridad con este término específico. } \\
\text { INMADUREZ PSICOLÓGICA: falta de maduración global } \\
\text { severa. } \\
\text { MEDIDAS DE SEGURIDAD: "privación o restricción del } \\
\text { derecho constitucional fundamental a la libertad, impuesta } \\
\text { judicialmente por el Estado, con fines de curación, tutela y } \\
\text { rehabilitación, a persona declarada previamente como } \\
\text { inimputable" (Instituto Nacional de Medicina Legal y Ciencias } \\
\text { Forenses, 2010, p.7). } \\
\text { PENA: "coartación o supresión de un derecho personal que el } \\
\text { Estado impone a través de su rama jurisdiccional a un sujeto } \\
\text { imputable que ha sido declarado responsable de infracción } \\
\text { penal" (Instituto Nacional de Medicina Legal y Ciencias } \\
\text { Forenses, 2010, p. 9). }\end{array}$ \\
\hline $\begin{array}{l}\text { Aspectos Psicológicos del } \\
\text { Fenómeno o teorías y } \\
\text { conceptos psicológicos } \\
\text { que explican el fenómeno. }\end{array}$ & $\begin{array}{l}\text { TRASTORNO MENTAL: disfunción o anomalía mental lo } \\
\text { suficientemente severa como para impedir a la persona, } \\
\text { comprender la ilicitud de su conducta o autodeterminarse con } \\
\text { base en dicho conocimiento. (Instituto Nacional de Medicina } \\
\text { Legal y Ciencias Forenses, } 2010, \text { p. } 10 \text { ). } \\
\text { - Trastorno mental permanente } \\
\text { - Trastorno mental transitorio con base patológica } \\
\text { - Trastorno mental transitorio sin base patológica }\end{array}$ \\
\hline
\end{tabular}




\section{LA PSICOLOGÍA JURÍDICA COMO UNA FUENTE DEL DERECHO}

\begin{tabular}{|c|c|}
\hline $\begin{array}{l}\text { Rama o área del Derecho } \\
\text { para la que trasciende este } \\
\text { fenómeno }\end{array}$ & Derecho Penal \\
\hline $\begin{array}{l}\text { Normatividad que regula } \\
\text { el fenómeno psicojurídico }\end{array}$ & $\begin{array}{l}\text { Constitución Política de Colombia: Artículos 2, 5, } 13 \text { y } 47 . \\
\text { Código Penal, Ley } 599 \text { del } 2000 \\
\text { Código de Procedimiento Penal, Ley } 600 \text { de } 2000 \\
\text { Código de Procedimiento Penal, Ley } 906 \text { del } 2004 \\
\text { Código Penitenciario y Carcelario, Ley } 65 \text { de } 1993 \\
\text { Código Penal Militar, Ley } 522 \text { de } 1999 \\
\text { Código de la Infancia y Adolescencia, Ley } 1098 \text { del } 2006\end{array}$ \\
\hline Responsables & $\begin{array}{l}\text { Peritos psiquiatras forenses del Instituto Nacional } \\
\text { de Medicina Legal y Ciencias Forenses o peritos médicos } \\
\text { psiquiatras oficiales }\end{array}$ \\
\hline
\end{tabular}

\subsubsection{Guía para la realización de pericias psiquiátricas sobre perturbación psíquica en presuntas víctimas de lesiones personales y otros.}

\begin{tabular}{|l|l|}
\hline $\begin{array}{l}\text { Nombre del Fenómeno } \\
\text { Psicojurídico }\end{array}$ & $\begin{array}{l}\text { Perturbación psíquica en presuntas víctimas de lesiones } \\
\text { personales y otros. }\end{array}$ \\
\hline Entidad creadora & $\begin{array}{l}\text { Instituto Nacional de Medicina Legal y Ciencias Forenses de } \\
\text { Colombia }\end{array}$ \\
\hline $\begin{array}{l}\text { Definición del fenómeno } \\
\text { psicojurídico. }\end{array}$ & $\begin{array}{l}\text { L A PERTURBACIÓN PSÍQUICA" es una forma de daño en } \\
\text { la salud, entendido éste como una respuesta psíquica intensa y } \\
\text { desadaptativa determinada por la naturaleza de la agresión en } \\
\text { interacción con la susceptibilidad emocional y los mecanismos }\end{array}$ \\
\hline
\end{tabular}




\begin{tabular}{|c|c|}
\hline & $\begin{array}{l}\text { adaptativos del individuo que la sufre. } \\
\text { Sin embargo, la perturbación psíquica debe diferenciarse del } \\
\text { daño moral o dolor psicológico, que se presenta como respuesta } \\
\text { a la agresión sufrida con los hechos y se asimila al duelo } \\
\text { normal" (Instituto Nacional de Medicina Legal y Ciencias } \\
\text { Forenses, 2011, p.7-8). }\end{array}$ \\
\hline $\begin{array}{l}\text { Aspectos Psicológicos del } \\
\text { Fenómeno o teorías y } \\
\text { conceptos psicológicos } \\
\text { que explican el fenómeno. }\end{array}$ & $\begin{array}{l}\text { Diagnóstico Clínico: El diagnóstico clínico debe ser expresado } \\
\text { en términos aceptados por la comunidad científica y según } \\
\text { códigos nosológicos vigentes. (Instituto Nacional de Medicina } \\
\text { Legal y Ciencias Forenses, 2011, p.11). } \\
\text { Diagnóstico Forense: Consiste en determinar si existe una } \\
\text { relación de causalidad entre el acontecimiento que se investiga } \\
\text { o y la condición de salud mental del evaluado. }\end{array}$ \\
\hline $\begin{array}{l}\text { Rama o área del Derecho } \\
\text { para la que trasciende este } \\
\text { fenómeno }\end{array}$ & Derecho penal \\
\hline $\begin{array}{l}\text { Normatividad que regula } \\
\text { el fenómeno psicojurídico }\end{array}$ & 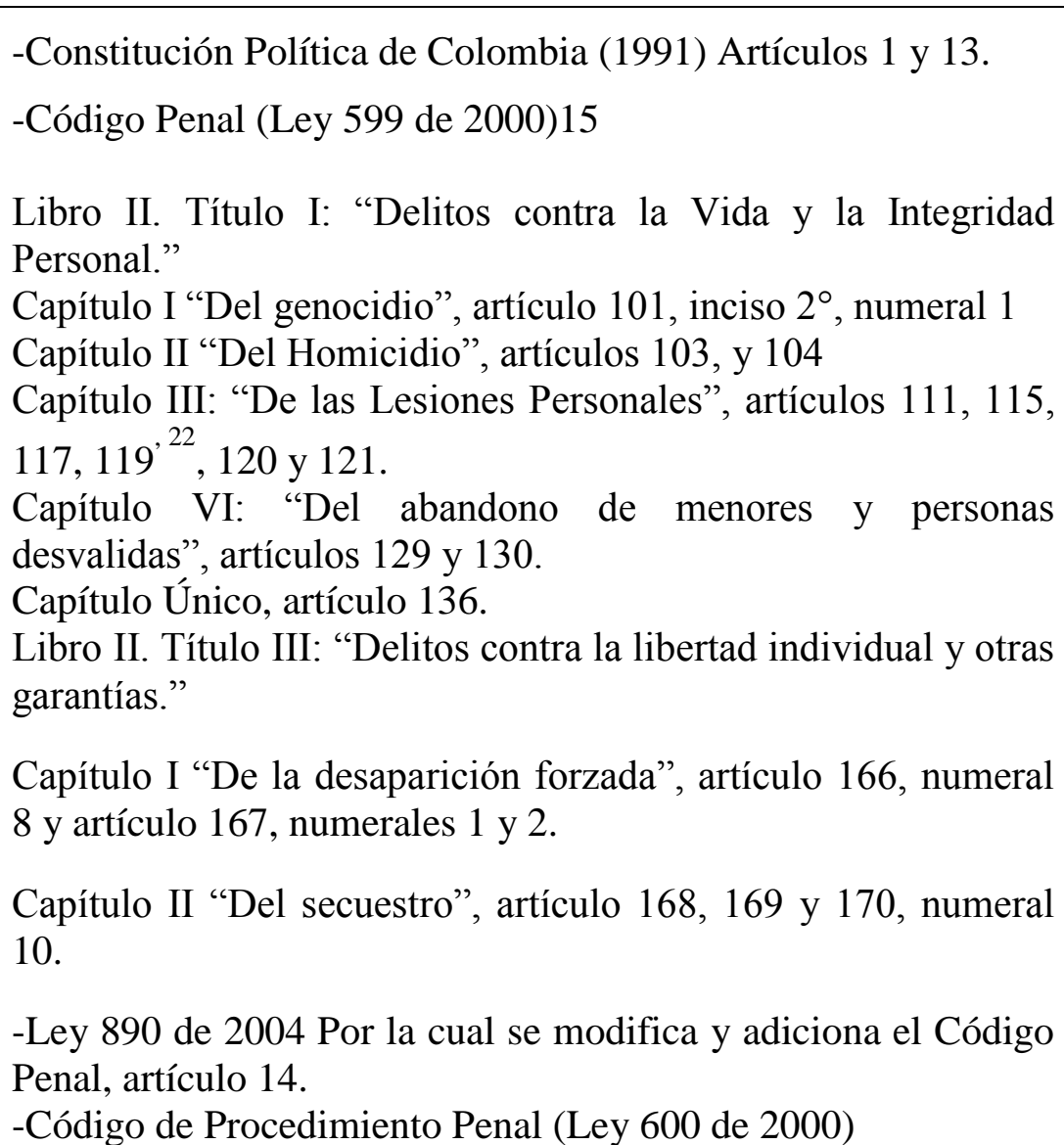 \\
\hline
\end{tabular}


Título Preliminar "Normas Rectoras” artículos 1, 5,9, 14 y 22.

Libro I "Disposiciones generales", Título VI "Pruebas",

Capítulo I "Principios generales”, artículos 232, 233 y 236.

Capítulo II “Inspección”, artículos 245 y 248.

Capítulo III "Prueba pericial”, artículos 249 a 258.

Capítulo VIII “Disposiciones especiales”, artículos 288 a 290 y 292.

-Código de Procedimiento Penal (Ley 906 de 2004)

Título Preliminar "Principios Rectores y garantías procesales", artículos 1, 4, 10, 11 y 18.

Libro II, Título I "La indagación y la investigación”:

Capítulo I "Órganos de indagación e investigación”, artículo 204.

Capítulo III “Actuaciones que requieren autorización judicial previa para su realización”, artículos 247, 249 y 250.

Capítulo V "Cadena de Custodia", artículos 254, 255, 257 a 265. Capítulo VI "Facultades de la defensa en la investigación", artículos 267 a 270.

Libro II, Título II "Medios cognoscitivos en la indagación e investigación"

Capítulo Único, artículos 275,276, 277 y 278.

Libro III "El juicio", Título IV "Juicio Oral”, Capítulo III "Práctica de la Prueba":

Parte I “Disposiciones generales”, artículos 372,378 y 379.

Parte III "Prueba Pericial” artículos 405 a 423.

Libro III "El juicio", Título IV “Juicio Oral”, Capítulo III "Práctica de la Prueba", Parte III "Prueba Pericial" artículos 405 a 423.

-Código de la Infancia y la Adolescencia, Ley 1098 de 200632

Libro I "La protección integral", Título I "Disposiciones generales":

Capítulo I "Principios y definiciones"; artículos 1, 2, 3, 4, 5, 7, $8,9,11$ y 15 .

Capítulo II "Derechos y libertades"; artículo 18, artículo 20, 


\begin{tabular}{|c|c|}
\hline & 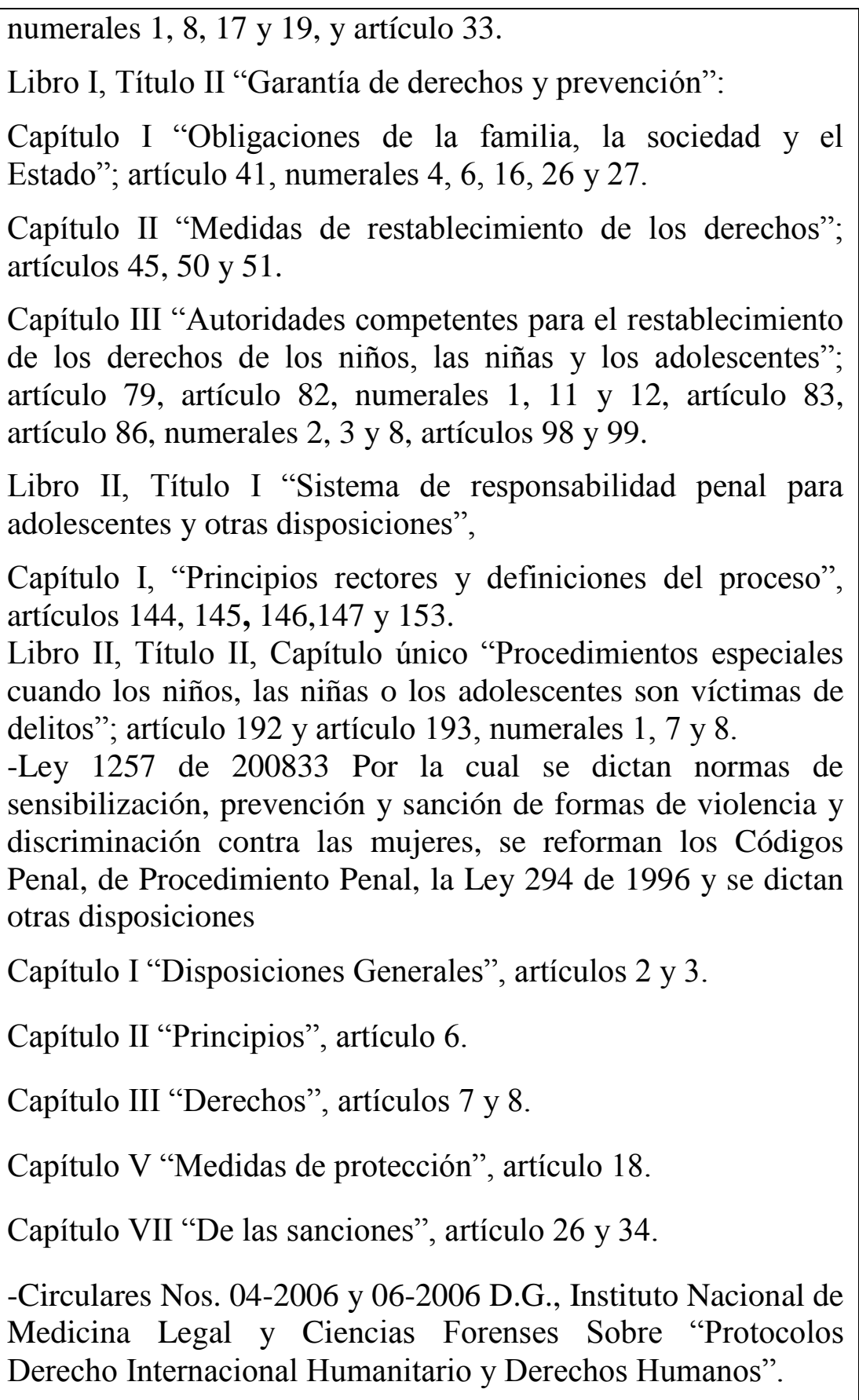 \\
\hline Responsables & $\begin{array}{l}\text { "Peritos psiquiatras o psicólogos forenses del Instituto Nacional } \\
\text { de Medicina Legal y Ciencias Forenses, o cualquier psiquiatra o } \\
\text { psicólogo debidamente entrenado y capacitado, que deba } \\
\text { realizar una evaluación forense sobre perturbación psíquica y } \\
\text { rendir el respectivo informe pericial o dictamen, en casos } \\
\text { relacionados con lesiones personales, genocidio, abandono de } \\
\text { menores y personas desvalidas, secuestro, desaparición forzada, }\end{array}$ \\
\hline
\end{tabular}




\begin{tabular}{|l|l|}
\hline $\begin{array}{l}\text { lesiones en persona protegida, tentativa de homicidio, entre } \\
\text { otros, así como en algunos casos de maltrato infantil o violencia } \\
\text { contra la mujer, fuera del contexto familiar, conforme a la } \\
\text { legislación colombiana pertinente, en todo el territorio nacional" } \\
\text { (Instituto Nacional de Medicina Legal y Ciencias Forenses, } \\
\text { 2011, p.12). }\end{array}$ \\
\hline
\end{tabular}

\subsubsection{Guía para la realización de pericias psiquiátricas sobre daño psíquico, con fines de indemnización, conciliación o reparación.}

\begin{tabular}{|c|c|}
\hline $\begin{array}{l}\text { Nombre del Fenómeno } \\
\text { Psicojurídico }\end{array}$ & $\begin{array}{l}\text { Evaluación del Daño psíquico, con fines de indemnización, } \\
\text { conciliación o reparación. }\end{array}$ \\
\hline Entidad creadora & $\begin{array}{l}\text { Instituto Nacional de Medicina Legal y Ciencias Forenses de } \\
\text { Colombia }\end{array}$ \\
\hline $\begin{array}{l}\text { Definición del fenómeno } \\
\text { psicojurídico. }\end{array}$ & $\begin{array}{l}\text { Según Tkaczuk (2001, citado por el Instituto Nacional de } \\
\text { Medicina Legal y Ciencias Forenses, 2011, p.15), "El daño } \\
\text { psíquico es la consecuencia de un acontecimiento que afecta la } \\
\text { estructura vital y generalmente acarrea trastornos y efectos } \\
\text { patógenos en la organización psíquica. El daño psíquico no } \\
\text { solo es el resultante de un acontecimiento inesperado y } \\
\text { sorpresivo, sino también puede presentarse como el efecto de } \\
\text { un proceso de erosión lenta y persistente, que va lesionando la } \\
\text { estructura física y psíquica que puede resultar hasta más } \\
\text { devastador". } \\
\text {-La conciliación preprocesal y el daño psíquico : Para delitos } \\
\text { querellables Art. 522 Código de Procedimiento Penal } \\
\text { colombiano. } \\
\text {-La conciliación en el incidente de reparación integral del daño } \\
\text { psíquico: Cuando está en firme la sentencia condenatoria Arts. } \\
\text { 102 a 108 Código de Procedimiento Penal colombiano. } \\
\text {-La mediación según lo establecido al respecto en los artículos }\end{array}$ \\
\hline
\end{tabular}




\begin{tabular}{|c|c|}
\hline & del 523 a 527 del Código de Procedimiento Penal colombiano. \\
\hline $\begin{array}{l}\text { Aspectos Psicológicos del } \\
\text { Fenómeno o teorías y } \\
\text { conceptos psicológicos } \\
\text { que explican el fenómeno. }\end{array}$ & $\begin{array}{l}\text { En la guía, "el daño psíquico está referido al deterioro de las } \\
\text { funciones psíquicas, derivado de la ocurrencia de un evento } \\
\text { externo sobre el cual puede reclamarse jurídicamente una } \\
\text { responsabilidad que origina la obligación de reparar el daño } \\
\text { causado y cuya búsqueda en lo forense va orientada a ayudar en } \\
\text { la determinación de las acciones de restauración que determine } \\
\text { la autoridad" (Instituto Nacional de Medicina Legal y Ciencias } \\
\text { Forenses, 2011, p.15). En todos los casos de debe especificar la } \\
\text { intensidad del daño psíquico, es decir, si éste es leve, } \\
\text { moderado, grave o profundo. }\end{array}$ \\
\hline $\begin{array}{l}\text { Rama o área del Derecho } \\
\text { para la que trasciende este } \\
\text { fenómeno }\end{array}$ & Derecho civil, Derecho Penal, Derecho de familia. \\
\hline $\begin{array}{l}\text { Normatividad que regula } \\
\text { el fenómeno psicojurídico }\end{array}$ & $\begin{array}{l}\text {-Constitución Política de Colombia (1991) Artículos } 1 \text { y } 13 . \\
\text { - Código Penal, Ley } 599 \text { de } 2000 \\
\text { - Código de Procedimiento Penal (Ley } 600 \text { de 2000) } \\
\text { - Código de Procedimiento Penal (Ley } 906 \text { de 2004) } \\
\text { - Ley } 1395 \text { de } 2010 \\
\text { - Ley } 975 \text { de } 2005 \text { (Ley de Justicia y Paz) } \\
\text { - Ley } 1448 \text { de } 2011 \text { (Ley de reparación de victimas). }\end{array}$ \\
\hline Responsables & $\begin{array}{l}\text { Peritos psiquiatras o psicólogos forenses del Instituto Nacional } \\
\text { de Medicina Legal y Ciencias Forenses, o cualquier psiquiatra } \\
\text { o psicólogo debidamente entrenado y capacitado. }\end{array}$ \\
\hline
\end{tabular}

3.1.6. Guía para la realización de pericias psiquiátricas y psicológicas forenses en niños, niñas y adolescentes presuntas víctimas de delitos sexuales. 


\begin{tabular}{|c|c|}
\hline $\begin{array}{l}\text { Nombre del Fenómeno } \\
\text { Psicojurídico }\end{array}$ & $\begin{array}{l}\text { Pericias Psiquiátricas o Psicológicas Forenses en Niños, } \\
\text { Niñas y Adolescentes presuntas víctimas de delitos sexuales }\end{array}$ \\
\hline Entidad creadora & $\begin{array}{l}\text { Instituto Nacional de Medicina Legal y Ciencias Forenses de } \\
\text { Colombia }\end{array}$ \\
\hline $\begin{array}{l}\text { Definición del fenómeno } \\
\text { psicojurídico. }\end{array}$ & $\begin{array}{l}\text { Según la Organización Mundial de la Salud (sf., citado por el } \\
\text { Instituto Nacional de Medicina Legal y Ciencias Forenses, } \\
\text { 2010, p. 8), el Abuso Sexual Infantil se entiende como una } \\
\text { acción en la cual "se involucra a un menor en una actividad } \\
\text { sexual que él o ella no comprende completamente, para la que } \\
\text { no tiene capacidad de libre consentimiento o su desarrollo } \\
\text { evolutivo (biológico, psicológico y social) no está preparado, o } \\
\text { también, que viola las normas o preceptos sociales. Los } \\
\text { menores pueden ser abusados sexualmente tanto por adultos } \\
\text { como por otros menores que tienen -en virtud de su edad o } \\
\text { estado de desarrollo- una posición de responsabilidad, } \\
\text { confianza o poder sobre la víctima, con el fin de gratificar o } \\
\text { satisfacer a la otra persona". }\end{array}$ \\
\hline $\begin{array}{l}\text { Aspectos Psicológicos del } \\
\text { Fenómeno o teorías y } \\
\text { conceptos psicológicos } \\
\text { que explican el fenómeno. }\end{array}$ & $\begin{array}{l}\text { IMPACTO DE LA VIOLENCIA SEXUAL EN EL } \\
\text { PSIQUISMO INFANTIL } \\
\text {-Alteración de la identificación con el adulto y debilitamiento } \\
\text { de la relación y vinculación afectiva. } \\
\text {-La imagen parental y de su propio cuerpo se ve afectada. } \\
\text { - Generalmente se presenta el TEPT (Trastorno por estrés } \\
\text { postraumático). "los niños y niñas presentan una amplia } \\
\text { variedad de reacciones al trauma, las que incluyen conductas } \\
\text { regresivas, ansiedad, miedos, somatizaciones, depresión, } \\
\text { problemas de conducta, aislamiento, déficit de atención, } \\
\text { disociaciones, trastornos del sueño y sentimientos de culpa". } \\
\text { (Instituto Nacional de Medicina Legal y Ciencias Forenses, } \\
\text { 2010, p. 23). }\end{array}$ \\
\hline
\end{tabular}




\section{LA PSICOLOGÍA JURÍDICA COMO UNA FUENTE DEL DERECHO}

\begin{tabular}{|c|c|}
\hline $\begin{array}{l}\text { Rama o área del Derecho } \\
\text { para la que trasciende este } \\
\text { fenómeno }\end{array}$ & Derecho Penal, Derecho de Familia, Derecho Civil. \\
\hline $\begin{array}{l}\text { Normatividad que regula } \\
\text { el fenómeno psicojurídico }\end{array}$ & 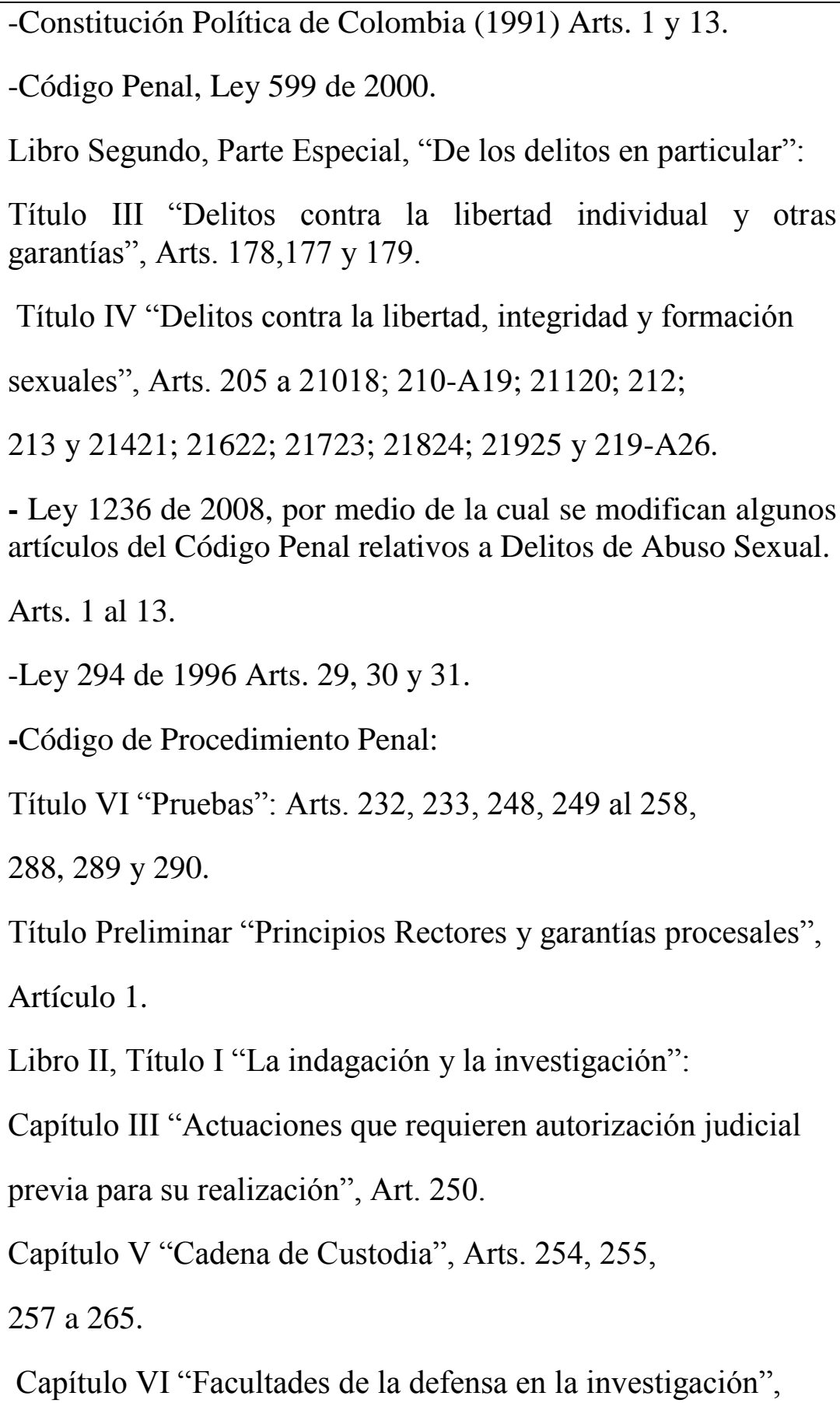 \\
\hline
\end{tabular}


Arts. 267 a 270 .

Libro II, Título II “Medios cognoscitivos en la indagación e investigación”, Capítulo Único, Arts. 275, 276 y 277.

Libro III “El juicio”, Título IV “Juicio Oral”, Capítulo III

"Práctica de la Prueba", Parte III "Prueba Pericial", Arts. 405 a 423.

- Código de la Infancia y la Adolescencia, Ley 1098 de 2006 Libro I, Título I "Disposiciones generales":

Capítulo I "Principios y definiciones"; Arts. 1, 2, 3, 4, $5,7,8,9,11$ у 15 .

Capítulo II "Derechos y libertades”; Arts. 17, 18, 20, Numerales 4, 7 y 18.

Libro I, Título II “Garantía de derechos y prevención”:

Capítulo I “Obligaciones de la familia, la sociedad y el

Estado"; Art.39, numerales 1, 6 y 9, artículo 41, numeral

26 y artículo 44, numeral 2.

Capítulo III "Autoridades competentes para el restablecimiento de los derechos de los niños, las niñas y los adolescentes";

Art. 82, numerales 1, 11, 12 y 16, Art. 86,

Numeral 3, Arts. 98 y 99.

Libro II, Título II, Capítulo Único "Procedimientos especiales cuando los niños, las niñas o los adolescentes son víctimas de delitos"; Arts. 192 y 193, numerales 1, 7 y 8.

-Sentencias de Casación, Sala Penal, Corte Suprema de Justicia Nos. 13.466 del 26 de septiembre de 2000 y 30.305 del 5 de noviembre de 2008 .

-Ley 1146 de 2007.

- Ley 1336 de 2009, por medio de la cual se adiciona y robustece la Ley 679 de 2001, de lucha contra la explotación, la pornografía y el turismo sexual con niños, niñas y adolescentes. 


\begin{tabular}{|c|c|}
\hline & $\begin{array}{l}\text {-“Convención sobre los Derechos del Niño”, Resolución } \\
\text { 44/25 de la Asamblea General de las Naciones Unidas del } \\
20 \text { de noviembre de } 198929 .\end{array}$ \\
\hline Responsables & $\begin{array}{l}\text { Peritos psiquiatras o psicólogos forenses del Instituto Nacional } \\
\text { de Medicina Legal y Ciencias Forenses, o cualquier psiquiatra } \\
\text { o psicólogo debidamente entrenado y capacitado, que deban } \\
\text { realizar una experticia forense en niños, niñas y adolescentes, } \\
\text { presuntas víctimas de delitos sexuales. }\end{array}$ \\
\hline
\end{tabular}

\subsubsection{Guía para la realización de pericias psiquiátricas sobre patria potestad (o potestad parental) y custodia.}

\begin{tabular}{|c|c|}
\hline $\begin{array}{l}\text { Nombre del Fenómeno } \\
\text { Psicojurídico }\end{array}$ & Patria Potestad (o Potestad Parental) y Custodia. \\
\hline Entidad creadora & $\begin{array}{l}\text { Instituto Nacional de Medicina Legal y Ciencias Forenses de } \\
\text { Colombia }\end{array}$ \\
\hline $\begin{array}{l}\text { Definición del fenómeno } \\
\text { psicojurídico. }\end{array}$ & $\begin{array}{l}\text { La patria potestad "es el conjunto de derechos y deberes que } \\
\text { tienen los padres sobre sus hijos menores de } 18 \text { años, no } \\
\text { emancipados". (Instituto Nacional de Medicina Legal y } \\
\text { Ciencias Forenses, } 2010 \text { p. 12) } \\
\text { La custodia "se refiere al cuidado de los niños que por ley } \\
\text { corresponde a los padres". ". (Instituto Nacional de Medicina } \\
\text { Legal y Ciencias Forenses, } 2010 \text { p. 18) }\end{array}$ \\
\hline $\begin{array}{l}\text { Aspectos Psicológicos del } \\
\text { Fenómeno o teorías y } \\
\text { conceptos psicológicos } \\
\text { que explican el fenómeno. }\end{array}$ & $\begin{array}{l}\text { Aspectos específicos a tener en cuenta en casos de patria } \\
\text { potestad. } \\
\text { Cuando se evalúa un adulto en calidad de padre o madre, se } \\
\text { recomienda: }\end{array}$ \\
\hline
\end{tabular}




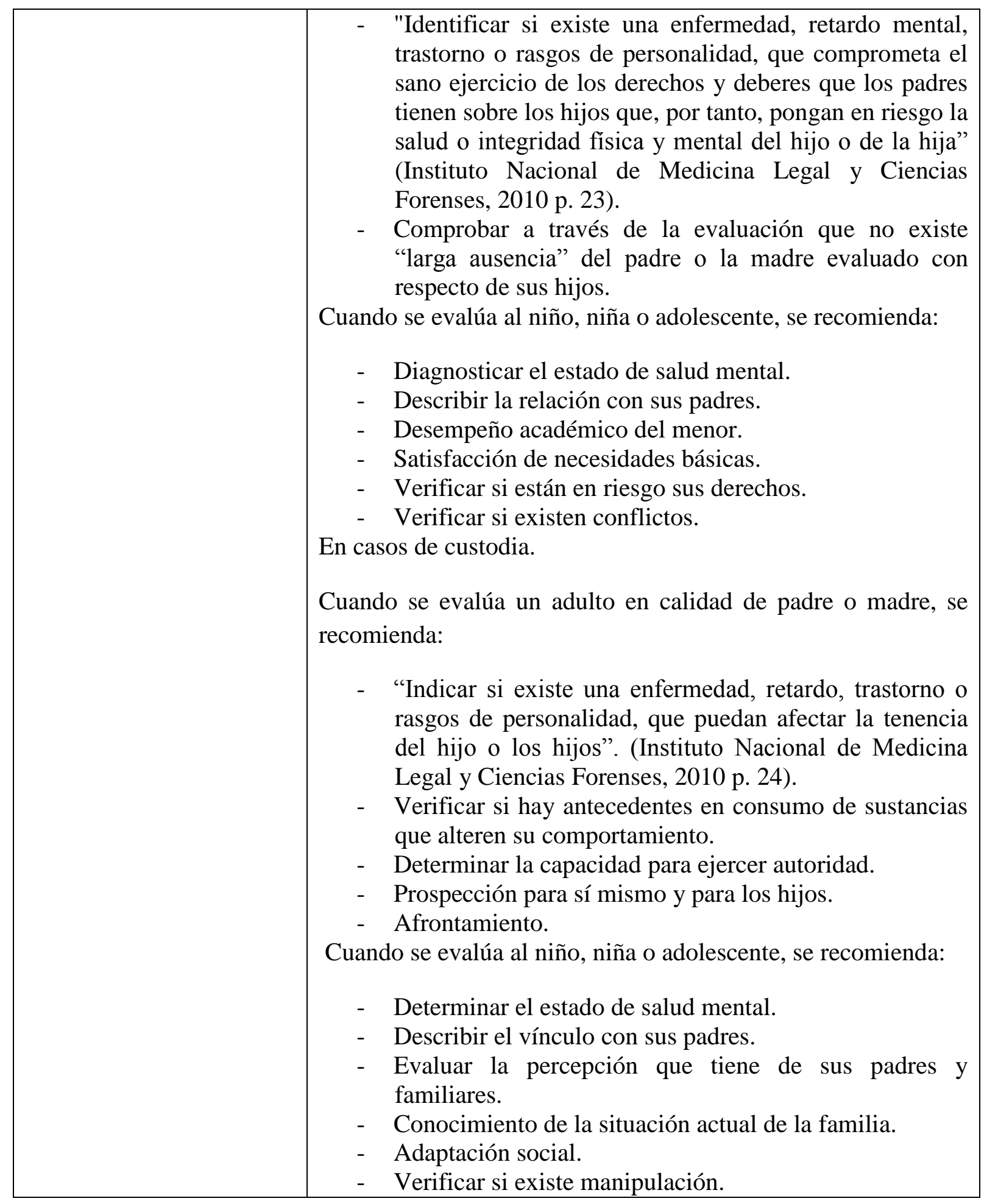




\section{LA PSICOLOGÍA JURÍDICA COMO UNA FUENTE DEL DERECHO}

\begin{tabular}{|c|c|}
\hline $\begin{array}{l}\text { Rama o área del Derecho } \\
\text { para la que trasciende este } \\
\text { fenómeno }\end{array}$ & Derecho de Familia, Derecho Civil. \\
\hline $\begin{array}{l}\text { Normatividad que regula } \\
\text { el fenómeno psicojurídico }\end{array}$ & 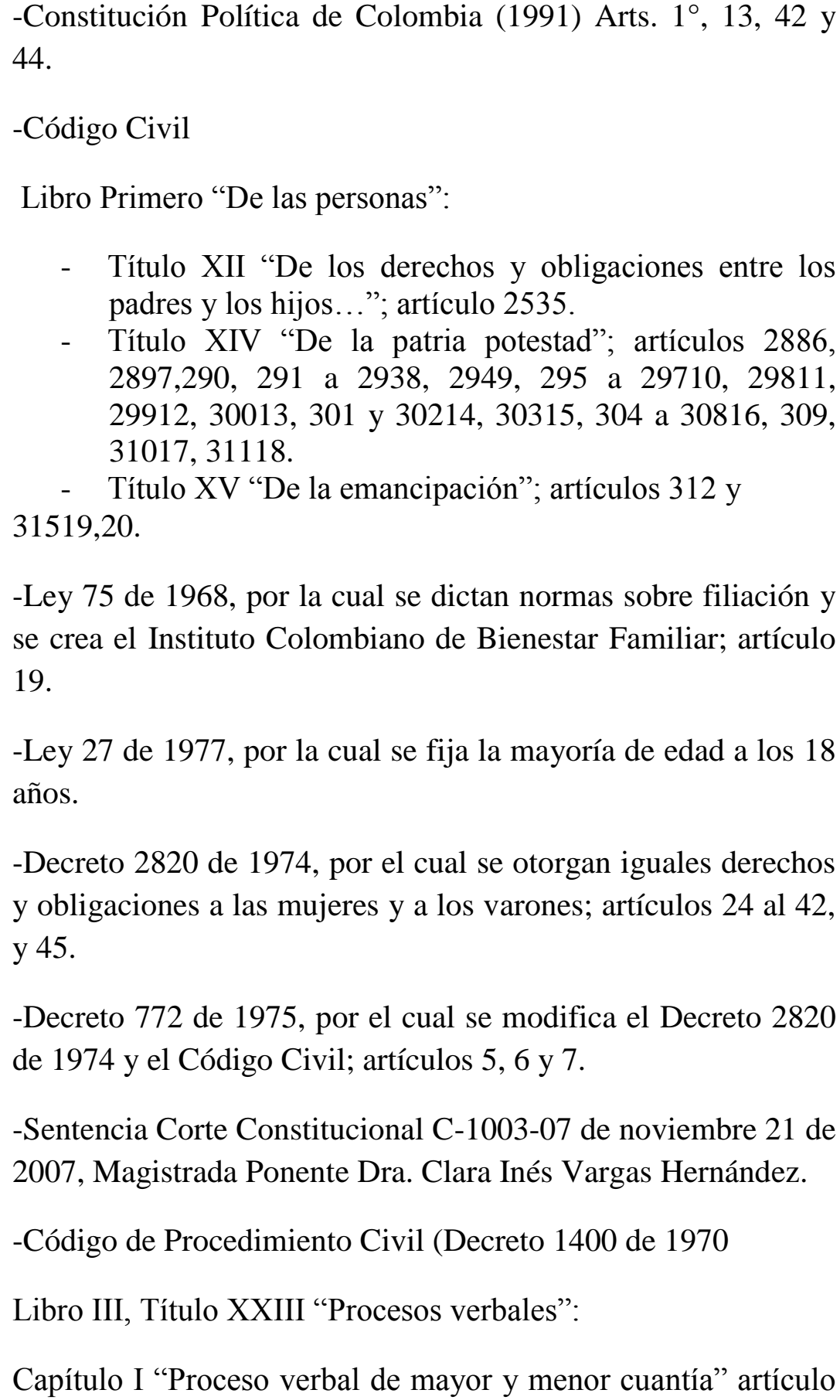 \\
\hline
\end{tabular}


427, parágrafo 1 , numeral 227

Capítulo III “Disposiciones especiales”, artículo 446

-Decreto 2272 de 1989, por el cual se organiza la Jurisdicción de Familia, se crean unos Despachos judiciales y se dictan otras disposiciones.

Capítulo II "De los Juzgados de Familia", artículo 5

(Particularmente en lo relativo al literal d en única instancia, y al numeral 5 en primera instancia) y artículo 8 .

-Código de la Infancia y la Adolescencia, Ley 1098 de 2006

- Libro I "La protección integral":

- Título I "Disposiciones generales":

- Capítulo I "Principios y definiciones"; artículo 14.

- Capítulo II “Derechos y libertades”; artículos 17 a 37.

• Título II “Garantía de derechos y prevención”:

- Capítulo III “Autoridades competentes para el restablecimiento de los derechos de los niños, las niñas y los adolescentes", artículos 82 y 86 .

- Capítulo IV "Procedimiento Administrativo y reglas especiales”, artículos 99 y 100.

-Ley 1306 de 200931, por la cual se dictan normas para la Protección de Personas con Discapacidad Mental y se establece el Régimen de la Representación Legal de Incapaces Emancipados

Capítulo I "Consideraciones preliminares", artículos 1 al 6, 8 y 10.

Capítulo II "Personas con discapacidad mental", Sección Primera "Personas con discapacidad mental absoluta", artículo 26. 
Responsables

Peritos psiquiatras o psicólogos forenses del Instituto Nacional de Medicina Legal y Ciencias Forenses, cualquier psiquiatra o psicólogo debidamente entrenado y capacitado.

\subsubsection{Guía para la realización de pericias psiquiátricas sobre estado de salud mental del privado de la libertad-estado grave por enfermedad o enfermedad muy grave incompatible con la vida en reclusión formal.}

\begin{tabular}{|c|c|}
\hline $\begin{array}{l}\text { Nombre del Fenómeno } \\
\text { Psicojurídico }\end{array}$ & $\begin{array}{l}\text { Salud mental del privado de la libertad- Estado grave por } \\
\text { enfermedad o enfermedad muy grave incompatible con la } \\
\text { vida en reclusión formal }\end{array}$ \\
\hline $\begin{array}{l}\text { Entidad creadora de la } \\
\text { guía y Participantes }\end{array}$ & $\begin{array}{l}\text { Instituto Nacional de Medicina Legal y Ciencias Forenses de } \\
\text { Colombia }\end{array}$ \\
\hline $\begin{array}{l}\text { Definición del fenómeno } \\
\text { psicojurídico. }\end{array}$ & $\begin{array}{l}\text { ESTADO DE SALUD MENTAL EN PERSONA PRIVADA } \\
\text { DE LIBERTAD: "Circunstancias de salud, en este caso mental, } \\
\text { contempladas en el Código Penal como mecanismo sustitutivo } \\
\text { de la pena o en el de Procedimiento Penal, como condición } \\
\text { para suspender o sustituir la detención preventiva, así como } \\
\text { para el aplazamiento, suspensión o sustitución de la ejecución } \\
\text { de la pena" (Instituto Nacional de Medicina Legal y Ciencias } \\
\text { Forenses, } 2009 \text { p. 7). } \\
\text { ESTADO GRAVE POR ENFERMEDAD O ENFERMEDAD } \\
\text { MUY GRAVE INCO MPATIBLE CON LA VIDA EN } \\
\text { RECLUSIÓN FORMAL: "condición de salud mental de una } \\
\text { persona privada de la libertad, que no puede ser atendida de } \\
\text { manera adecuada en el sitio de reclusión y que requiere } \\
\text { tratamiento o manejo en un centro hospitalario, o en centro de } \\
\text { reclusión que ofrezca las condiciones requeridas, o en su } \\
\text { domicilio" (Instituto Nacional de Medicina Legal y Ciencias } \\
\text { Forenses, 2009 p. 8). }\end{array}$ \\
\hline
\end{tabular}




\section{LA PSICOLOGÍA JURÍDICA COMO UNA FUENTE DEL DERECHO}

\begin{tabular}{|c|c|}
\hline $\begin{array}{l}\text { Aspectos Psicológicos del } \\
\text { Fenómeno o teorías y } \\
\text { conceptos psicológicos } \\
\text { que explican el fenómeno. }\end{array}$ & $\begin{array}{l}\text { El estado de salud mental en persona privada de libertad debe } \\
\text { ser determinado por un perito médico psiquiatra oficial, de } \\
\text { acuerdo con la siguiente denominación prescrita por la ley: } \\
\text { Enfermedad Grave, expresión utilizada en el Artículo } 106 \text { del } \\
\text { Código Penitenciario y Carcelario, y Enajenación Mental } \\
\text { prescrita el artículo } 107 \text { del Código Penitenciario y Carcelario, }\end{array}$ \\
\hline $\begin{array}{l}\text { Rama o área del Derecho } \\
\text { para la que trasciende este } \\
\text { fenómeno }\end{array}$ & ho Penal, Derecho Penitenciario, Derecho Procesal Penal. \\
\hline $\begin{array}{l}\text { Normatividad que regula } \\
\text { el fenómeno psicojurídico }\end{array}$ & 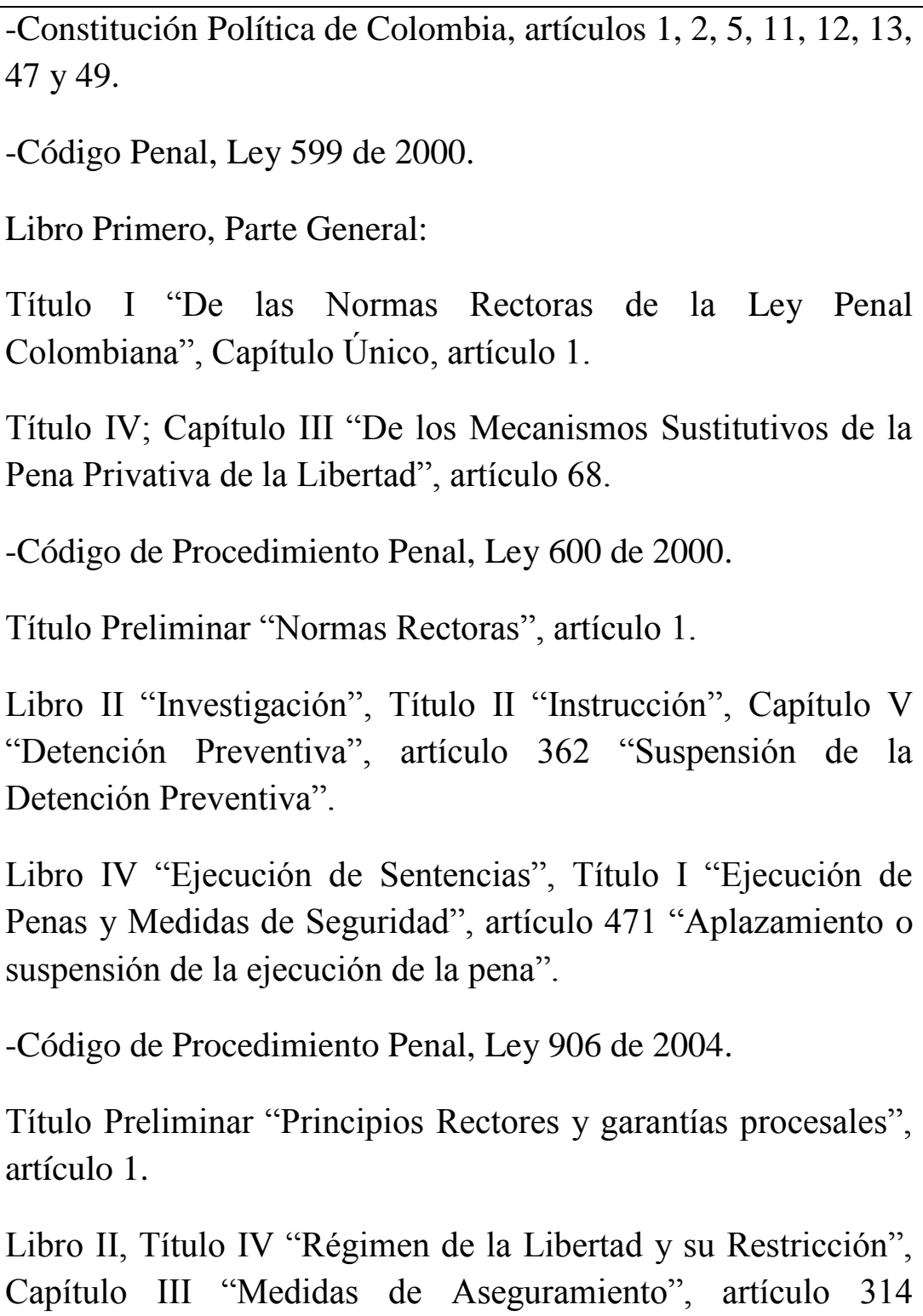 \\
\hline
\end{tabular}




\begin{tabular}{|c|c|}
\hline & 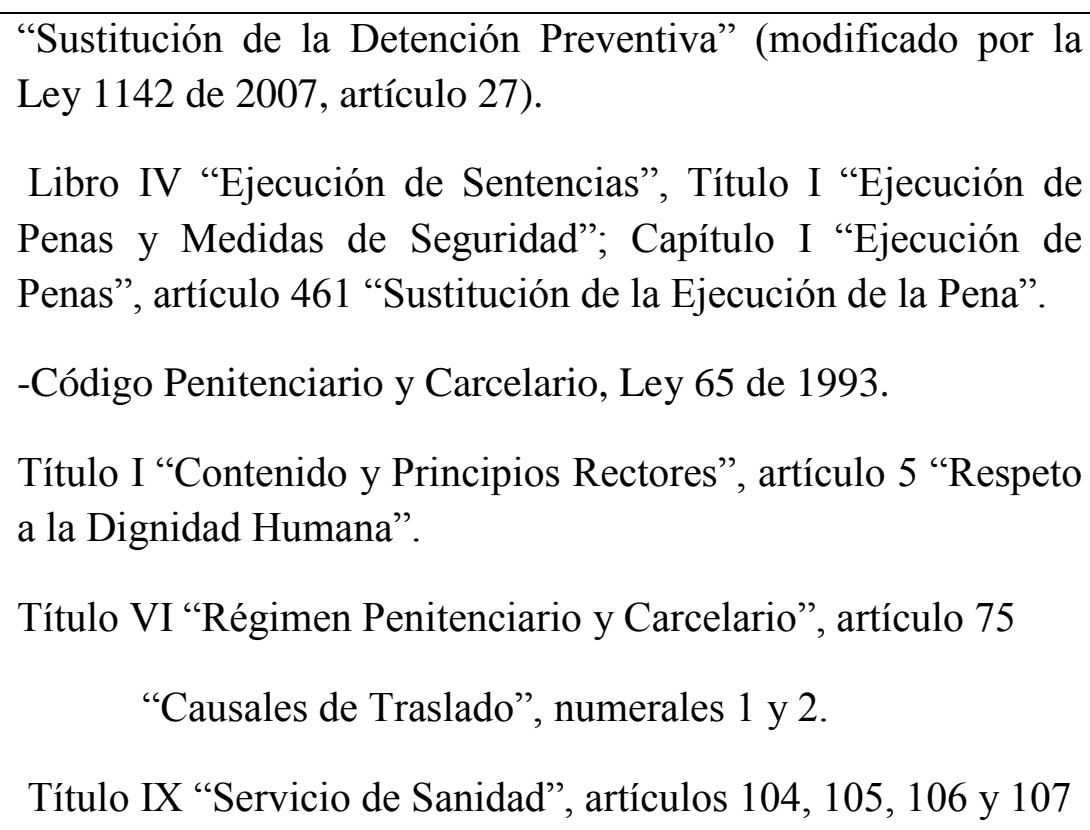 \\
\hline $\begin{array}{l}\text { Procedimiento Psi- } \\
\text { jurídico y Responsable. }\end{array}$ & $\begin{array}{l}\text { Peritos psiquiatras forenses del Instituto Nacional de Medicina } \\
\text { Legal y Ciencias Forenses, o médicos psiquiatras oficiales. }\end{array}$ \\
\hline
\end{tabular}

\subsubsection{Guía para la realización de pericias psiquiátricas y psicológicas forenses con fines de reglamentación de visitas y regulación de alimentos.}

\begin{tabular}{|l|l|}
\hline $\begin{array}{l}\text { Nombre } \\
\text { Fenómeno } \\
\text { Psicojurídico }\end{array}$ & $\begin{array}{l}\text { Guía para la realización de pericias psiquiátricas y psicológicas } \\
\text { forenses con fines de reglamentación de visitas y regulación de } \\
\text { alimentos. }\end{array}$ \\
\hline Entidad creadora & $\begin{array}{l}\text { Instituto Nacional de Medicina Legal y Ciencias Forenses de } \\
\text { Colombia. }\end{array}$ \\
\hline $\begin{array}{l}\text { Definición del } \\
\text { fenómeno } \\
\text { psicojurídico. }\end{array}$ & $\begin{array}{l}\text { El artículo 256 del Código Civil colombiano prescribe lo siguiente: } \\
\text { "Al padre o madre de cuyo cuidado personal se sacaren los hijos, no } \\
\text { por eso se prohibirá visitarlos con la frecuencia y libertad que el juez }\end{array}$ \\
\hline
\end{tabular}




\begin{tabular}{|c|c|}
\hline & $\begin{array}{l}\text { juzgare convenientes", porque el niño el derecho fundamental a la } \\
\text { familia a pesar de la separación de sus padres. } \\
\text { - El régimen de alimentos: } \\
\text { Como lo ha expresado la Corte Constitucional colombiana (2001, } \\
\text { citada por el Instituto Nacional de Medicina Legal y Ciencias } \\
\text { Forenses, 2010, p. 15) "el derecho de alimentos es aquél que le } \\
\text { asiste a una persona para reclamar de quien está obligado legalmente } \\
\text { a darlos, lo necesario para su subsistencia, cuando no está en } \\
\text { capacidad de procurársela por sus propios medios. Así, la obligación } \\
\text { alimentaria está en cabeza de la persona que por ley, debe sacrificar } \\
\text { parte de su propiedad con el fin de garantizar la supervivencia y } \\
\text { desarrollo del acreedor de los alimentos". }\end{array}$ \\
\hline $\begin{array}{l}\text { Aspectos Psicológicos } \\
\text { del Fenómeno o } \\
\text { teorías y conceptos } \\
\text { psicológicos que } \\
\text { explican el fenómeno. }\end{array}$ & $\begin{array}{l}\text { CICLO VITAL DE LA FAMILIA: "Es el proceso evolutivo de la } \\
\text { familia, caracterizado por una serie de etapas y transiciones que } \\
\text { hasta cierto punto son predecibles. Aunque el ciclo vital familiar es } \\
\text { vivido por cada familia de manera singular en sus etapas se } \\
\text { encuentra un marco de referencia para el estudio, análisis, } \\
\text { comprensión y diagnóstico de la familia, así como para proyectar } \\
\text { acciones preventivas y/o terapéuticas a sus miembros" (Instituto } \\
\text { Nacional de Medicina Legal y Ciencias Forenses, } 2010 \text { p. 6-7). }\end{array}$ \\
\hline $\begin{array}{ll}\text { Rama o área } & \text { del } \\
\text { Derecho para la que } \\
\text { trasciende } & \text { este } \\
\text { fenómeno } & \end{array}$ & Derecho de Familia, Derecho Penal. \\
\hline $\begin{array}{l}\text { Normatividad que } \\
\text { regula el fenómeno } \\
\text { psicojurídico }\end{array}$ & $\begin{array}{l}\text {-Constitución Política de Colombia (1991) Artículos } 1^{\circ}, 13,42,44 \text { y } \\
46 . \\
\text {-Código Civil: Libro Primero “De las personas”: Título XII, artículo } \\
\text { 256. Título XXI, artículos 411, 412, 41317, } 414 \text { y } 422 . \\
\text {-Código Penal, Ley } 599 \text { de } 2000 \\
\text {-Ley } 1181 \text { de } 2007, \text { por la cual se modifica el artículo } 233 \text { de la Ley } \\
599 \text { de } 2000 . \\
\text {-Decreto } 2272 \text { de } 1989\end{array}$ \\
\hline
\end{tabular}




\begin{tabular}{|l|l|}
\hline -Capítulo II "De los Juzgados de Familia", artículo 5 y 8. \\
-Código de la Infancia y la Adolescencia, Ley 1098 de 2006 \\
-Capítulo V "Procedimiento Judicial y reglas especiales", \\
artículos 119,120 y 129 a 135 \\
-Decreto 2737 de 1989, Código del Menor \\
-Sentencias de la Corte Constitucional, números T-290/93, \\
T-500/93, C-388/00, C-919/01, C-1033/02, C- \\
029/09 y C-055/10. \\
$\begin{array}{l}\text { Peritos psiquiatras o psicólogos forenses del Instituto Nacional de } \\
\text { Medicina Legal y Ciencias Forenses, o cualquier psiquiatra o } \\
\text { psicólogo debidamente entrenado y capacitado. }\end{array}$ \\
\hline Responsables & \begin{tabular}{l} 
\\
\hline
\end{tabular} \\
\hline
\end{tabular}

\subsubsection{Guía para la realización de pericias psiquiátricas y psicológicas forenses en adultos víctimas de delitos sexuales.}

\begin{tabular}{|l|l|}
\hline $\begin{array}{l}\text { Nombre del Fenómeno } \\
\text { Psicojurídico }\end{array}$ & $\begin{array}{l}\text { Evaluación psiquiátrica o psicológica forense de adultos } \\
\text { víctimas de delitos sexuales }\end{array}$ \\
\hline Entidad creadora & $\begin{array}{l}\text { Instituto Nacional de Medicina Legal y Ciencias Forenses de } \\
\text { Colombia }\end{array}$ \\
\hline $\begin{array}{l}\text { pefinición del fenómeno } \\
\text { psicojurídico. }\end{array}$ & $\begin{array}{l}\text { La violencia sexual según Londoño (2002, citada por el } \\
\text { Instituto Nacional de Medicina Legal y Ciencias Forenses, } \\
\text { 2013, p. 5) es un acto de sometimiento en donde mediante la } \\
\text { fuerza, la amenaza, el chantaje emocional o económico, la } \\
\text { presión, los engaños o sobornos y aprovechando la condición } \\
\text { de superioridad física, de edad, de autoridad, económica o } \\
\text { afectiva se somete a otra persona a realizar conductas } \\
\text { sexuales". En el sistema jurídico colombiano, la violencia } \\
\text { sexual se tipifica así: }\end{array}$ \\
\hline
\end{tabular}




\begin{tabular}{|c|c|}
\hline & $\begin{array}{l}\text { Art. 205. Código Penal colombiano: Acceso carnal violento. } \\
\text { Art. 206. Código Penal colombiano: Acto sexual violento. } \\
\text { Art.207. Código Penal colombiano: Acceso carnal o acto } \\
\text { sexual en persona puesta en incapacidad de resistir. } \\
\text { Art. 212. Código Penal colombiano: Definición de acceso } \\
\text { carnal. }\end{array}$ \\
\hline $\begin{array}{l}\text { Aspectos Psicológicos del } \\
\text { Fenómeno o teorías y } \\
\text { conceptos psicológicos } \\
\text { que explican el fenómeno. }\end{array}$ & $\begin{array}{l}\text { Impactos psicológicos de la violencia sexual en el adulto: } \\
\text { Durante los hechos: resistencia o no resistencia por disociación } \\
\text { en el caso de esta última. } \\
\text { A corto plazo: "temor, ansiedad, confusión, vergüenza, culpa, } \\
\text { humillación, miedo, rabia, tristeza y asilamiento social" } \\
\text { (Instituto Nacional de Medicina Legal y Ciencias Forenses, } \\
2013 \text {, p. 17). } \\
\text { A largo plazo: Trastorno por Estrés Postraumático. } \\
\text { Se debe tener especial atención con los casos en los que una } \\
\text { mujer víctima de estos delitos resulta embarazada o con } \\
\text { enfermedades de transmisión sexual causas por el acto. }\end{array}$ \\
\hline $\begin{array}{l}\text { Rama o área del Derecho } \\
\text { para la que trasciende este } \\
\text { fenómeno }\end{array}$ & Derecho Penal. \\
\hline $\begin{array}{l}\text { Normatividad que regula } \\
\text { el fenómeno psicojurídico }\end{array}$ & $\begin{array}{l}\text {-Constitución Política de Colombia (1991) Arts. } 1 \text { y } 13 . \\
\text {-Código Penal colombiano (Ley } 599 \text { de 2000). } \\
\text {-Ley } 1236 \text { de } 2008 \text { de la República de Colombia. } \\
\text {-Ley } 1257 \text { de } 2008 \text { de la República de Colombia. } \\
\text {-Ley } 1329 \text { de } 2009 \text { de la República de Colombia. }\end{array}$ \\
\hline
\end{tabular}




\begin{tabular}{|l|l|}
\hline & $\begin{array}{l}\text {-Código de Procedimiento Penal colombiano (Ley } 906 \text { de } \\
2004) .\end{array}$ \\
\hline Responsables & $\begin{array}{l}\text { Peritos psiquiatras o psicólogos forenses del Instituto Nacional } \\
\text { de Medicina Legal y Ciencias Forenses, cualquier psiquiatra o } \\
\text { psicólogo debidamente entrenado y capacitado. }\end{array}$ \\
\hline
\end{tabular}

\subsubsection{Guía para la realización de pericias psiquiátricas sobre adicción a sustancias.}

\begin{tabular}{|l|l|}
\hline $\begin{array}{l}\text { Nombre del Fenómeno } \\
\text { Psicojurídico }\end{array}$ & $\begin{array}{l}\text { Pericias psiquiátricas o psicológicas forenses sobre adicción } \\
\text { a sustancias }\end{array}$ \\
\hline Entidad creadora & $\begin{array}{l}\text { Instituto Nacional de Medicina Legal y Ciencias Forenses de } \\
\text { Colombia }\end{array}$ \\
\hline $\begin{array}{l}\text { Definición del fenómeno } \\
\text { psicojurídico. }\end{array}$ & $\begin{array}{l}\text { Las pericias psiquiátricas y psicológicas forenses sobre } \\
\text { adicción a sustancias son solicitadas en los procesos por } \\
\text { Tráfico, fabricación o porte de estupefacientes, tipificada en el } \\
\text { art.367 del Código Penal colombiano, con el objetivo de } \\
\text { determinar si la persona que se encuentra "en posesión de una } \\
\text { sustancia que produce dependencia es un adicto a dicha } \\
\text { sustancia para considerarlo garante de su derecho a portar la } \\
\text { dosis personal o, por el contrario, no es adicto y por lo tanto se } \\
\text { puede procesar en los términos del artículo 376 del Código } \\
\text { Penal. Eventualmente las autoridades judiciales civiles, } \\
\text { administrativas y militares solicitan pericias para determinar } \\
\text { adicción a sustancias en el marco de procesos de divorcio, } \\
\text { custodia, patria potestad o potestad parental e investigaciones } \\
\text { disciplinarias o por infracción de normas castrenses" (Instituto } \\
\text { Nacional de Medicina Legal y Ciencias Forenses, 2009, p.13). }\end{array}$ \\
\hline $\begin{array}{l}\text { Aspectos Psicológicos del } \\
\text { conceptos }\end{array}$ & $\begin{array}{l}\text {-Dependencia psicológica: consiste en la necesidad de consumo } \\
\text { de una droga sin importar las consecuencias de la misma. La } \\
\text { psicología ofrece todos los mecanismos para la intervención de }\end{array}$ \\
\hline
\end{tabular}




\begin{tabular}{|c|c|}
\hline que explican el fenómeno. & $\begin{array}{l}\text { este fenómeno. } \\
\text { - Adicción. } \\
\text {-Tratamiento. } \\
\text {-Farmacodependencia. } \\
\text {-Rehabilitación. }\end{array}$ \\
\hline $\begin{array}{l}\text { Rama o área del Derecho } \\
\text { para la que trasciende este } \\
\text { fenómeno }\end{array}$ & $\begin{array}{l}\text { Derecho Penal, Derecho de Familia, Derecho Penal Militar, } \\
\text { Derecho Civil, Derecho Disciplinario. }\end{array}$ \\
\hline $\begin{array}{l}\text { Normatividad que regula } \\
\text { el fenómeno psicojurídico }\end{array}$ & $\begin{array}{l}\text {-Estatuto Nacional de Estupefacientes, Ley } 30 \text { de } 1986 . \\
\text {-Decreto } 3788 \text { de } 1986 \text { por el cual se reglamenta la Ley } \\
30 \text { de } 1986 \text { o Estatuto Nacional de Estupefacientes. } \\
\text {-Código Penal colombiano, Ley } 599 \text { de } 2000 \\
\text {-Resolución } 001315 \text { del } 25 \text { de abril 2006, Ministerio de la } \\
\text { Protección Social. } \\
\text {-Sentencias de la Corte Constitucional Nos. C-221/94 y } \\
\text { T-814/08. }\end{array}$ \\
\hline Responsables & $\begin{array}{l}\text { Peritos psiquiatras o psicólogos forenses del Instituto Nacional } \\
\text { de Medicina Legal y Ciencias Forenses, cualquier psiquiatra o } \\
\text { psicólogo debidamente entrenado y capacitado. }\end{array}$ \\
\hline
\end{tabular}

Ahora, se presentan las denominaciones que los autores consultados en este trabajo dan a los fenómenos psicojurídicos, además se muestra la relación de éstos con el derecho desde dos perspectivas, la primera de ellas hace referencia a la rama del derecho que los contempla, y la segunda se refiere al momento jurídico en el que éstos aparecen. 


\subsection{Fenómenos psicojurídicos en la literatura psicojurídica.}

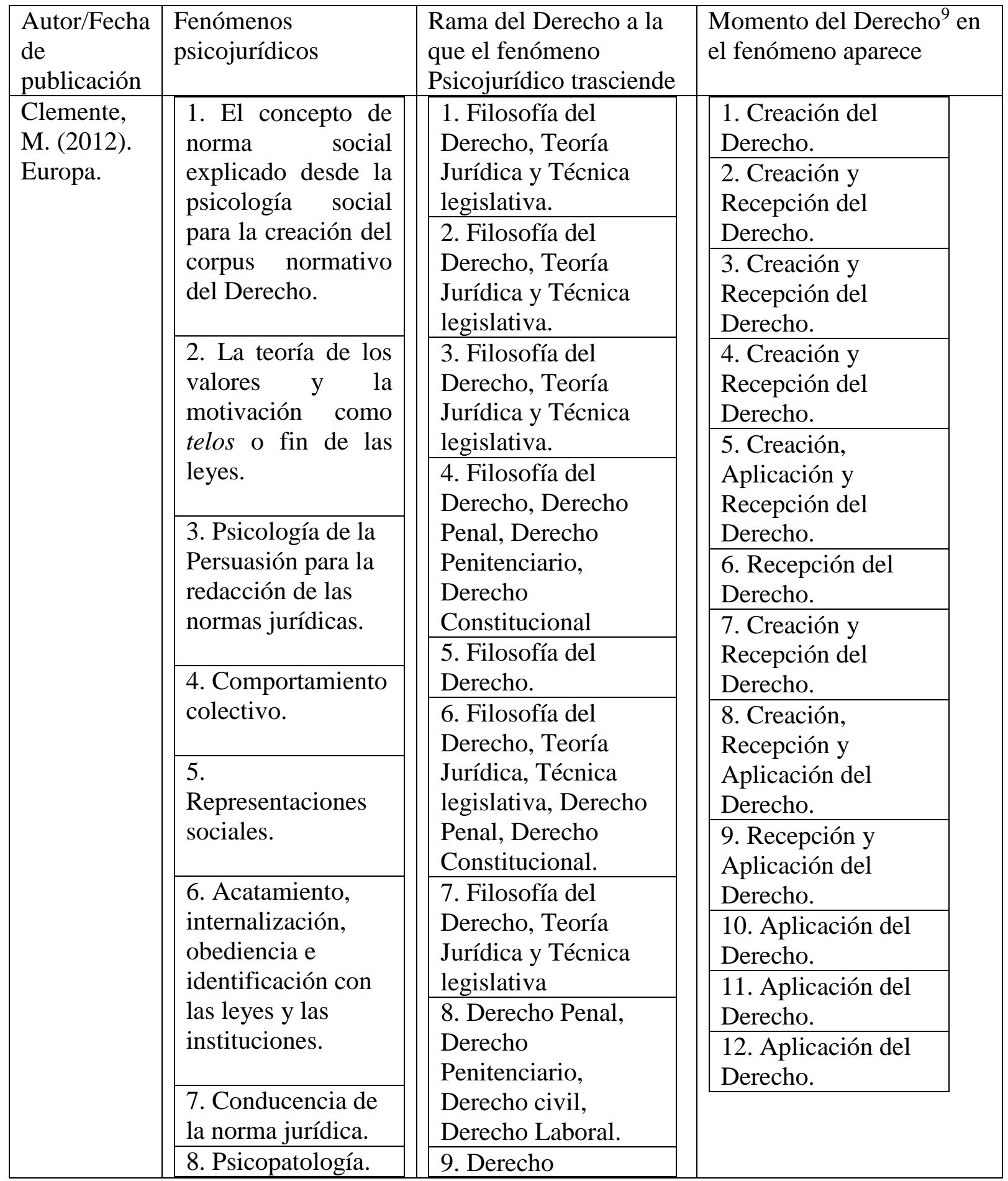

\footnotetext{
${ }^{9}$ Ver Definición de los Momentos del Derechos, apartado 1.3 y páginas 29 y 30 de este trabajo.
} 


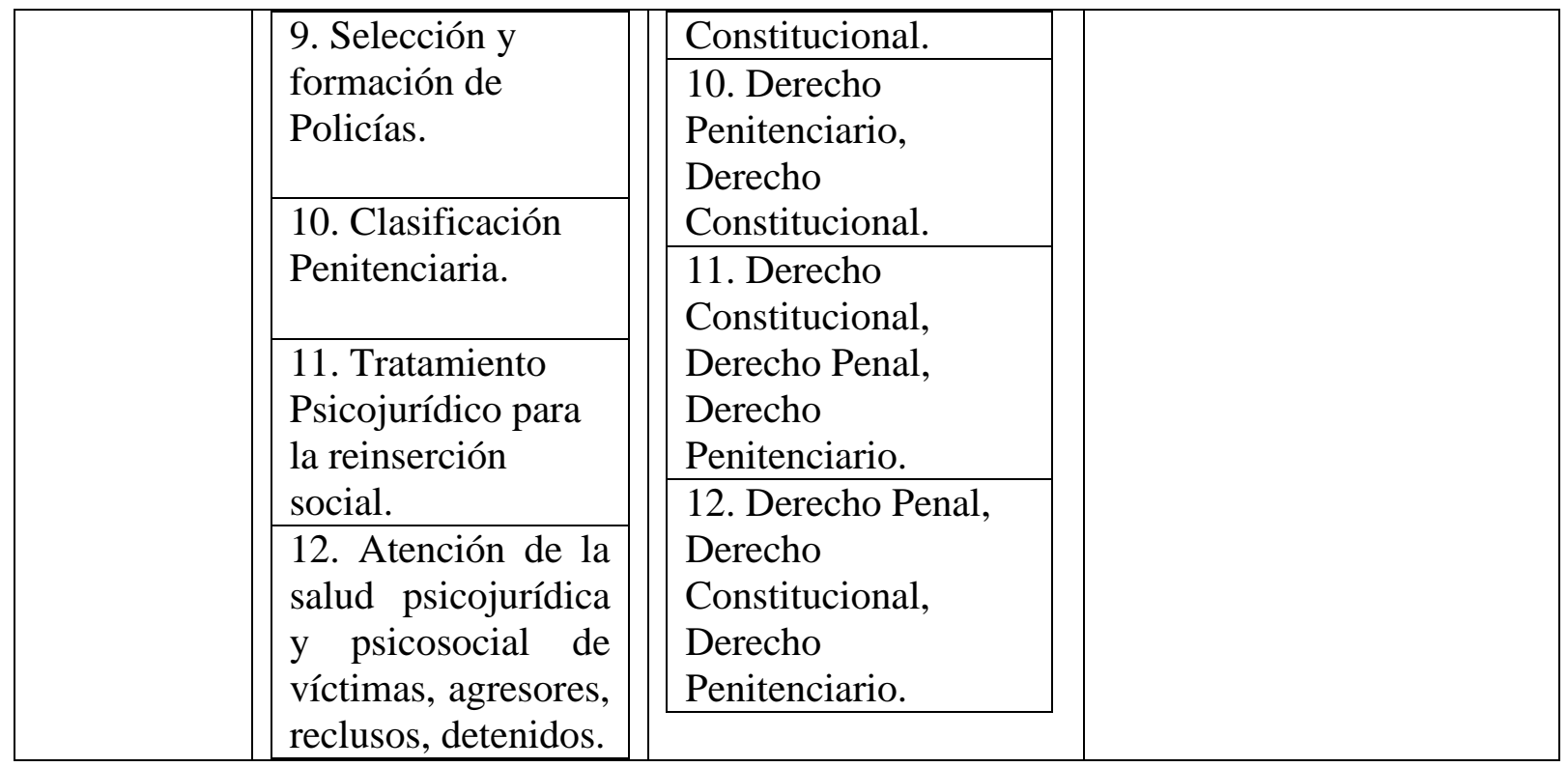

\begin{tabular}{|c|c|c|c|}
\hline $\begin{array}{l}\text { Autor/Fecha } \\
\text { de } \\
\text { publicación/ } \\
\text { Contexto }\end{array}$ & $\begin{array}{l}\text { Fenómenos } \\
\text { psicojurídicos }\end{array}$ & $\begin{array}{l}\text { Rama del Derecho a } \\
\text { que el fenómeno } \\
\text { Psicojurídico trascie }\end{array}$ & $\begin{array}{l}\text { Momento del Dere } \\
\text { el fenómeno aparec }\end{array}$ \\
\hline $\begin{array}{l}\text { Muñoz, J., } \\
\text { González, J. } \\
\text { Manzanero, } \\
\text { A., Pérez, } \\
\text { M., Alcázar, } \\
\text { M., Yela, } \\
\text { M. (2011). } \\
\text { España. }\end{array}$ & $\begin{array}{l}\text { 1. } \text { Procesos }^{10} \text { de } \\
\text { guarda y custodia } \\
-\quad \text { Procesos } \\
\text { relacionados con } \\
\text { el desarrollo del } \\
\text { régimen de visitas } \\
- \text { Procesos de } \\
\text { impugnación de } \\
\text { tutelas } \\
-\quad \text { Procesos de } \\
\text { acogimiento } \\
\text { familiar } \\
- \text { Procesos sobre } \\
\text { adopción } \\
\text { - Privación de la } \\
\text { patria potestad } \\
\text { - Nulidad civil del } \\
\text { matrimonio } \\
-\quad \text { Procesos de } \\
\text { emancipación de } \\
\text { menores de edad }\end{array}$ & $\begin{array}{l}\text { 1.Derecho de } \\
\text { Familia } \\
\text { 2. Derecho Civil } \\
\text { 3.Derecho Penal } \\
\text { 4. Derecho } \\
\text { Penitenciario, } \\
\text { Derecho Penal. } \\
\text { 5. Derecho Penal, } \\
\text { Derecho } \\
\text { Constitucional. } \\
\text { 6. Derecho } \\
\text { Penitenciario, } \\
\text { Derecho Penal, } \\
\text { derecho } \\
\text { Constitucional. } \\
\text { 7. Derecho } \\
\text { Disciplinario. } \\
\text { 8. Derecho Penal, } \\
\text { Derecho Civil, } \\
\text { Derecho, Derecho } \\
\text { de Familia. }\end{array}$ & $\begin{array}{l}\text { 1. Aplicación del } \\
\text { Derecho. } \\
\text { 2. Aplicación del } \\
\text { Derecho. } \\
\text { 3. Aplicación del } \\
\text { Derecho. } \\
\text { 4. Aplicación del } \\
\text { Derecho. } \\
\text { 5. Aplicación del } \\
\text { Derecho. } \\
\text { 6. Aplicación y } \\
\text { recepción del } \\
\text { Derecho. } \\
\text { 7. Creación, } \\
\text { Recepción y } \\
\text { Aplicación del } \\
\text { Derecho. } \\
\text { 8. Creación, y } \\
\text { Aplicación del } \\
\text { Derecho. } \\
\text { 9. Creación, y } \\
\end{array}$ \\
\hline
\end{tabular}

${ }^{10}$ Los procesos pueden ser entendidos como fenómenos, en tanto que son objetos de al percepción. Ver pies de páginas 6,7 y 8 de este trabajo, página 68 . 


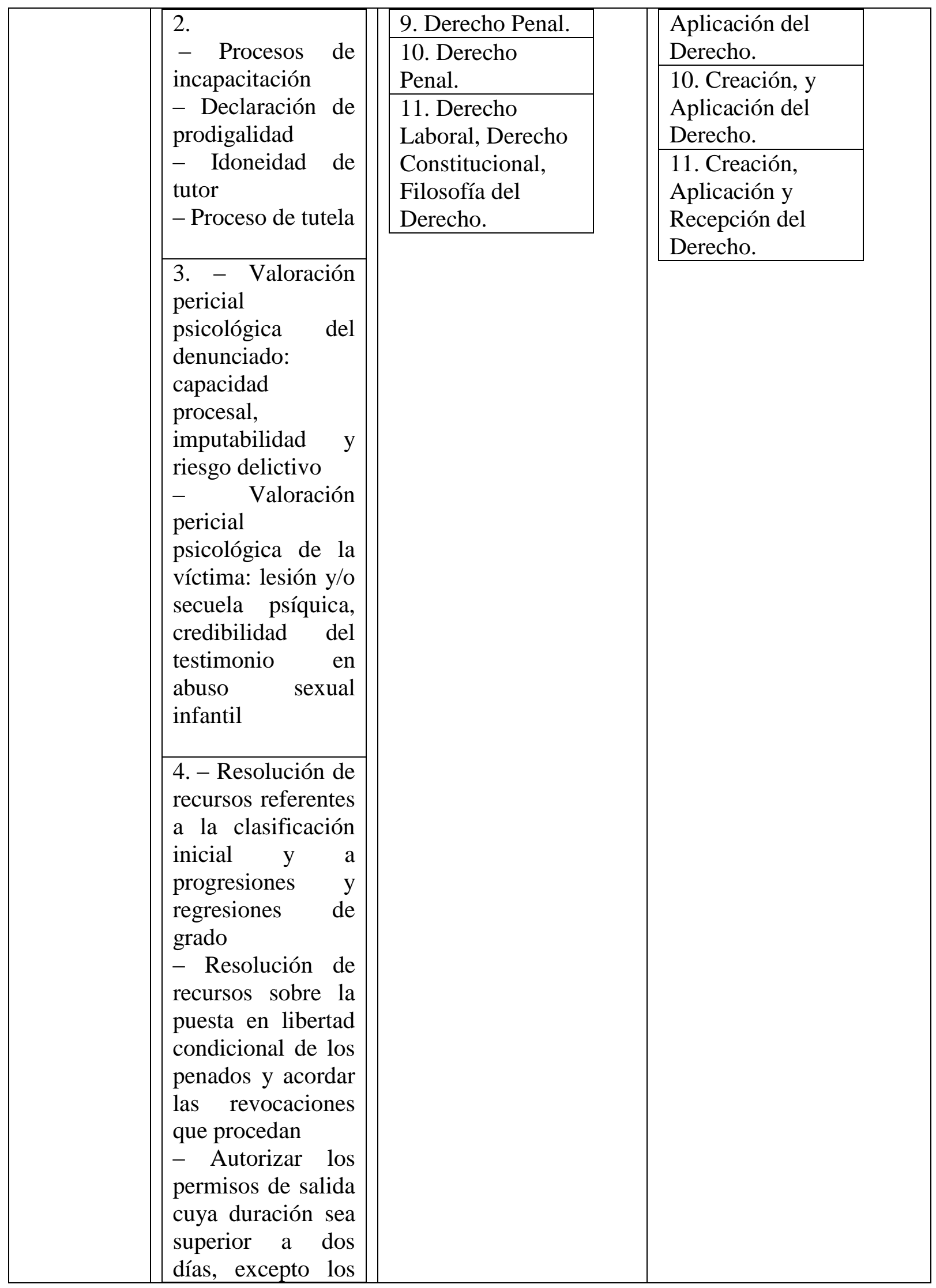




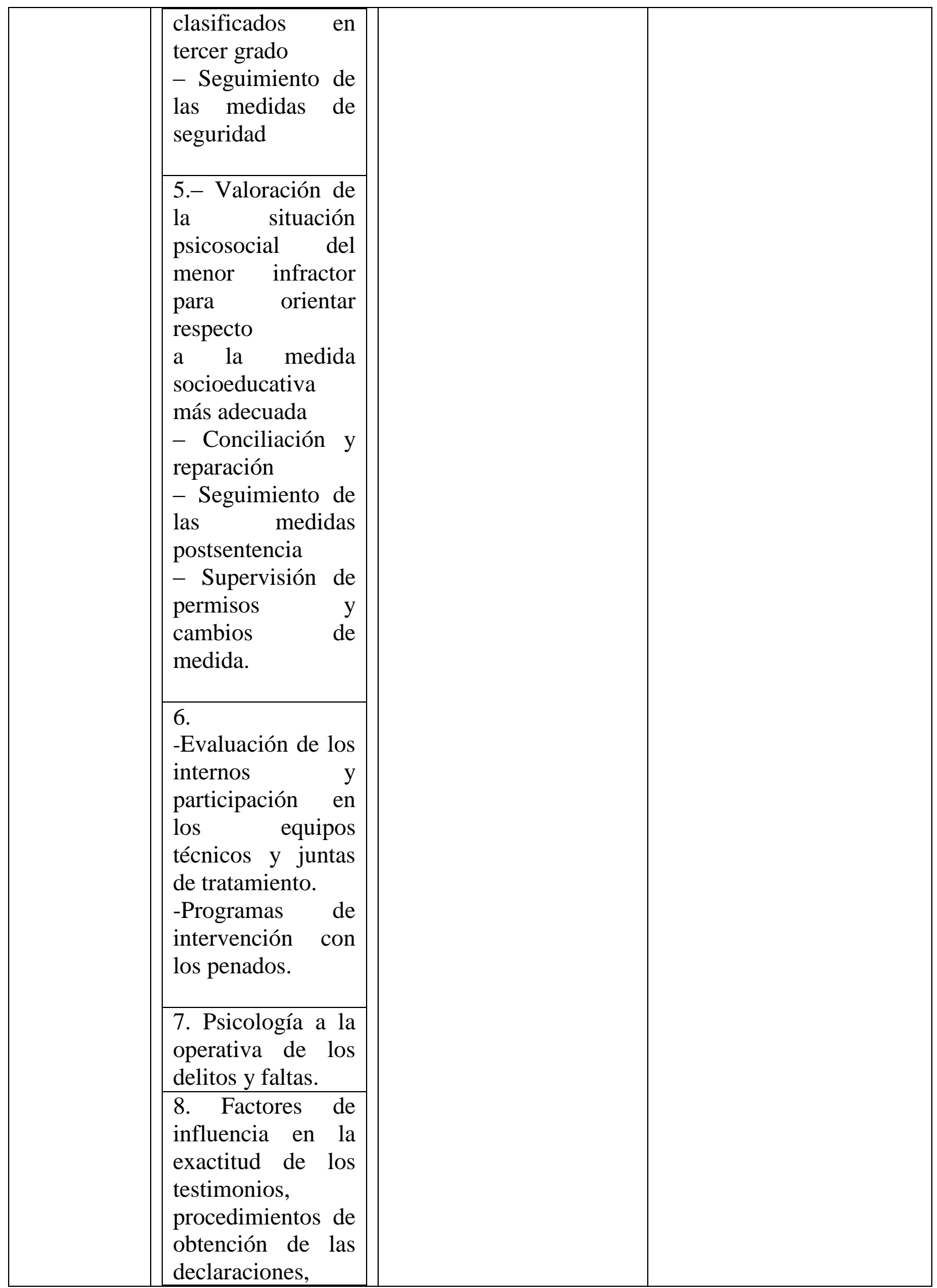




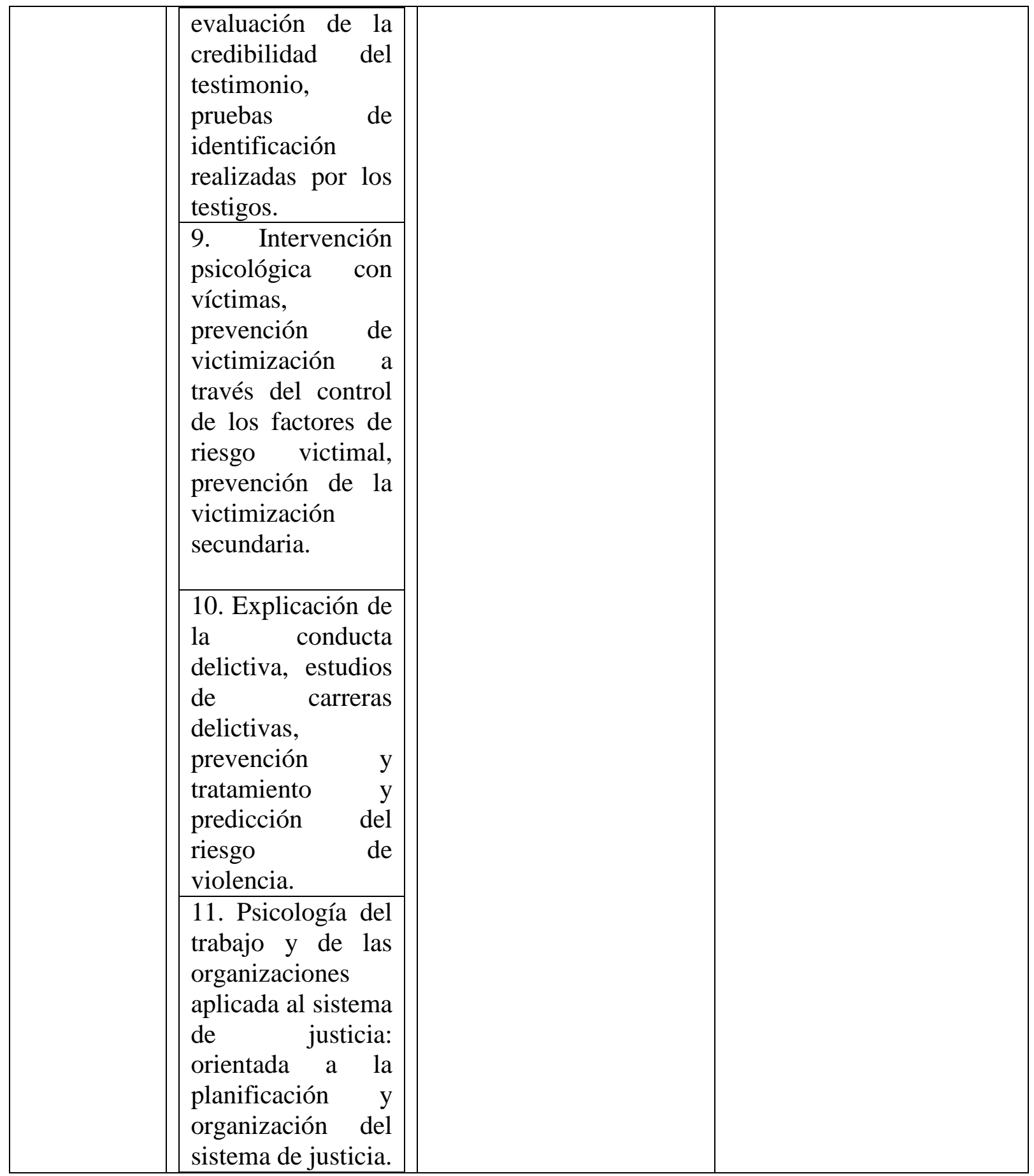

\begin{tabular}{|l|l|l|l|}
\hline $\begin{array}{l}\text { Autor/Fecha } \\
\text { de } \\
\text { publicación/ } \\
\text { Contexto }\end{array}$ & $\begin{array}{l}\text { Fenómenos } \\
\text { psicojurídicos }\end{array}$ & $\begin{array}{l}\text { Rama del Derecho a la } \\
\text { que el fenómeno } \\
\text { Psicojurídico trasciende }\end{array}$ & $\begin{array}{l}\text { Momento del Derecho en } \\
\text { el fenómeno aparece }\end{array}$ \\
\hline $\begin{array}{l}\text { Kapardis, A } \\
(2010) .\end{array}$ & $\begin{array}{l}\text { 1. Honestidad en } \\
\text { el pago de }\end{array}$ & $\begin{array}{l}\text { 1. Derecho } \\
\text { Tributario. }\end{array}$ & $\begin{array}{l}\text { 1. Creación, } \\
\text { Aplicación y }\end{array}$ \\
\hline
\end{tabular}




\begin{tabular}{|c|c|c|c|}
\hline $\begin{array}{l}\text { Europa, } \\
\text { Estados } \\
\text { Unidos. }\end{array}$ & 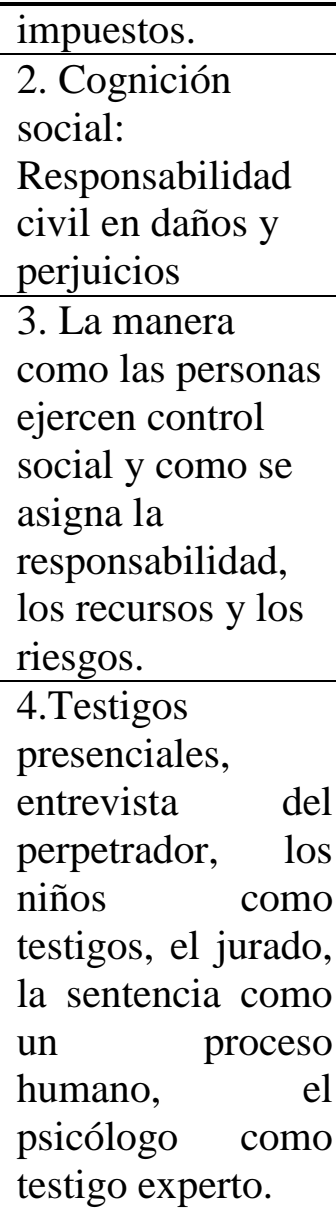 & $\begin{array}{l}\text { 2. Derecho civil, } \\
\text { Filosofía del } \\
\text { Derecho. } \\
\text { 3. Derecho } \\
\text { Constitucional, } \\
\text { Derecho Civil. } \\
\text { 4. Derecho Penal. }\end{array}$ & $\begin{array}{l}\text { Recepción del } \\
\text { Derecho. } \\
\text { 2. Creación, } \\
\text { Aplicación y } \\
\text { Recepción del } \\
\text { Derecho. } \\
\text { 3. Creación, } \\
\text { Aplicación y } \\
\text { Recepción del } \\
\text { Derecho. } \\
\text { 4. Aplicación del } \\
\text { Derecho. } \\
\end{array}$ \\
\hline
\end{tabular}

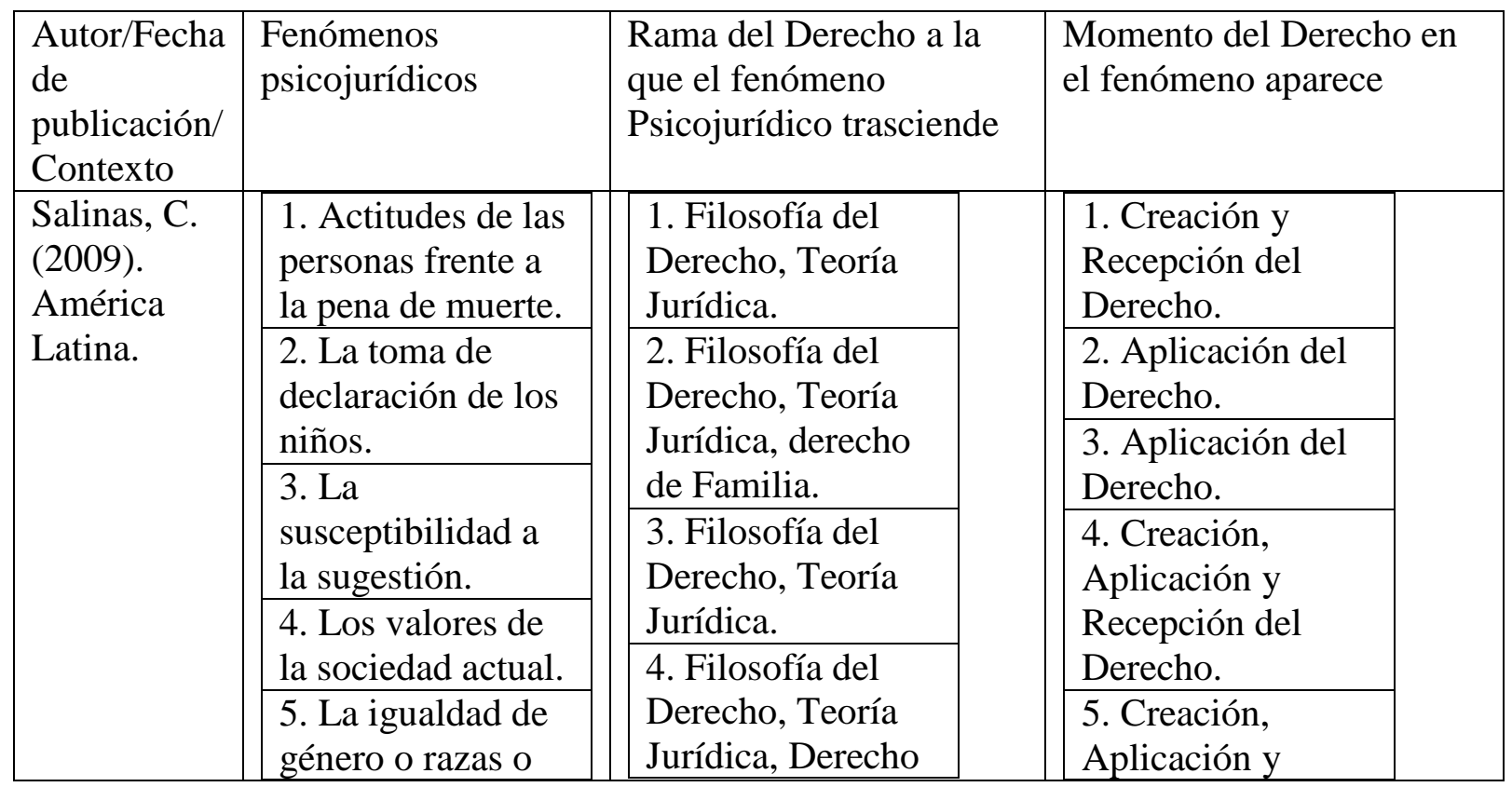




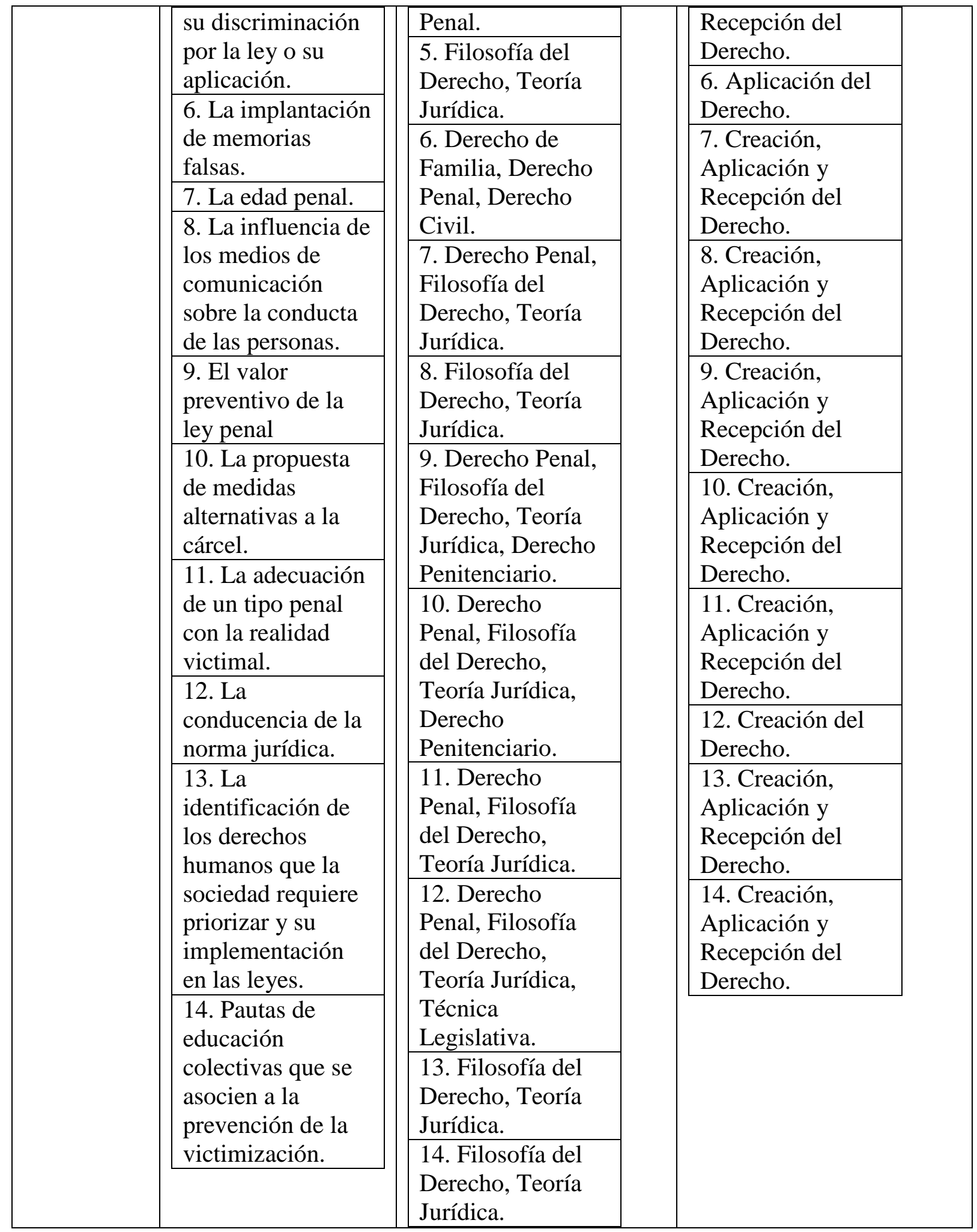




\begin{tabular}{|c|c|c|c|}
\hline $\begin{array}{l}\text { de } \\
\text { publicación/ } \\
\text { Contexto }\end{array}$ & & $\begin{array}{l}\text { Derecho a la que } \\
\text { el fenómeno } \\
\text { Psicojurídico } \\
\text { trasciende }\end{array}$ & $\begin{array}{l}\text { Derecho en el } \\
\text { fenómeno } \\
\text { aparece }\end{array}$ \\
\hline $\begin{array}{l}\text { Hare y } \\
\text { Neumann } \\
(2009) \\
\text { Canadá y } \\
\text { Estados } \\
\text { Unidos. }\end{array}$ & $\begin{array}{l}\text { La Psicopatía es considerada por los } \\
\text { autores como un "desorden de } \\
\text { personalidad que incluye un grupo de } \\
\text { características y comportamientos } \\
\text { interpersonales, afectivos, de estilo de } \\
\text { vida y antisociales. En el nivel } \\
\text { interpersonal, las personas con } \\
\text { psicopatía son ambiciosas, engañosas, } \\
\text { dominantes, superficiales } \\
\text { manipuladoras. Afectivamente son } \\
\text { planos, incapaces de formar lazos } \\
\text { fuertes con otros, carecen de empatía, } \\
\text { culpabilidad o remordimiento. Las } \\
\text { características interpersonales y } \\
\text { afectivas están ligados a un estilo de } \\
\text { vida socialmente anormal (no } \\
\text { necesariamente criminal) que incluye } \\
\text { irresponsabilidad y comportamiento } \\
\text { impulsivo, y una tendencia a ignorar o } \\
\text { violar las normas sociales y las } \\
\text { costumbres" (Hare y Neumann, 2009, p. } \\
\text { 792). }\end{array}$ & $\begin{array}{l}\text { Derecho Penal, } \\
\text { Derecho Civil, } \\
\text { Derecho } \\
\text { Penitenciario. }\end{array}$ & $\begin{array}{l}\text { Creación, } \\
\text { Aplicación y } \\
\text { Recepción del } \\
\text { Derecho. }\end{array}$ \\
\hline
\end{tabular}

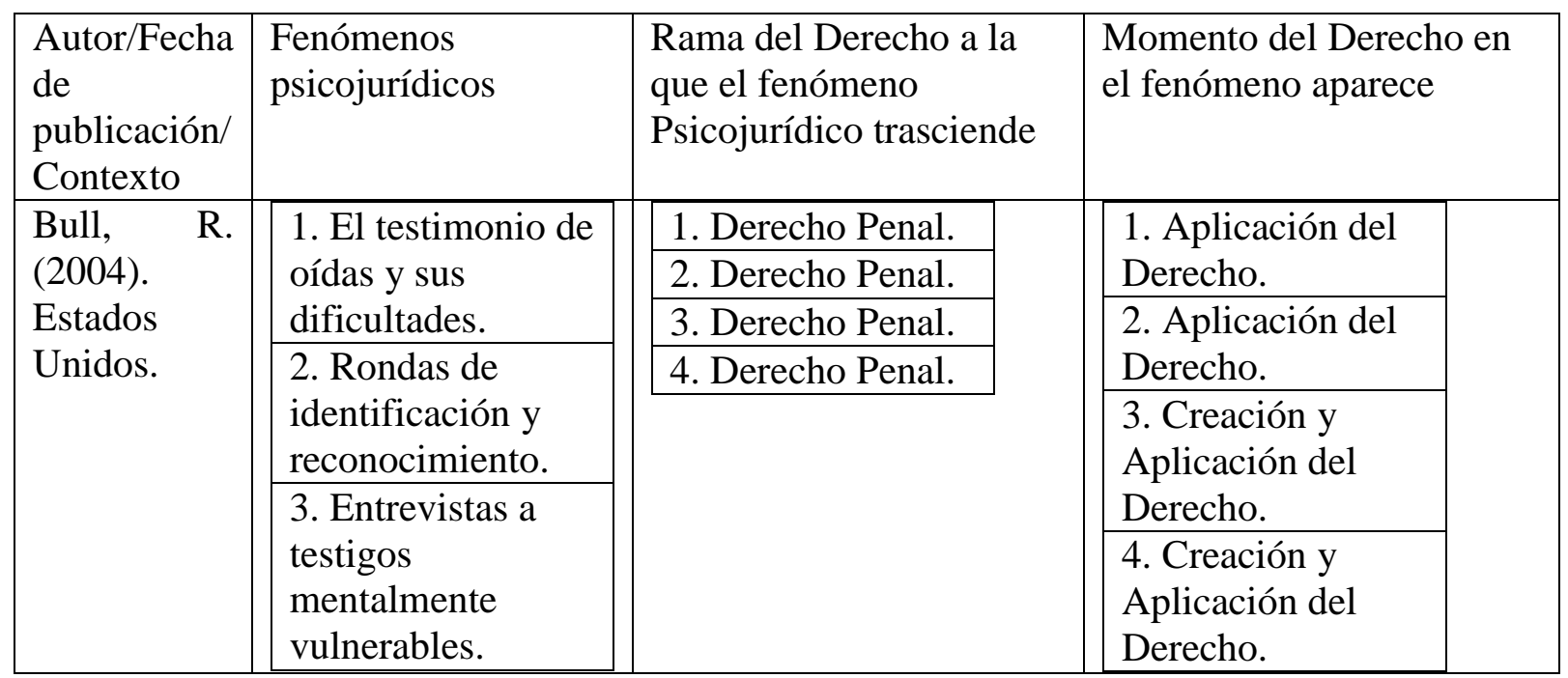




\begin{tabular}{|c|c|c|c|}
\hline & $\begin{array}{l}\text { 4. Interrogatorio } \\
\text { policial a los } \\
\text { sospechosos. }\end{array}$ & & \\
\hline $\begin{array}{l}\text { Autor/Fecha } \\
\text { de } \\
\text { publicación/ } \\
\text { Contexto }\end{array}$ & $\begin{array}{l}\text { Fenómenos } \\
\text { psicojurídicos }\end{array}$ & $\begin{array}{l}\text { Rama del Derecho a la } \\
\text { que el fenómeno } \\
\text { Psicojurídico trasciende }\end{array}$ & $\begin{array}{l}\text { Momento del Derecho en } \\
\text { el fenómeno aparece }\end{array}$ \\
\hline $\begin{array}{l}\text { Memon, A., } \\
\text { Vrij, A \& } \\
\text { Bull, } \\
\text { R.(2003). } \\
\text { Europa. }\end{array}$ & 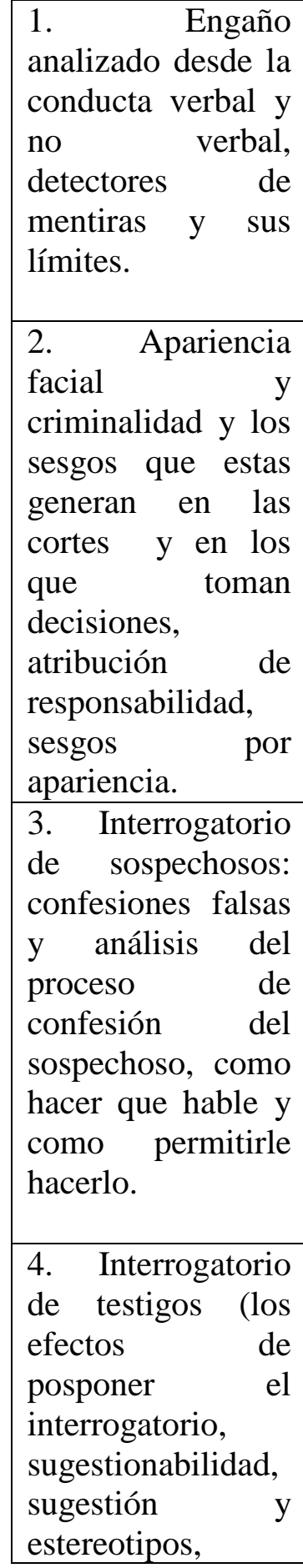 & $\begin{array}{l}\text { 1. Derecho Penal, } \\
\text { Derecho de } \\
\text { Derecho } \\
\text { Familia, Derecho } \\
\text { Laboral, Derecho } \\
\text { Disciplinario. } \\
\text { 2. Derecho Penal, } \\
\text { Derecho } \\
\text { Penitenciario. } \\
\text { 3. Derecho Penal, } \\
\text { Derecho civil, } \\
\text { Derecho de } \\
\text { Familia, Derecho } \\
\text { Laboral, Derecho } \\
\text { Disciplinario. } \\
\text { 4. Derecho Penal, } \\
\text { Derecho civil, } \\
\text { Derecho de } \\
\text { Familia, Derecho } \\
\text { Laboral, Derecho } \\
\text { Disciplinario. } \\
\text { 5. Derecho Penal, } \\
\text { Derecho civil, } \\
\text { Derecho de } \\
\text { Familia, Derecho } \\
\text { Laboral, Derecho } \\
\text { Disciplinario } \\
\text { 6. Derecho Penal, } \\
\text { Derecho civil, } \\
\text { Derecho de } \\
\text { Familia, Derecho } \\
\text { Laboral, Derecho } \\
\text { Disciplinario. } \\
\text { 7. Derecho Penal, } \\
\text { Derecho Civil, } \\
\text { Derecho Procesal, } \\
\text { Derecho } \\
\text { probatorio, } \\
\text { Derecho de }\end{array}$ & $\begin{array}{l}\text { 1. Aplicación del } \\
\text { Derecho. } \\
\text { 2. Aplicación y } \\
\text { Recepción del } \\
\text { Derecho. } \\
\text { 3. Aplicación del } \\
\text { Derecho. } \\
\text { 4. Aplicación del } \\
\text { Derecho. } \\
\text { 5. Aplicación y } \\
\text { del Derecho. } \\
\text { 6. Aplicación y } \\
\text { del Derecho. } \\
\text { 7. Aplicación y } \\
\text { del Derecho. } \\
\end{array}$ \\
\hline
\end{tabular}




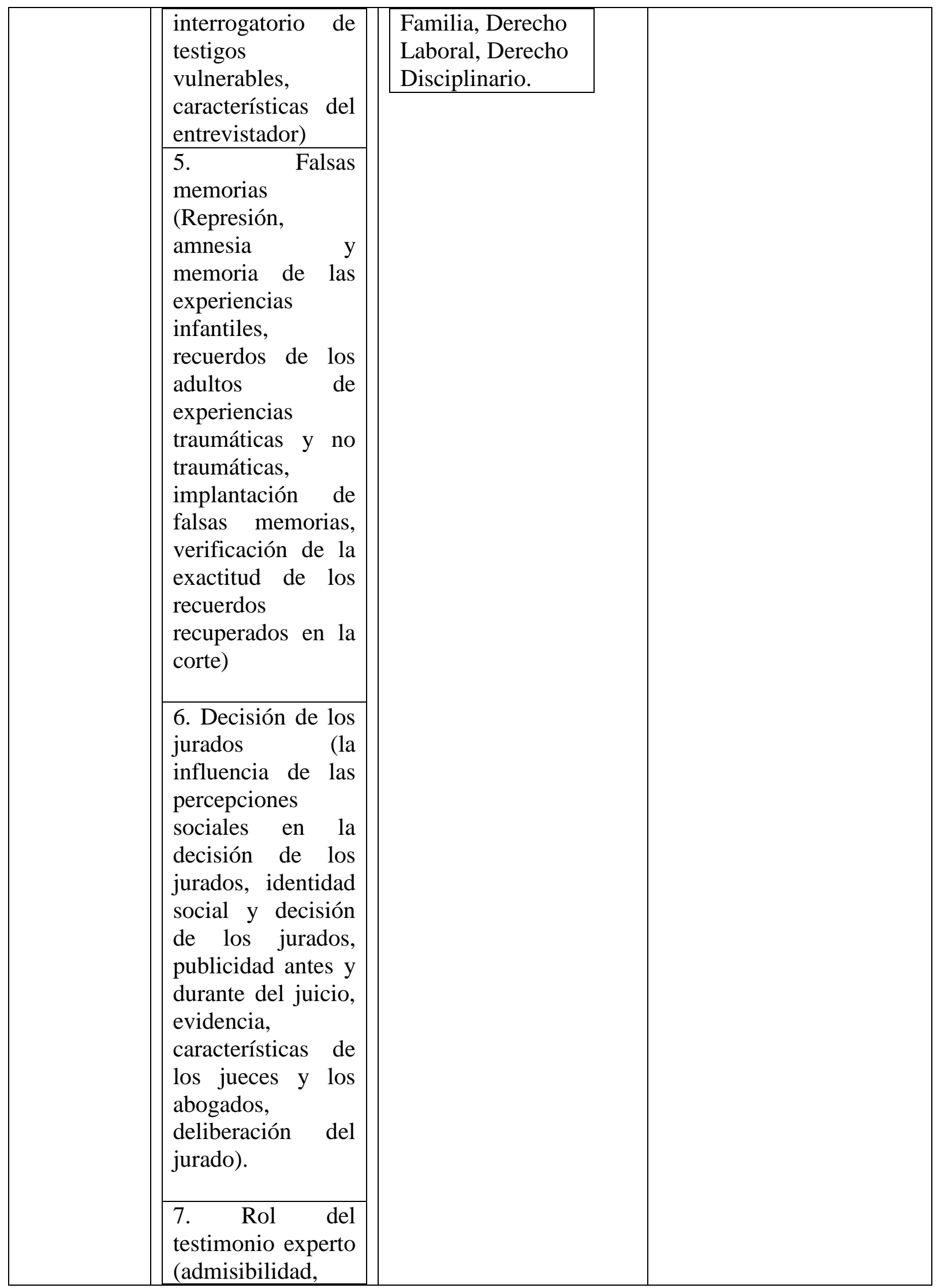




$\left.\begin{array}{|l|l|l|l|}\hline \text { impacto del } \\
\text { testimonio experto } \\
\text { sobre la decisión } \\
\text { del rurado, } \\
\text { cuestiones éticas, } \\
\text { objetividad en } \\
\text { juicios de abuso } \\
\text { de menores). }\end{array}\right] \mid$\begin{tabular}{l|l}
$\mid$ \\
\hline
\end{tabular}

\begin{tabular}{|c|c|c|c|}
\hline $\begin{array}{l}\text { Autor/Fecha } \\
\text { de } \\
\text { publicación/ } \\
\text { Contexto }\end{array}$ & $\begin{array}{l}\text { Fenómenos } \\
\text { psicojurídicos }\end{array}$ & $\begin{array}{l}\text { Rama del Derecho a la } \\
\text { que el fenómeno } \\
\text { Psicojurídico trasciende }\end{array}$ & $\begin{array}{l}\text { Momento del Derecho en } \\
\text { el fenómeno aparece }\end{array}$ \\
\hline $\begin{array}{l}\text { Thomas, F. } \\
(2000) \text {. } \\
\text { Alemania. }\end{array}$ & 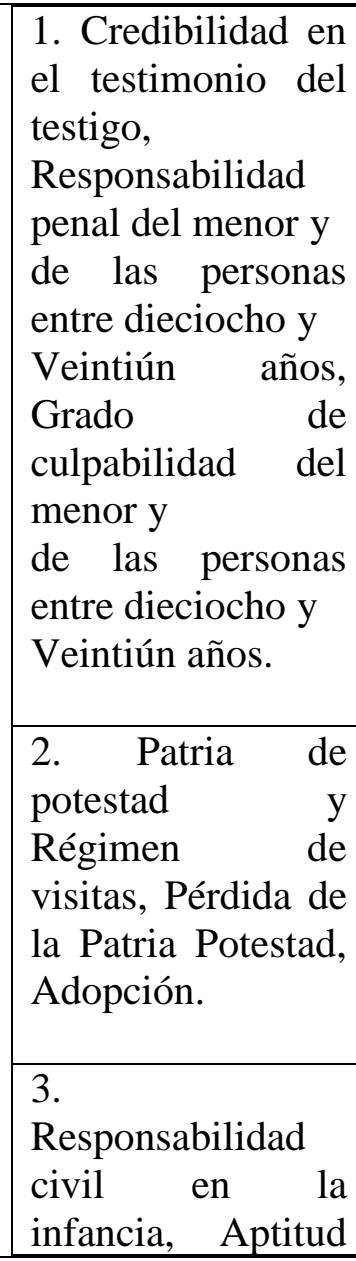 & $\begin{array}{l}\text { 1. Derecho Penal. } \\
\text { 2. Derecho de } \\
\text { Familia. } \\
\text { 3. Derecho } \\
\text { Constitucional, } \\
\text { Derecho Civil. } \\
\text { 4. En Alemania } \\
\text { adscriben estos } \\
\text { fenómenos al } \\
\text { Derecho } \\
\text { Administrativo. } \\
\text { 5. Derecho } \\
\text { Laboral. } \\
\text { 6. Derecho Penal. } \\
\end{array}$ & $\begin{array}{l}\text { 1. Aplicación del } \\
\text { Derecho. } \\
\text { 2. Aplicación del } \\
\text { Derecho. } \\
\text { 3. Creación, } \\
\text { Aplicación y } \\
\text { Recepción del } \\
\text { Derecho. } \\
\text { 4. Aplicación y } \\
\text { recepción del } \\
\text { Derecho. } \\
\text { 5. Aplicación del } \\
\text { Derecho. } \\
\text { 6. Aplicación del } \\
\text { Derecho. } \\
\end{array}$ \\
\hline
\end{tabular}




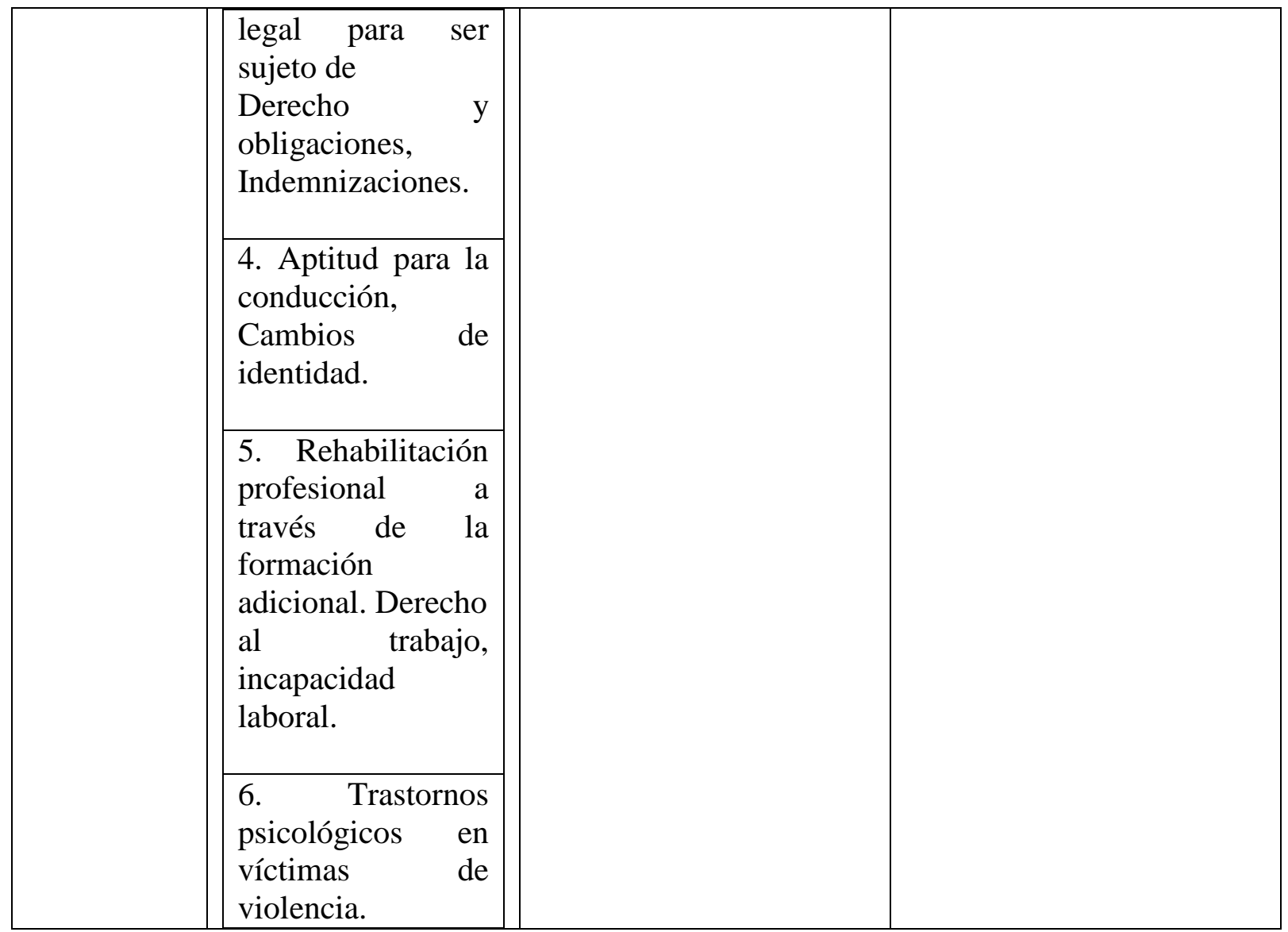

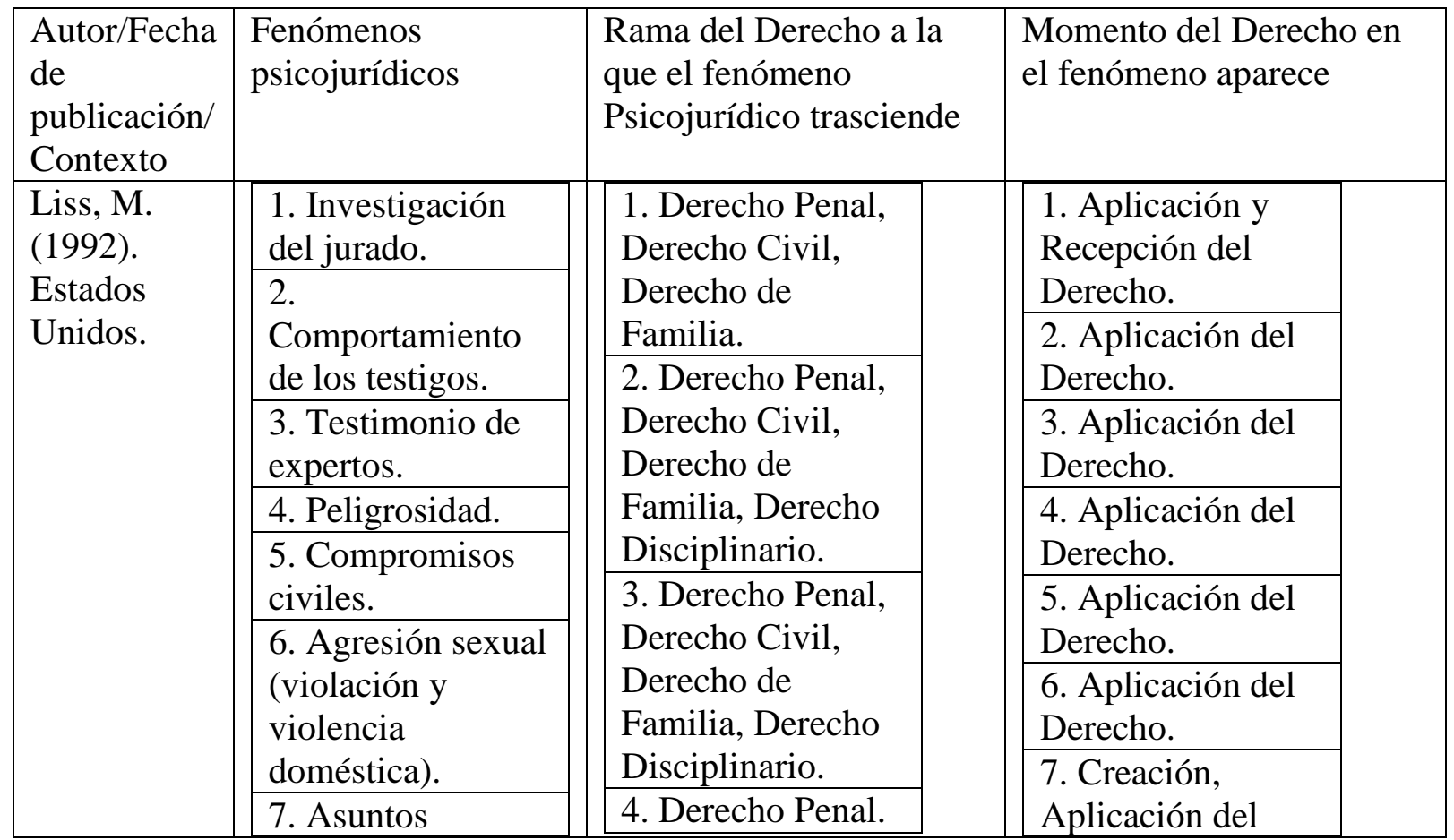




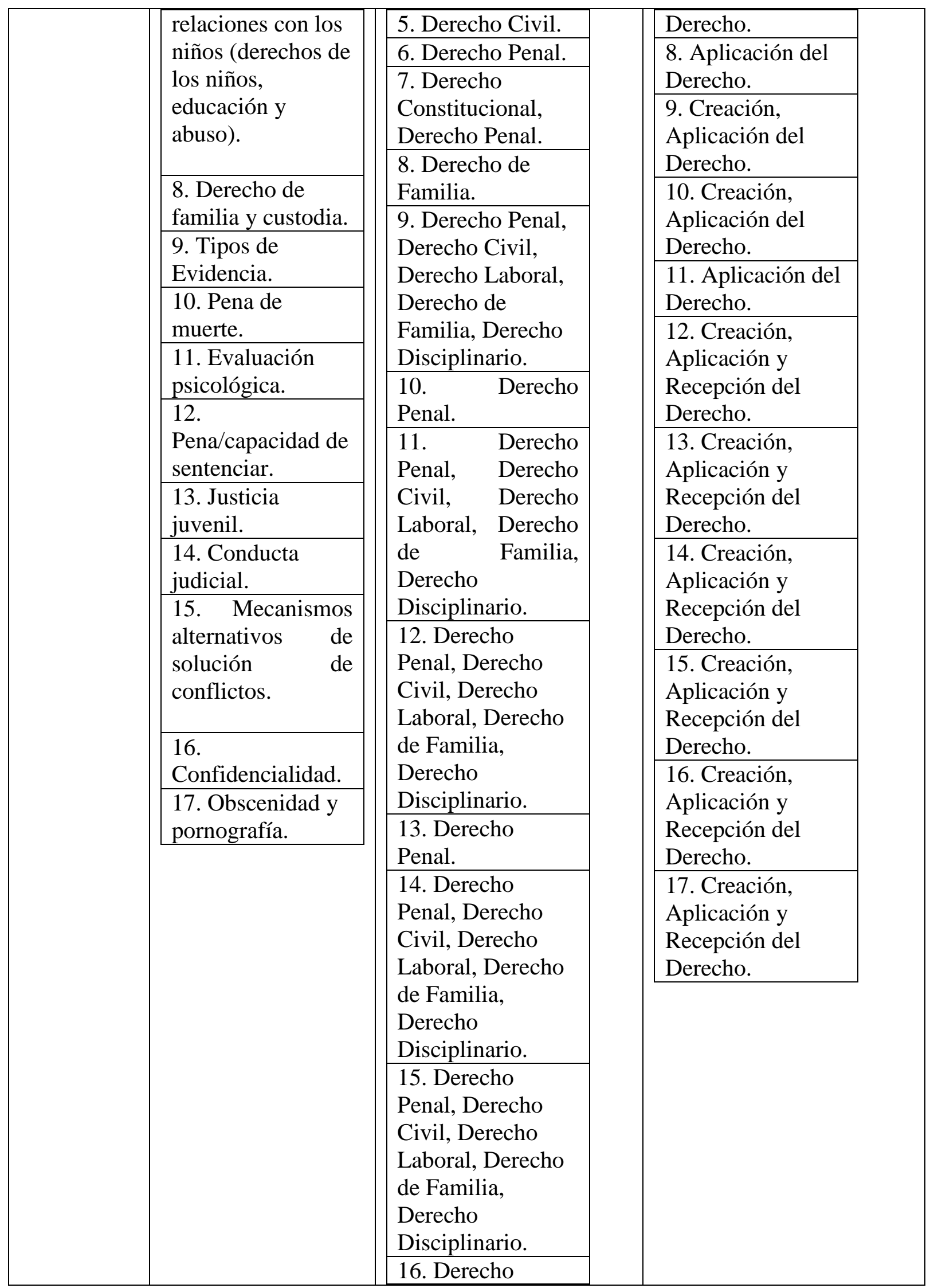




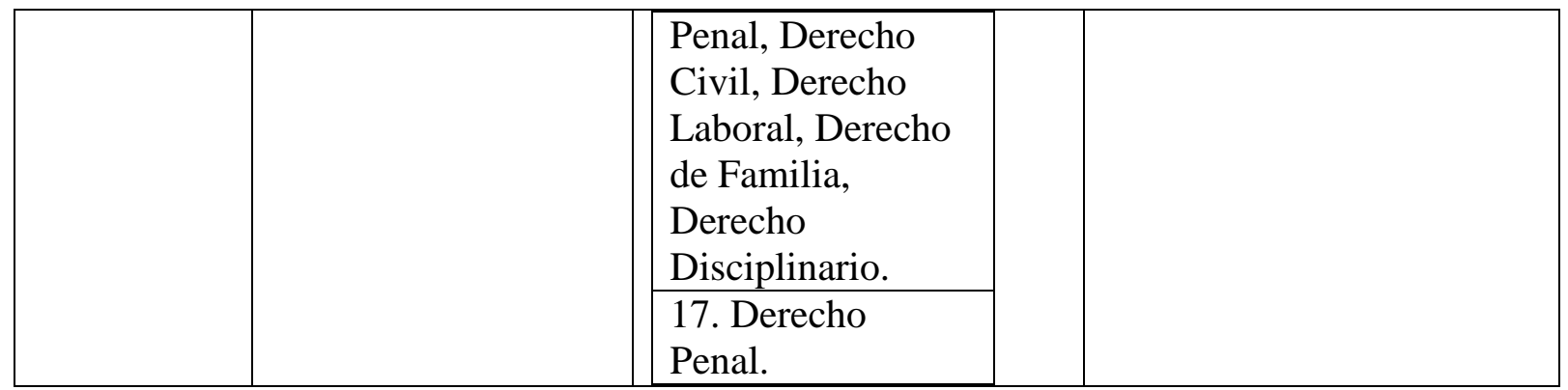

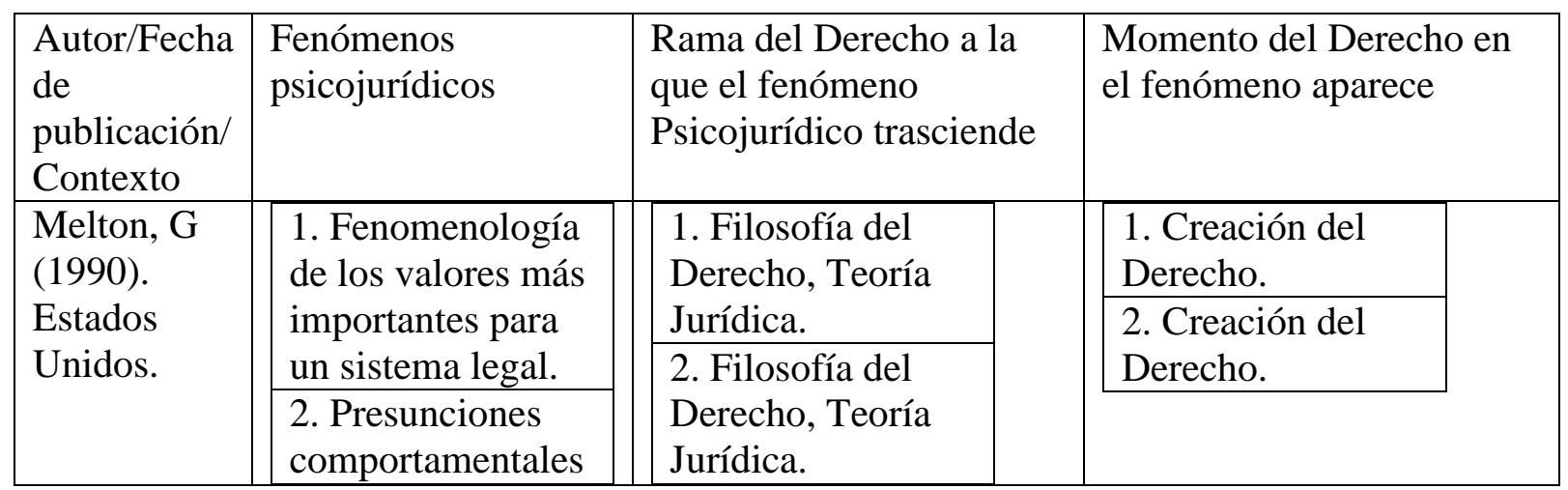

\begin{tabular}{|c|c|c|c|}
\hline $\begin{array}{l}\text { Autor/Fecha } \\
\text { de } \\
\text { publicación/ } \\
\text { Contexto }\end{array}$ & $\begin{array}{l}\text { Fenómenos } \\
\text { psicojurídicos }\end{array}$ & $\begin{array}{l}\text { Rama del Derecho a la } \\
\text { que el fenómeno } \\
\text { Psicojurídico trasciende }\end{array}$ & $\begin{array}{l}\text { Momento del Derecho en } \\
\text { el fenómeno aparece }\end{array}$ \\
\hline \multirow[t]{7}{*}{$\begin{array}{l}\text { Lloyd, S. } \\
\text { (1988). } \\
\text { Europa. }\end{array}$} & $\begin{array}{l}\text { 1. Credibilidad del } \\
\text { testimonio: } \\
\text { investigación en } \\
\text { memoria } \\
\text { percepción. }\end{array}$ & $\begin{array}{l}\text { 1. Derecho penal, } \\
\text { Derecho civil, Derecho } \\
\text { de Familia, Derecho } \\
\text { Laboral, Derecho } \\
\text { Disciplinario. }\end{array}$ & $\begin{array}{l}\text { 1. Aplicación del } \\
\text { Derecho. } \\
\text { 2. Creación y } \\
\text { Aplicación del } \\
\text { Derecho. }\end{array}$ \\
\hline & \multirow{5}{*}{$\begin{array}{lr}2 . \quad \text { Toma } & \text { de } \\
\text { decisiones } & \text { legales } \\
\text { incluyendo } & \text { las } \\
\text { sentencias } & \\
\text { judiciales, } & \text { la } \\
\text { libertad } & \\
\text { condicional y } & \text { el } \\
\text { decreto de fianza. }\end{array}$} & \multirow{2}{*}{$\begin{array}{l}\text { 2. Derecho Penal, } \\
\text { derecho penitenciario, } \\
\text { Filosofía del Derecho. }\end{array}$} & $\begin{array}{l}\text { 3. Aplicación del } \\
\text { Derecho. }\end{array}$ \\
\hline & & & 4. Aplicación del \\
\hline & & \multirow{2}{*}{$\begin{array}{l}\text { 3. Derecho de Familia. } \\
\text { 4. Derecho penal, } \\
\text { Derecho civil, Derecho } \\
\text { de Familia, Derecho } \\
\text { Laboral, Derecho } \\
\text { Disciplinario. }\end{array}$} & $\begin{array}{l}\text { 5. Creación y } \\
\text { Aplicación del } \\
\text { Derecho. }\end{array}$ \\
\hline & & & $\begin{array}{l}\text { 6. Aplicación del } \\
\text { Derecho. }\end{array}$ \\
\hline & & 5. Derecho & 7. Creación \\
\hline & $\begin{array}{l}\text { 3. Derecho de } \\
\text { familia y cuidado } \\
\text { de los menores. }\end{array}$ & $\begin{array}{l}\text { Constitucional, } \\
\text { Filosofía del Derecho, } \\
\text { Técnica Legislativa. }\end{array}$ & $\begin{array}{l}\text { Aplicación y } \\
\text { Recepción del } \\
\text { Derecho. }\end{array}$ \\
\hline
\end{tabular}




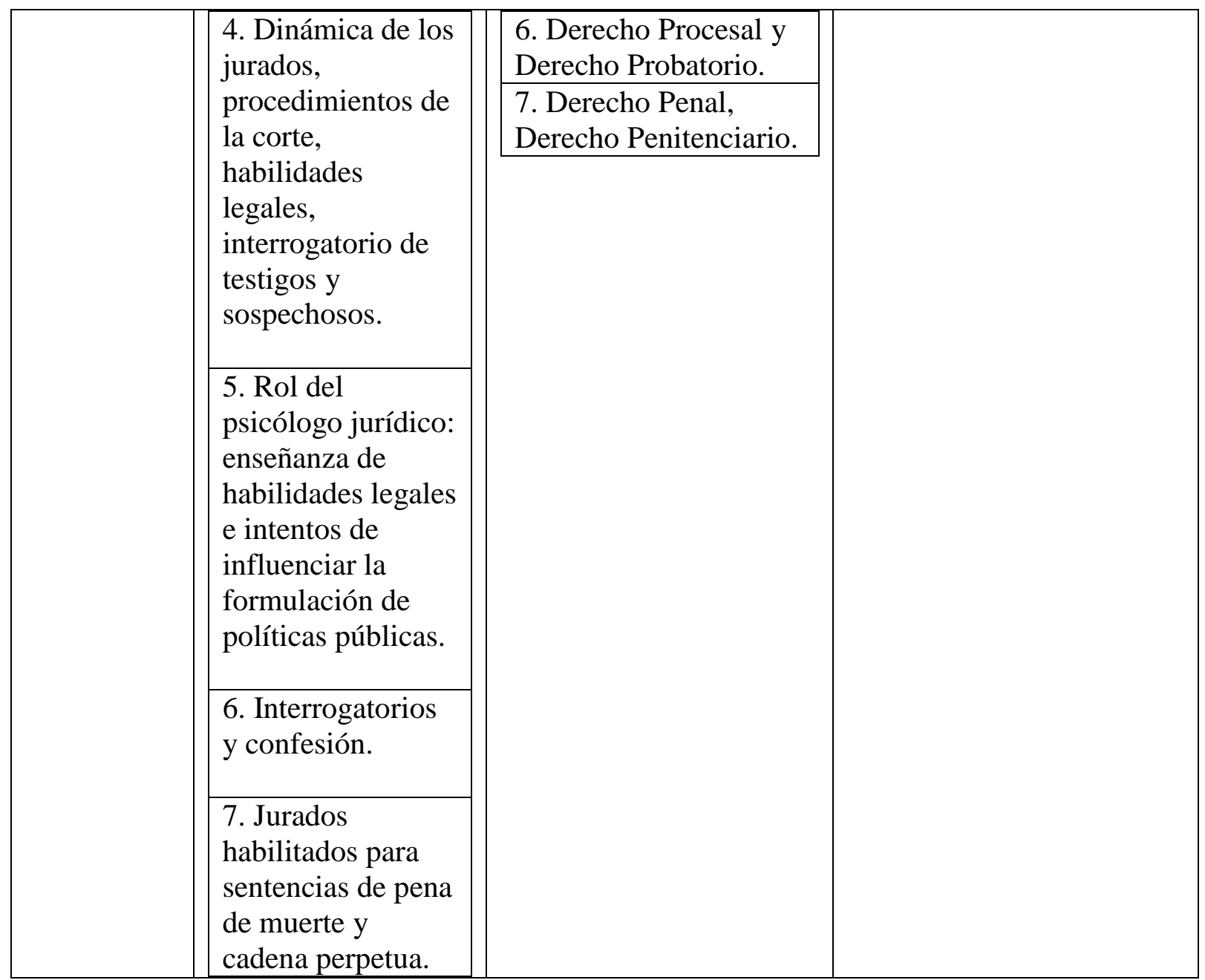

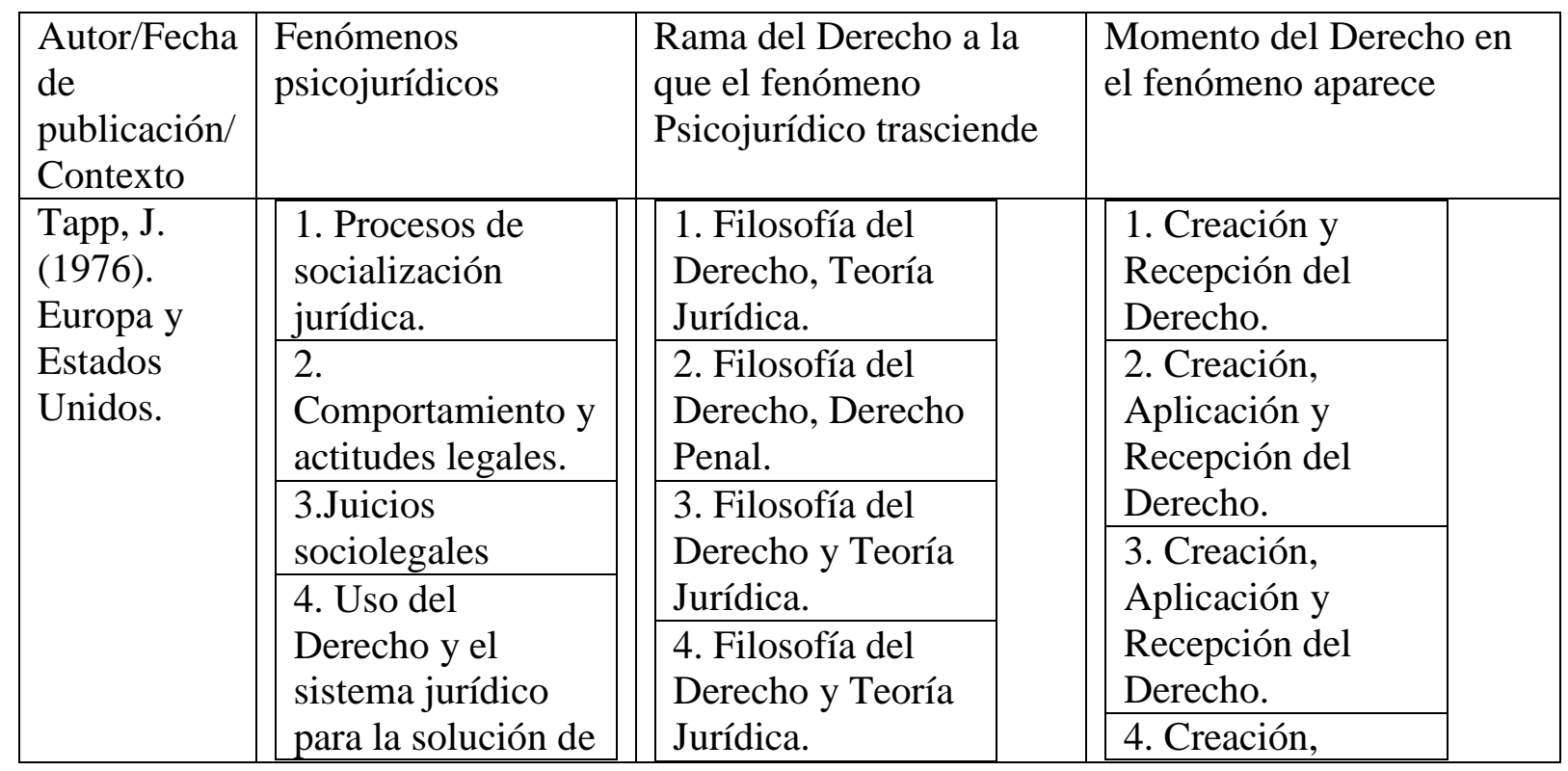




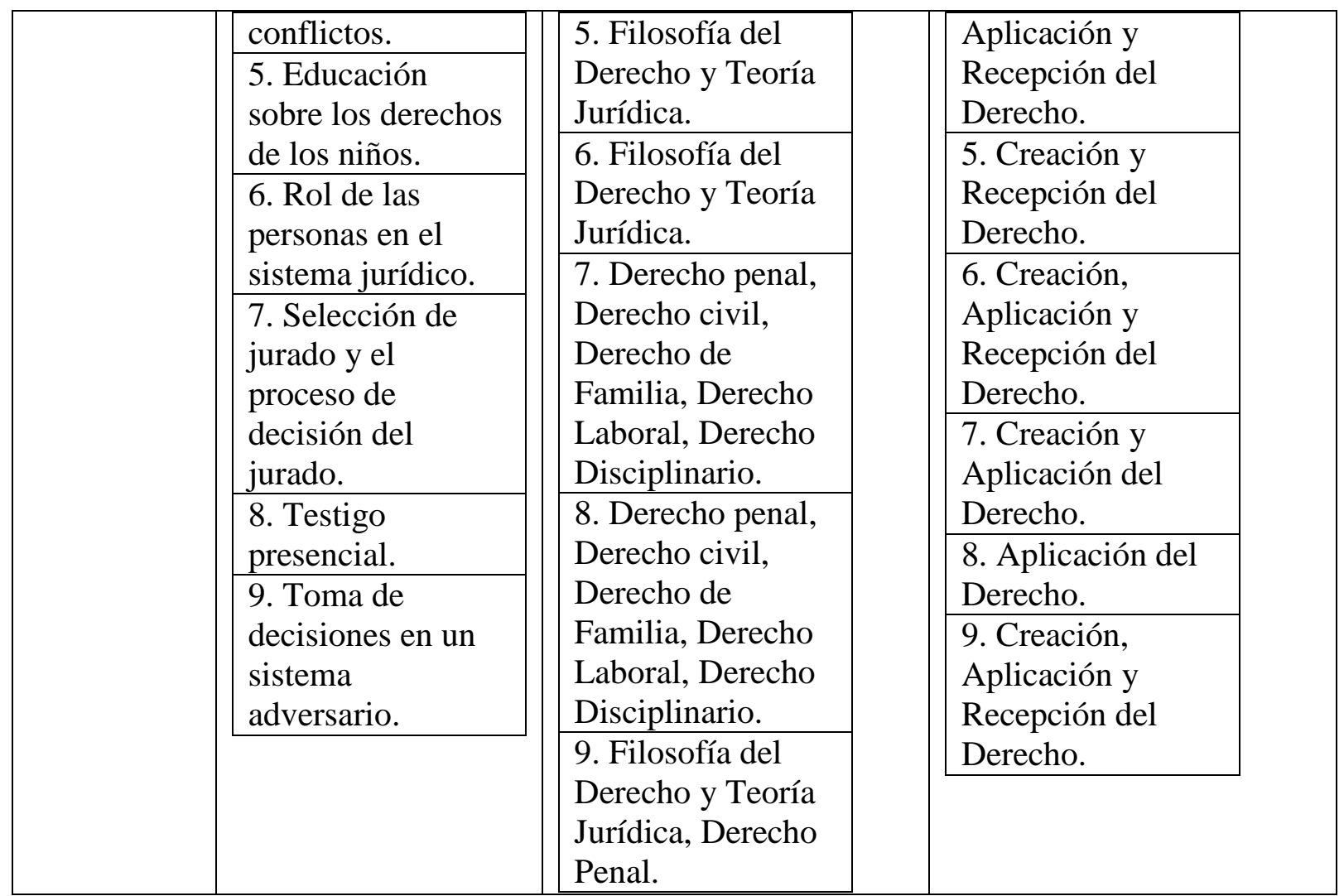

Después de la revisión de los fenómenos psicojurídicos propuestos por autores de diversas nacionalidades y diferentes épocas, se debe advertir que de acuerdo con el contexto en el que escribieron los autores, la percepción de los fenómenos jurídicos y la posición de la psicología jurídica con respecto al derecho cambia.

Por ejemplo, en el contexto español, se puede observar en el recorrido que hacen Muñoz et. al (2011) de la Psicología Jurídica en España, que la mayoría de los fenómenos jurídicos propuestos corresponden a la Psicología Jurídica forense y a la Psicología Jurídica penitenciaria, por tanto la posición que ocupa la Psicología Jurídica con respecto al Derecho en este caso, puede decirse que se limita a ser una disciplina o ciencia auxiliar del Derecho, la cual sólo está presente en el momento de aplicación del Derecho, es decir, de la norma jurídica. 


\section{LA PSICOLOGÍA JURÍDICA COMO UNA FUENTE DEL DERECHO}

Ocurre algo diferente en el caso de Kapardis (2010) que escribe para un destinatario de habla inglesa, tanto para el europeo como para el norteamericano. En este caso, los fenómenos psicojurídicos que plantea el autor permean o trascienden a todas las ramas del derecho y están presentes en los tres momentos del derecho, la creación, la aplicación y la recepción, verbigracia, la honestidad en el pago de impuestos.

También, cabe resaltar el trabajo disciplinado de Liss (1992), quien señala la importancia de pensar, investigar e intervenir desde la Psicología Jurídica, fenómenos como la pena de muerte y la conducta judicial, asuntos que una vez se estudien a profundidad desde la Psicología Jurídica pueden llegar a plantear un cuestionamiento profundo de la estructura misma del sistema jurídico anglosajón.

En el caso latinoamericano, Salinas (2009) propone unos fenómenos psicojurídicos que deben ser discutidos e investigados con urgencia en nuestro contexto, tales como la edad penal, los valores de la sociedad actual, la igualdad de razas y la influencia de los medios de comunicación en el comportamiento humano con trascendencia jurídica.

En conclusión, se puede afirmar que la Psicología Jurídica debería estar presente en los tres momentos del Derecho colombiano, tal y como se recomendó en el capítulo III de este trabajo, ya que ofrece datos con fundamento científico que la sustenta, como se puede observar en los cuadros anteriores, acerca del comportamiento humano con trascendencia jurídica, lo cual le permitiría al Derecho en Colombia crear normas jurídicas que permitan el progreso real y equilibrado de la sociedad colombiana, imponiendo un compromiso serio a los representantes de las instituciones sociales y políticas en la transformación de los contextos. 


\section{Capítulo IV. Indagación Ética o Deontológica de la Psicología Jurídica}

La indagación ética o deontológica de la Psicología Jurídica que se propone desde la metodología iusfilosófica, sintetiza o reúne los datos adquiridos en las anteriores indagaciones, es decir, en la indagación epistemológica de la Psicología Jurídica y en la indagación fenomenológica de esta ciencia o disciplina, con el objetivo de valorar la cualidad de estos datos y plantear el lugar que debe ocupar la Psicología Jurídica con respecto al Derecho, en este caso, en el Derecho colombiano.

Como se mencionó en el capítulo I de este trabajo, dos de las definiciones de la Psicología Jurídica contienen las perspectivas pragmática e intelectualista que orientó esta indagación de la Psicología Jurídica, éstas son las definiciones de Clemente (2012) y la de Díaz (2009), adicionalmente se mostró que la perspectiva de Díaz (2009) a propósito de la Psicología Jurídica plantea el mandato ético de esta ciencia, en el siguiente pensamiento: 


\section{LA PSICOLOGÍA JURÍDICA COMO UNA FUENTE DEL DERECHO}

La Psicología Jurídica, antes que un campo del conocimiento psicológico que aporta sus hallazgos y conocimientos a la Ley, debe estar al servicio de la construcción de un mejor derecho, de un derecho más cercano al anhelo de alcanzar unas condiciones de existencia que posibiliten materializar una auténtica dignidad humana. La postura ética está fundamentada en que todo conocimiento debe estar al servicio del mejoramiento de las condiciones de existencia del ser humano y principalmente de los más necesitados”. (Díaz, 2009, p. 18).

Esta perspectiva ética y pragmática de la Psicología Jurídica de Díaz (2009), se encuentra en consonancia con la propuesta de esta investigación, es decir, la de relacionar a la Psicología Jurídica y el Derecho desde la óptica de una relación causal y de recambio, en la que la Psicología Jurídica contribuya desde el corpus de su conocimiento y la investigación a construir un mejor Derecho y se posicione como una de las fuentes para la transformación de éste, con el fin de contribuir a mejorar las condiciones de existencia de los individuos y la sociedad, como lo propone Díaz (2009).

En el texto trabajo de Díaz (2009), citado anteriormente, titulado Psicología y Ley, se puede encontrar una definición de Psicología Jurídica de corte eminentemente ético, que invoca la relación interdisciplinaria entre la Psicología y el Derecho para el servicio de la humanidad:

En mi opinión, la Psicología Jurídica es el campo del conocimiento psicológico que se encarga de abordar de manera amplia, la relación interdisciplinaria entre la Psicología y el Derecho, con el fin a de aportar en la construcción de un 


\section{LA PSICOLOGÍA JURÍDICA COMO UNA FUENTE DEL DERECHO}

mejor Derecho, un Derecho más cercano a la condición y a los intereses humanos, fundamentado en el principio ético de defensa de la dignidad del vivir. Antes que ser herramienta útil de alguien, en este caso del Derecho, la Psicología y los psicólogos tenemos el deber ético de aportar para que ese Derecho tienda a defender los intereses de los más necesitados, de los excluidos, de las víctimas, de los que no son considerados en los acuerdos que más tarde se traducen en normas de alcance general en una sociedad determinada (Díaz, 2009, p.72).

Así, la Psicología Jurídica no se limita a ser una fuente interdisciplinaria del Derecho en Colombia, debería de acuerdo con esta propuesta de Díaz (2009) ser un también una fuente ética del Derecho, la cual ayude a reconstruir un Derecho que atienda y esté al servicio de la dignidad humana y aquellos que han sido excluidos por el poder y los intereses particulares de quienes hacen las normas en Colombia y de las víctimas de los conflictos políticos, armados, culturales, raciales, familiares, de género, etc.

De otro lado, desde la definición de la Psicología Jurídica de Clemente (2012), expuesta en el capítulo I, se puede observar que la Psicología Jurídica como ciencia sincrética que reúne los conocimientos de la Psicología Social y la Psicología Política, tiene unos aportes concretos y transformadores para hacerle al Derecho, no sólo en la manera en que éste se aplica, sino en las bases mismas de su estructura.

Esto se debe a que la Psicología Social afirma, desde los datos obtenidos a través de investigaciones empíricas, que el comportamiento humano está condicionado por el contexto en el que nace, crece, vive y sobrevive el individuo y los grupos humanos, lo cual 


\section{LA PSICOLOGÍA JURÍDICA COMO UNA FUENTE DEL DERECHO}

cambia radicalmente el supuesto teórico sobre el que está montado todo el derecho, según el cual, la causa del comportamiento humano es la voluntad libre del individuo.

Este aporte de la psicología social debe ser trabajado profundamente por los psicólogos jurídicos con el fin de intervenir en aquellas ramas o áreas del Derecho encargadas de teorizar acerca del comportamiento ético de los seres humanos, tales como la filosofía del derecho, la teoría jurídica y las ciencias penales.

Desde este horizonte epistemológico planteado por Clemente (2012), en el que la Psicología Jurídica es orientada por la Psicología Social y la Psicología Política, se debe volver a Haney (2002), quien afirma, en el mismo sentido de Clemente, que el modelo de comportamiento humano de la Psicología Jurídica debe ser aquél modelo propuesto por la Psicología Social, en el que el contexto y la situación del individuo determinan su comportamiento.

Pero lo que realmente deseo resaltar del texto de Haney (2002), es la invocación que hace a las ciencias de las relaciones para que ésta haga parte de las teorías que orientan el caminar de la psicología jurídica. Este llamado lo hace Haney, al citar el trabajo de Berscheid (1999) titulado The Greening of Relationship Science, que en castellano puede ser traducido como La Ecología de las Ciencias de las Relaciones, texto al que acudí de inmediato para comprender a profundidad esta particular cita de Haney (2002).

En este bello texto Helle Berscheid (1999) sugiere que por la salud de la ciencia y la humanidad, la psicología debe desarrollarse como una ciencia de las relaciones interpersonales, con el objetivo de integrar las ciencias que estudian la conducta humana y su naturaleza y cerrar la brecha entre la investigación y la práctica. Además de extender el conocimiento acerca de la conducta humana a la vida cotidiana de las personas y sus alrededores naturales. De acuerdo con la autora, 


\section{LA PSICOLOGÍA JURÍDICA COMO UNA FUENTE DEL DERECHO}

El objeto de estudio de la ciencia de las relaciones es el tejido de la relación y el ritmo oscilante de la influencia observada en la interacción de dos personas. La meta de esta ciencia es identificar las condiciones causales o responsables del ritmo de las influencias entre individuos en una relación. El ritmo de la relación es dinámico y se revela con el tiempo, esto no está en el individuo. La relación es invisible, sólo se pueden observar sus efectos. (Berscheid, 1999, p. 261)

Berscheid afirma que la ciencia de las relaciones acude a las interconexiones entre individuos más que a sus propiedades psicológicas. Por ello, “el intento de crecimiento de las ciencias sociales y de las ciencias de la conducta consiste en trascender el estudio de los individuos al estudio de las interconexiones entre individuos" (Berscheid, 1999, p. 261). El mayor potencial de la ciencia de las relaciones es mejorar la comprensión de la conducta humana y contribuir al desarrollo de la psicología social, y desde la lectura que hace Haney (2002) de esta ciencia, la ciencia de las relaciones debe impulsar el crecimiento de la psicología jurídica.

La ciencia de las relaciones también propone estudiar la influencia del ambiente en el que se construyen las relaciones y se desarrolla la conducta. Aunque es necesario de acuerdo con Berscheid (1999) mayor investigación acerca de los efectos del entorno o el contexto en las relaciones humanas.

En conclusión, la autora propone que el surgimiento de la ciencia de las relaciones es un acontecimiento saludable para la Psicología, ya que esta ciencia ayuda a las diferentes áreas de la psicología a relacionarse entre sí e integrar el conocimiento acerca de la 


\section{LA PSICOLOGÍA JURÍDICA COMO UNA FUENTE DEL DERECHO}

conducta humana y extender este conocimiento del comportamiento humano a la vida cotidiana de la gente y a sus alrededores naturales.

Entonces, desde la perspectiva Deóntica de este trabajo se hace un llamado a los psicólogos jurídicos que están de acuerdo con las propuestas de Clemente (2012) y de Díaz (2009), a investigar en el ámbito de las ciencias de las relaciones y a llevar al Derecho los hallazgos de estas investigaciones, con la intención de posibilitar el movimiento del paradigma conservador de autoridad e individualista que ha orientado la teoría y la práctica jurídica desde el siglo XIX, con el fin de contribuir a la reconstrucción del Derecho y las Instituciones Jurídicas y Políticas para de las condiciones de existencia de los seres humanos en general y especialmente de aquéllos que se encuentran excluidos o en condiciones especiales, tales como los pobres, las víctimas, los presos, los discapacitados, los niños, los ancianos, los exiliados, etc.

En este mismo sentido ético y teniendo presente que el enfoque epistemológico de este trabajo es pragmático e intelectualista, es necesario advertir que con el objetivo de

promover el cambio social a través de la relación causal y de recambio entre la Psicología Jurídica y el Derecho, la Psicología Jurídica debe enfocar conjuntamente los esfuerzos de la Psicología y el Derecho para el cambio y la transformación social (Kapardis 2010) , y superar la lucha intestina entre el conservadurismo del Derecho y la variedad de método y experimentación científica de las diversas escuelas de la psicología.

En cambio, la Psicología Jurídica debe construir un campo para la investigación que promueva el cambio social, pues como afirma Kapardis (2010), la psicología jurídica es futurista en el sentido de que reconoce la influencia del contexto social en la conducta o el comportamiento del individuo y los grupos. 


\section{LA PSICOLOGÍA JURÍDICA COMO UNA FUENTE DEL DERECHO}

Por ello, desde una perspectiva ética el deber ser de la Psicología Jurídica en Colombia consiste en ser fuente del derecho y actuar como mediadora entre las ciencias jurídicas, la psicología en general y todas sus ramas y las ciencias sociales, puesto que poner a dialogar el Derecho con las demás ciencias es de vital importancia en nuestra sociedad, ya que el derecho tiene la importante misión de construir las normas que moldean el comportamiento de los seres humanos y la Psicología Jurídica puede llevar a la reflexión a la Psicología, al Derecho y a las demás ciencias acerca de este hecho.

El segundo aspecto importante de la dimensión ética de la Psicología Jurídica corresponda al ejercicio de la actividad del psicólogo en el ámbito jurídico, a este respecto Urra, J (2010) señala entre los criterios éticos del Psicólogo Jurídico, los siguientes:

La práctica profesional y ética del psicólogo que trabaja en la Administración de Justicia, tiene la obligación de conocer en profundidad las características, conceptos y operaciones del sistema jurídico en el que actúa. En su rol profesional está obligado a evitar ofrecer conclusiones sobre las leyes, su interpretación o el sistema legal. Asimismo debe ser cauteloso haciendo predicciones sobre la conducta antisocial; expresar claramente sus recomendaciones o calificaciones, justificando en qué medida están soportadas por el estado actual de la teoría e investigación psicológica; mantener su independencia y autonomía profesional; no prestarse a situaciones confusas; informar al sujeto explorado aunque la solicitud de informe venga realizada por otra persona o institución y no olvidar nunca que el conocimiento de un delito le obliga a denunciarlo. (Urra, 2010, p. 94). 


\section{LA PSICOLOGÍA JURÍDICA COMO UNA FUENTE DEL DERECHO}

De otro lado menciona Urra (2010), que el psicólogo jurídico no debe dejarse instrumentalizar ni por el sistema de justicia, ni por los abogados, por ello no debe presentar contrainformes periciales que sólo pretendan criticar y/o desnotar un informe presentado por otro profesional. Tampoco debe el psicólogo jurídico vender corruptamente sus dictámenes, y debe hacer prevalecer en todos sus actuaciones el consentimiento informado.

En el contexto colombiano, la actividad del psicólogo está regulada en Colombia por la Ley 1090 de 2006, Código Deontológico y Bioético del Psicólogo, que prescribe para el ejercicio de la profesión psicológica, los principios de responsabilidad, competencia, cumplimientos de los estándares morales y legales, prudencia en la publicación de anuncios públicos, confidencialidad, bienestar al usuario, respeto en las relaciones personales, evaluación de técnicas, límites en la investigación con participantes humanos, y cuidado y uso de animales.

El psicólogo jurídico no sólo debe atender a los principios imperativos que las leyes éticas de su profesión les impongan, sino también al marco legal que regula el ámbito jurídico en el que están ejerciendo su profesión. A este respecto Díaz (2013) afirma que:

Es importante que el psicólogo tenga un conocimiento amplio de las disposiciones éticas y deontológicas señaladas en la ley colombiana, así como de las consecuencias legales que corresponden tanto al deber de guardar confidencialidad, como al deber de denunciar que tiene todo ciudadano colombiano, cuando se tiene conocimiento de la ocurrencia de un hecho 


\section{LA PSICOLOGÍA JURÍDICA COMO UNA FUENTE DEL DERECHO}

delictivo. La actuación del psicólogo en el escenario legal lo obliga a conocer la ley y a conducirse de acuerdo con esa comprensión (Díaz, 2013, p.219-220).

En el contexto colombiano se espera de los psicólogos jurídicos un comportamiento ético conforme al alto grado de responsabilidad, que no sólo cumpla con los deberes y principios prescritos por la normatividad ética que gobierna su profesión, sino también que se pueda predicar de ellos, valores tales como la honestidad, la responsabilidad, el compromiso, la veracidad, la sensibilidad, la aceptación de la comunidad, la reserva, la neutralidad, la aceptación de las normas, el compromiso, la discreción , la tolerancia, la lealtad y el celo por la justicia, como lo afirman Tapias et.al (sf).

Y se espera de los juristas, una mente flexible y una postura epistemológica pragmática, que les permita ceder al diálogo con los psicólogos jurídicos y reconocer que todo paradigma puede ser cambiado por el progreso real de la sociedad.

De acuerdo con Tapias et.al (sf) existen unos requerimientos profesionales específicos que cualifican al psicólogo jurídico y forense para el conocimiento de los objetos de estudio de la psicología jurídica y para el ejercicio de la misma.

Estos requerimientos tienen que ver, según los autores, en primer lugar con la cualidad y cantidad de conocimientos que posee el psicólogo jurídico, por ello se espera de él una formación profesional en psicología y postgradual en psicología jurídica y/o forense, y una educación continuada, lo que implica una participación permanente en eventos y cursos académicos en los que se presenten y estudien asuntos relacionados con la psicología jurídica y la lectura de artículos científicos en esta área del conocimiento humano. 


\section{LA PSICOLOGÍA JURÍDICA COMO UNA FUENTE DEL DERECHO}

Los conocimientos jurídicos, la cultura general, competencias básicas en inglés como segunda lengua, uso de computadores, conocimientos operativos y uso de equipos técnicos criminalísticas son otros conocimientos que se espera se puedan predicar de un psicólogo jurídico.

Para Tapias et. al. (sf)., otra cualificación del psicólogo jurídico deben ser las características relacionadas con su experiencia profesional, por ello se espera del psicólogo jurídico un curriculum vitae que demuestre por lo menos un año de trabajo profesional en instituciones jurídicas, políticas, penitenciarias, organismo internacionales u ONG que trabajen por los derechos humanos.

La tercera característica que proponen los autores hace referencia a las habilidades del psicólogo jurídico, entre ellas se presentan la habilidad para realizar diagnóstico psicológico, la habilidad psicoterapéutica, la asertividad, la habilidad para hacer empatía y para asesorar, la habilidad para diseñar y aplicar programas de salud ocupacional, capacidad para realizar entrevistas y presentar pruebas judiciales, habilidad para transmitir sus conocimientos a través de la docencia, habilidad para reaccionar frente a situaciones extremas y fluidez de ideaciones.

Dentro de las cualidades intelectuales, Tapias et. al (sf) proponen las siguientes características: inteligencia, agilidad intelectual, lógica, abstracción, asociación-relación, síntesis, análisis, capacidad de aprendizaje y de comprensión, capacidad para tomar decisiones, precepción de detalles, pensamiento crítico, capacidad incitiva, creatividad, sagacidad, capacidad de investigación, memoria verbal y visuoperceptiva. 


\section{LA PSICOLOGÍA JURÍDICA COMO UNA FUENTE DEL DERECHO}

En relación con la inteligencia emocional, se espera del psicólogo jurídico, la capacidad para enfrentar crisis personales, manejo del sufrimiento y la capacidad de adaptación a situaciones sociales.

A propósito de los rasgos personales, Tapias et. al (sf) sugieren que el psicólogo jurídico debe ser una persona activa, con alta autoestima, autónoma, afectuosa, meticulosa, emocionalmente estable, prudente, meticulosa, práctica, previsiva, serena, crítica, práctica, con capacidad de interacción y autocontrol, con tolerancia a la frustración y aceptación de la autoridad.

En el terreno de la ética, los valores que se espera poder predicar de los psicólogos jurídicos según Tapias et. al (sf) son: la lealtad, la tolerancia, la discreción, el compromiso, la aceptación de las normas, la neutralidad, la reserva, las buenas relaciones familiares, la aceptación de la comunidad, la sensibilidad, el compromiso, la responsabilidad, la veracidad y la honestidad. Además de los principios éticos prescritos por el Código ético de la APA, tales como, la beneficencia y no maleficencia, fidelidad y responsabilidad, integridad, justicia, respeto por los derechos y la dignidad de las personas ${ }^{11}$

11 De acuerdo con los Principios Éticos de los Psicólogos y Código de Conducta American Pshychological Association (APA)- Enmiendas 2010, los Principios General que orientan a los psicólogos son: Principio A: Beneficencia y no maleficencia. Los psicólogos se esfuerzan por hacer el bien a aquellos con quienes interactúan profesionalmente y asumen la responsabilidad de no hacer daño. En sus acciones profesionales, tratan de salvaguardar el bienestar y los derechos de aquellos con quienes interactúan profesionalmente y de otras personas afectadas, como asimismo el bienestar de animales utilizados en la investigación. Cuando aparecen conflictos entre las obligaciones o intereses de los psicólogos, intentan resolverlos de una manera responsable que evite o minimice el daño. Ya que los juicios y acciones científicos y profesionales de los psicólogos pueden afectar la vida de otros, están atentos a y se cuidan de factores personales, financieros, sociales, institucionales o políticos que pudieran llevar al mal uso de su influencia. Los psicólogos se esfuerzan por ser conscientes de los posibles efectos de su propia salud física y mental sobre su habilidad para ayudar a aquellos con quienes trabajan.

Principio B: Fidelidad y responsabilidad. Los psicólogos establecen relaciones de confianza con aquellos con quienes trabajan. Son conscientes de sus responsabilidades profesionales y científicas 


\section{LA PSICOLOGÍA JURÍDICA COMO UNA FUENTE DEL DERECHO}

Finalmente, proponen los autores (Tapias et. al (sf)) que para el ambiente laboral, el psicólogo jurídico debe ser capaz de adaptarse a la presión, al congestionamiento, al trabajo al aire libre, a la exposición al peligro y desarrollar tolerancia al estrés. En este mismo ámbito laboral, se espera que el psicólogo jurídico posea la capacidad auditiva y visual suficiente para realizar adecuadamente su trabajo.

Como se puede observar, la descripción que hacen del perfil profesional del psicólogo jurídico Tapias et. al (sf) es una descripción detallada pero bastante utópica de la forma de ser, hacer y pensar del psicólogo jurídico, pero es necesario advertir que la

con la sociedad y las comunidades específicas donde interactúan. Los psicólogos apoyan las normas de conducta profesional, determinan sus roles y obligaciones profesionales, aceptan la adecuada responsabilidad por sus acciones y procuran manejar los conflictos de intereses que puedan llevar a explotación o daño. Los psicólogos consultan con, se dirigen a, o cooperan con otros profesionales e instituciones según sea necesario para servir los mejores intereses de aquellos con quienes trabajan. Se preocupan por el cumplimiento ético de las conductas científicas y profesionales de sus colegas. Los psicólogos se esfuerzan por aportar una parte de su dedicación profesional a cambio de una compensación o beneficio personal muy bajos o nulos.

Principio C: Integridad Los psicólogos buscan promover la exactitud, honestidad y veracidad en la ciencia, docencia, y práctica de la psicología. En estas actividades, los psicólogos no roban, ni engañan, ni se involucran en fraude, subterfugio, o tergiversación intencional de hechos. Los psicólogos se esfuerzan por mantener sus promesas y evitan asumir compromisos poco claros o imprudentes. En situaciones en las cuales el engaño pueda ser éticamente justificable para maximizar los beneficios y minimizar el daño, los psicólogos tienen la obligación seria de considerar la necesidad, las posibles consecuencias y la responsabilidad de corregir cualquier pérdida de confianza resultante $\mathrm{u}$ otros efectos nocivos que surjan por el uso de tales técnicas.

Principio D: Justicia. Los psicólogos reconocen que la imparcialidad y la justicia permiten que todas las personas accedan y se beneficien de los aportes de la psicología, y que se equipare la calidad de los procesos, procedimientos y servicios llevados a cabo por los psicólogos. Los psicólogos ejercen un juicio razonable y toman las precauciones necesarias para asegurar que sus potenciales prejuicios, los límites de su competencia, y las limitaciones de su pericia no los conduzcan ni les permitan aprobar prácticas injustas.

Principio E: Respeto por los derechos y la dignidad de las personas. Los psicólogos respetan la dignidad y el valor de todas las personas y el derecho a la privacidad, a la confidencialidad y a la autodeterminación de los individuos. Los psicólogos tienen conocimiento de que puede ser necesario proteger los derechos y el bienestar de las personas y las comunidades cuya vulnerabilidad afecte la toma de decisiones de manera autónoma. Los psicólogos conocen y respetan las diferencias de roles, culturales e individuales, incluso las relacionadas con la edad, el género, la raza, el origen étnico, la cultura, la nacionalidad, la religión, la identidad u orientación sexual, la discapacidad, el idioma y el nivel socio-económico y consideran estos factores al trabajar con miembros de estos grupos. Los psicólogos intentan eliminar el efecto que pueda producir en su trabajo cualquier tipo de prejuicio basado en estos factores y no participan ni permiten actividades de terceros basadas en dichos prejuicios a sabiendas. 


\section{LA PSICOLOGÍA JURÍDICA COMO UNA FUENTE DEL DERECHO}

responsabilidad ética de los psicólogos jurídicos en Colombia no sólo tiene que ver con sus características personales y profesionales, sino también con el deber de contribuir a la transformación del Derecho para mejorar las condiciones vitales de los seres humanos que habitamos este territorio y especialmente de aquellos que son o han sido víctimas del algún delito.

Más allá de los límites disciplinares y profesionales, en el ámbito de la investigación psicojurídica, es inminente el trabajo y la investigación interdisciplinar y transdisciplinar entre psicólogos jurídicos, juristas, sociólogos, antropólogos, neurólogos, psiquiatras, neurocientíficos, médicos, politólogos, economistas, filósofos, humanistas, representantes de los pueblos originarios, dirigentes políticos y religiosos, , pedagogos, místicos, etc., con el objetivo de observar holísticamente fenómenos tales como el calentamiento global, las crisis migratorias humanas, el maltrato y la explotación de los niños, el poder del dinero, los problemas de género, los acuerdos de paz, la subrogación de vientre, las avances de la inteligencia artificial que cambian el paradigma de lo humano, los delitos informáticos, el trasplante de útero en mujeres y hombres, etc.

Por ello se requieren profesionales y humanos de mentes abiertas y epistemológicamente flexibles para el diálogo con el otro, profesional o no profesional, que hacen parte del mundo que habitamos y que a gritos nos pide acciones transformadoras. 
5. Capítulo V. La Psicología Jurídica como una Fuente Interdisciplinaria del Derecho en Colombia. Una propuesta de Política Pública desde la Academia

"A policy refers to a direction of activities, to a line, project, plan, program, or doctrine.

Policy has, thus, a teleological connotation, an orientation toward the future, which is considered to be a priority over the present state of affairs as well as the activity itself. In addition, policy has a normative character as a criterion in the selection of what should be realized more possible futures" (Palonen, K. 2003. pp. 175)

\subsection{Origen de la política pública.}




\section{LA PSICOLOGÍA JURÍDICA COMO UNA FUENTE DEL DERECHO}

La Universidad en Colombia sufre en la actualidad una crisis funcional que atenta contra su propia naturaleza. Se le imponen desde afuera unas funciones mercantilistas, mecánicas y burocráticas que la distraen de su labor intrínseca que es la de educar a seres humanos integrales y la de intervenir positivamente a través del conocimiento y el diálogo racional en la vida política, económica, social y cultural de la región donde ella se encuentra. La Universidad colombiana está en mora de atender al llamado de la sociedad colombiana que la reclama como "un proyecto político, social, económico y cultural, que desde su quehacer interpreta, interpela y participa de los procesos sociales con un sentido crítico y de responsabilidad, fundamentado en el desarrollo humano, social y sustentable" (Malagón, 2005, p.49).

La Universidad está legitimada en Colombia constitucional, social y culturalmente como el espacio de encuentro con la verdad de la vida y el contacto con lo real a través de la razón, los sentidos y la formulación de leyes científicas que describen el funcionamiento éste. Por ello la academia debe constituirse en un actor político que intervenga desde el ámbito conceptual, investigativo y educativo en la definición de las reglas del juego que regulan la vida cotidiana de los habitantes del territorio colombiano. En términos científico políticos la universidad debe hacer parte de las redes de colaboradores que definen las políticas que programan el futuro de la sociedad colombiana.

La Universidad Santo Tomás es el Primer Claustro Universitario de Colombia y está construida sobre la base de los principios pedagógicos, filosóficos y teológicos de Santo Tomás de Aquino, su misión humanista, científica y formadora de seres humanos integrales se ha consolidado y contextualizado a través de los 434 años de presencia en este país como una Universidad con compromiso social que forma profesionales con sentido 


\section{LA PSICOLOGÍA JURÍDICA COMO UNA FUENTE DEL DERECHO}

humanista y con identidad latinoamericana. El objetivo de la comunidad académica tomasina y el Plan General de Desarrollo 2012-2015 consiste en lograr por medio de las actividades de docencia, investigación y proyección social la vigencia y realización de los derechos de las personas a través de tres acciones propuestos por Santo Tomás, la construcción del bien común, la difusión de las posibilidades del bien común, y las relaciones de intercambio para la obtención de los bienes necesarios para la vida.

La Universidad Santo Tomás es la pionera en formalizar a partir de los programas académicos de posgrado la Psicología Jurídica como una ciencia que permite comprender e intervenir los problemas sociales e individuales de violencia y agresión que vive cotidianamente la sociedad colombiana. Como estudiante investigadora de la maestría y docente de las facultades de Derecho y Humanidades de esta alma mater se ha propuesto al largo de este trabajo, la fundamentación conceptual de la psicología jurídica como una fuente interdisciplinaria del Derecho en Colombia y ahora se concreta a través de la formulación de una política pública.

\subsection{Propuesta.}

Esta propuesta de política pública plantea fortalecer el proceso de creación de la ley y la jurisprudencia en Colombia, a través de la inclusión del conocimiento reunido por la Psicología Jurídica sobre la naturaleza humana, su realidad y los factores que determinan la formación psíquica, cultural y conductual del individuo en relación con su participación en los diferentes espacios del derecho colombiano descritos en el capítulo II de este texto.

Las teorías que sustentan esta política pública que propone incluir los conocimientos de la psicología jurídica como una fuente interdisciplinaria del derecho en Colombia 


\section{LA PSICOLOGÍA JURÍDICA COMO UNA FUENTE DEL DERECHO}

resultan de los modelos teóricos recopilados y descritos por Roth (2002) en su texto sobre formulación, implementación y evaluación de políticas públicas.

La Networks Theory, por ejemplo, justifica la intervención de la Universidad Santo Tomás a través de las investigaciones de los docentes y estudiantes de la Especialización y la Maestría en Psicología Jurídica, como un actor político legitimado desde el enfoque para participar activamente en la propuesta de políticas públicas constitutivas o de infraestructura que permitan la inclusión de los conocimientos científicos de la psicología jurídica en el proceso de creación de ley y jurisprudencia en Colombia.

Esta propuesta de política pública es de infraestructura debido a que se propone un cuestionamiento y reforma del Sistema Jurídico colombiano a partir la creación de una ley orgánica- o leyes que tratan del ejercicio de la actividad legislativa, requiere de la mayoría absoluta o mitad más uno de los miembros del Congreso para su aprobación- que prescriba la necesidad de incluir los conocimientos de la psicología jurídica las demás ciencias como fuente interdisciplinaria del derecho en Colombia, conocimientos que debe ser tenidos en cuenta al momento de crear, modificar y aplicar ley y jurisprudencia en Colombia.

La Networks Theory o la teoría de redes considera que los límites entre "lo estatal y lo no estatal son movedizas y que existe una serie de puentes entre estas dos esferas. Las políticas públicas se conciben como el resultado de interrelacioones e interdependencias entre varias instituciones, grupos e individuos que conforman una red" (Roth, 2002, p. 33). Por ello se propone el fortalecimiento de la Universidad Santo Tomás, Colombia y el Estado para logara la formulación y la implementación de la política pública que este trabajo presenta. 


\section{LA PSICOLOGÍA JURÍDICA COMO UNA FUENTE DEL DERECHO}

El impacto social de esta política podrá verse reflejado en la creación de normas jurídicas conducentes que correspondan a las necesidades reales del hombre y la sociedad colombiana, y a la solución de problemas sociales tales como la pobreza, el conflicto armado, la violencia intrafamiliar, el desplazamiento, el maltrato infantil, el terrorismo, la extorsión, el secuestro, etc. así como también el logro de la creación de normas propias y auténticas, no copias de otros ordenamientos jurídicos ajenos al contexto colombiano, contando con la asesoría de los psicólogos jurídicos expertos en la materia.

\subsection{Diagnóstico del problema socio-jurídico.}

Proponer una nueva fuente del derecho en Colombia implica fundamentar epistemológica, fenomenológica y deontológicamente la Psicología Jurídica en un espaciotiempo determinado como se realizó en los capítulos anteriores. Con esta propuesta conceptual y política se pretende abrir un nuevo espacio en el ámbito jurídico colombiano para la Academia como actor político y para la psicología jurídica y los psicólogos jurídicos a través de la justificación filosófica de esta disciplina como una fuente del Derecho tanto en el ámbito legislativo como jurisprudencial.

En efecto, la asesoría e intervención en los procesos de creación de ley en el Congreso de la República y en el de jurisprudencia de las altas cortes colombianas sería uno de los nuevos roles asignados al profesional de la disciplina en cuestión, ya que el derecho en tanto ciencia social y humana que controla la actividad social del hombre a través de postulados normativos respaldados por el poder coercitivo del Estado, debe conocer de manera integral su objeto de estudio, que es la conducta social del hombre, con 


\section{LA PSICOLOGÍA JURÍDICA COMO UNA FUENTE DEL DERECHO}

el fin de permitir el dinamismo de sí mismo determinado por el movimiento eterno del universo.

Los conocimientos de otras ciencias poco se han tenido en cuenta en el contexto real colombiano para la producción de leyes generales y jurisprudencia, puesto que la mayoría de ellas son importadas de otros sistemas jurídicos, tales como el español, el alemán y el estadounidense, y han sido incluidas en nuestro sistema a través de la metodología del Derecho Comparado.

El problema que genera la práctica del Derecho Comparado es la ineficacia e incumplimiento del sistema jurídico colombiano por parte de sus destinatarios, ya que en muchos casos no existe una correspondencia real entre las leyes del sistema y los fenómenos culturales, sociales, políticos y climáticos que suceden en la cotidianidad del individuo colombiano.

El proceso de creación de ley y jurisprudencia en Colombia permanece anclado a un atavismo ideológico eurocéntrico que le impide constituirse en una herramienta efectiva de intervención social. Por ello es necesario según lo insinúan en sus trabajos de Filosofía jurídica Carnelutti (2002) y Vanni (2008), que el Derecho se comunique con otras ciencias y disciplinas que estudian al individuo y la influencia del contexto en su proceso de formación y acción social, como lo hace la psicología jurídica.

Por ello, desde la perspectiva de la relación causal y de recambio entre la Psicología Jurídica y el Derecho que plantea esta propuesta de política pública se propone oxigenar al derecho con los datos científicos aportados por la psicología jurídica como ciencia sincrética (Clemente, 2012) para dar un paso adelante en la justicia social y la vida digna 


\section{LA PSICOLOGÍA JURÍDICA COMO UNA FUENTE DEL DERECHO}

de los ciudadanos colombianos a través de la creación de leyes y jurisprudencia adecuada al contexto nuestro.

\subsection{Causas del problema.}

1. Utilización de la metodología del Derecho Comparado para la importación de normas jurídicas al sistema jurídico colombiano de otros ordenamientos jurídicos.

2. Falta de intervención política de la Academia en la formulación de políticas públicas.

3. Desconocimiento de las necesidades económicas, políticas y culturales del pueblo colombiano en la creación, aplicación y modificación del Derecho.

4. Creación de normas jurídicas favorables sólo para determinadas clases sociales.

5. Se ignoran los saberes y los resultados de investigación publicados por ciencias y disciplinas diferentes al derecho y a la filosofía.

6. Poco conocimiento de la técnica legislativa psicológica, las ciencias del lenguaje, la lógica jurídica y las teorías acerca de la conducencia de la norma jurídica.

7. La concepción individualista del comportamiento humano sobre la cual se fundamenta el derecho desconoce la influencia del contexto en la forma de ser del individuo para el cual se crea y aplica el Derecho. 


\section{LA PSICOLOGÍA JURÍDICA COMO UNA FUENTE DEL DERECHO}

\subsection{Política pública: objetivos, escenarios, metas, estrategias, fundamentos constitucionales.}

\subsubsection{Objetivos.}

- Creación de una Ley Orgánica por parte del congreso de la República de Colombia en la que se prescriba la psicología jurídica y las demás ciencias como fuentes interdisciplinarias del derecho en Colombia.

- Proponer la utilización de las investigaciones psicojurídicas realizadas en Colombia como fuente necesaria para la creación, aplicación y modificación del Derecho.

- Crear interés en los funcionarios de las instituciones y en los profesionales en derecho y psicología de conocer la realidad política, económica y cultural de nuestro país y evitar el uso de teorías europeas para entendernos como sociedad y sujetos.

- Propiciar el conocimiento de los saberes de la psicología jurídica a propósito de la técnica legislativa psicológica, la conducencia de la norma jurídica. Además del contenido de las ciencias del lenguaje y la lógica jurídica.

\subsubsection{Escenarios.}

- Congreso de la República, Corte Constitucional, Corte Suprema de Justicia, Consejo de Estado, Colegio Nacional de Abogados, Colegio Nacional de Psicólogos. 


\section{LA PSICOLOGÍA JURÍDICA COMO UNA FUENTE DEL DERECHO}

\subsubsection{Metas.}

- Persuasión de los funcionarios de estas instituciones y profesionales del derecho y la psicología jurídica.

- Identificación de la realidad social y las necesidades de la misma, que puedan ser satisfechas a través de las herramientas jurídicas.

- Aplicación de los saberes de la psicología jurídica en las normas jurídicas y la jurisprudencia.

\subsubsection{Estrategias.}

- Creación de herramientas didácticas para la capacitación de los funcionarios públicos y profesionales del derecho y la psicología jurídica.

- Presentación de casos ejemplares a nivel mundial de normas conducentes.

- Escenarios de praxis en técnica legislativa psicológica y jurisprudencial. Para ello se presentarán en las jornadas de capacitación, cortometrajes o documentales que muestren diferentes realidades colombianas que puedan ser intervenidas por el derecho a través de las instituciones jurídicas del Estado colombiano. Posteriormente, se entregará a los participantes diferentes normas jurídicas y argumentos jurisprudenciales creados con anterioridad por expertos en técnicas legislativa y jurisprudencial. Algunas de las normas y argumentos estarán construidos conforme a los postulados de la teoría de la conducencia de la norma jurídica y otros contrarios a ésta, con el fin de que los participantes construyan con ellos leyes y 


\section{LA PSICOLOGÍA JURÍDICA COMO UNA FUENTE DEL DERECHO}

jurisprudencias que resuelvan la realidad social colombiana presentada en el documental. La actividad terminará con una autoevaluación a propósito de la conducencia de las normas elegidas y su eficacia para resolver el problema social.

\subsubsection{Fundamentos constitucionales.}

Los fundamentos normativos de esta propuesta, se encuentran en la Constitución Políticas de Colombia de 1991. Por ejemplo, los artículos 68, 69, 70 y 71 prescriben la existencia y las características de las instituciones de educación particulares, su deber dentro del Estado Social de Derecho colombiano y la posibilidad que tienen estas instituciones de fomentar y desarrollar la ciencia a través de su función educativa.

En el caso de esta propuesta, la Universidad Santo Tomás, Bogotá como institución particular o privada de educación superior puede demostrar a través de sus programas de Especialización y Maestría en Psicología Jurídica los aportes científicos que la psicología jurídica puede ofrecerle al derecho colombiano para su renovación y modificación.

Los artículos 151, 154, 155 y 156 describen las diferentes clases de leyes que integran el ordenamiento jurídico colombiano, sus características y los sujetos u organismos competentes para su creación. En nuestro caso es de especial interés el artículo 151 que señala las características de las leyes orgánicas, las cuales prescriben el ejercicio de la actividad legislativa, ejercicio que pretende ser oxigenado con la presencia de los conocimientos de la psicología jurídica.

\subsection{Actores de la política pública y estrategias de inclusión en la agenda}

\section{política.}




\section{LA PSICOLOGÍA JURÍDICA COMO UNA FUENTE DEL DERECHO}

Según Roth (2002), la materia prima para la construcción de una política pública es la identificación y la definición del problema social a intervenir y para ello afirma que:

Se necesita que personas o grupos tengan la capacidad (y el interés) de llevar la vocería del problema, y le den una definición y lo expresen en un lenguaje adaptado, para que se vuelva "público" a través de los medios de expresión pública. En este punto cabe resaltar el papel importante que pueden jugar los medios de comunicación, los círculos académicos y científicos y los actores políticos en la definición y la difusión del problema. Definir un problema obliga necesariamente a dar elementos sobre las causas y, por lo tanto, a dar soluciones posibles (Roth, 2002. Pp.59)

La Universidad Santo Tomás Colombia se propone en su Plan General de Desarrollo 2012-2015, la apertura a la comunidad nacional a través del fortalecimiento de la investigación "que relacione los desarrollos académicos con los problemas del entorno y que contribuya con su solución" (Plan General de Desarrollo 2012-2015. USTA Excelencia que transforma el país. pp. 25). De otro lado, se manifiesta en dicho documento que la Universidad Santo Tomás debe asumir la responsabilidad social constitucional, debido a que la academia es el espacio privilegiado "para pensar los problemas sociales desde la perspectiva de intereses universales y el compromiso con el bien común, reducida a la política de rendición de cuentas. (ibidem. pp. 23).

Es así como la USTA Colombia reconoce y define su horizonte de acción investigativa y de intervención socio-política para el periodo 2012-2015 y encuentra la 


\section{LA PSICOLOGÍA JURÍDICA COMO UNA FUENTE DEL DERECHO}

legitimidad de estos propósitos, en tanto que se constituye en una Institución legal, constitucional, histórica y socialmente legitimada para ingresar a las redes sociales y políticas promotoras de políticas públicas para la transformación positiva de los problemas sociales de nuestro país y nuestra región.

Este Plan general se encuentra dividido en tres ejes o temas centrales, programas y estrategias para el logro de los objetivos propuestos.

El eje de USTA y SOCIEDAD a través del programa de Investigación e innovación busca el fortalecimiento de la relación de la investigación con el sector externo, el cual está constituido por el Estado, la Empresa, la Comunidad y la Sociedad Civil. Para ello se proponen las siguientes estrategias:

- Consolidación de los campos de acción por medio del enfoque problematizador. Este enfoque permite contrastar los problemas de orden nacional, regional y local que suscitan el interés de la USTA, en el marco de sus objetivos misionales, con las fortalezas y el potencial de sus programas académicos. La identificación precisa de problemas clave del país es una condición necesaria y suficiente para orientar, consolidar y proyectar socialmente las investigaciones relevantes en los diferentes programas académicos de la USTA. La interdisciplinariedad y la transdisciplinariedad deben hacerse visibles en la consolidación de los campos de acción.

- Fortalecimiento de la relación investigación sector externo (empresa, Estado, comunidad y sociedad civil). Investigación y conocimiento se han identificado como variables importantes para el desarrollo de los países. La 


\section{LA PSICOLOGÍA JURÍDICA COMO UNA FUENTE DEL DERECHO}

experiencia internacional ha demostrado que la relación universidad empresa se constituye virtuosa para la innovación y el cambio técnico y tecnológico. La USTA tiene un acumulado histórico de saberes que permite prefigurar niveles y tipos de relación con el sector empresarial. (Plan General de Desarrollo 2012-2015. USTA Excelencia que transforma el pp.29)

Se propone por tanto que la Maestría en Psicología Jurídica a través de las asignaturas, el trabajo docente, las investigaciones de los estudiantes, los coloquios y los convenios con instituciones públicas y privadas sea la pionera en el cumplimiento de las estrategias del Plan General de Desarrollo USTA-Colombia 2012-2015, y la encargada de diseñar y proponer soluciones a los problemas psicojurídicos colombianos que se identifican y estudian a través de las investigaciones realizadas por los estudiantes de la Maestría para obtener su título de Magísteres.

Estas investigaciones de carácter científico incluyen todos los campos de acción de la psicología jurídica y los fenómenos psicojurídicos expuestos en el capítulo de la indagación fenomenológica, que van desde la psicología criminológica hasta la psicología

penitenciaria, la psicología forense, la victimología, la justicia restaurativa, la conciliación, etc con el fin de identificar las causas de la conducta antisocial, los factores que la determinan y los mecanismos de prevención e intervención, a partir de procesos empíricos reveladores de las realidades colombianas, tales como la pobreza, la violencia intrafamiliar, el terrorismo, el conflicto armado, los procesos de paz, la violencia de género, la corrupción, el maltrato infantil, etc. 


\section{LA PSICOLOGÍA JURÍDICA COMO UNA FUENTE DEL DERECHO}

Con estos resultados investigativos avalados por la academia y la comunidad científica nacional, docentes, egresados y directivos de la Maestría en Psicología Jurídica pueden proponer la capacitación y el diálogo académico, racional, político y cultural desde la óptica científica y académica con los congresistas y magistrados de las altas cortes colombianas para que se creen leyes orgánicas que prescriba la necesidad de consultar los conocimientos de la psicología jurídica y de las demás ciencias obtenidos a través de la investigación científica y la práctica psicojurídica en Colombia, antes de proponer proyectos de ley, modificar y aplicar el derecho en Colombia, para que las normas jurídicas estén conformes a la realidad de la sociedad colombiana y puedan intervenir de manera efectiva los problemas de violencia entre los individuos y grupos humanos de nuestro país.

Esto se justifica por el hecho innegable de que las nuevas tecnologías han permitido el avance en la acerca de la conducta humana y la evaluación de las funciones cerebrales, sus procesos psicológico, moleculares y genéticos, así como también mejorar el entendimiento de las interacciones recíprocas entre el cerebro, el cuerpo y el comportamiento" (Maestripieri, 2014, p. 2). Por ello es necesaria la integración interdisciplinaria de la investigación en los diferentes aspectos del cuerpo, el comportamiento y cerebro, las cuales deben ser integradas a través del diálogo interdisciplinario y llevadas al derecho para la reforma del mismo.

Nota: Teniendo en cuenta que este trabajo se presenta en el año 2016, queda abierta la puerta para revisar el rol en esta propuesta de política pública de la Universidad Santo Tomás, Colombia, a través de sus programas de Especialización y Maestría en Psicología Jurídica, a la luz del nuevo Plan General de Desarrollo de la USTA Colombia, en el marco 


\section{LA PSICOLOGÍA JURÍDICA COMO UNA FUENTE DEL DERECHO}

de la Acreditación Institucional Multicampus que ha recibido recientemente esta Universidad.

\section{Conclusiones}

Se puede concluir después de este estudio de indagación iusfilosófica con una orientación epistemológica pragmática, que la psicología jurídica como ciencia sincrética (Clemente, 2012), ofrece las teorías, los conocimientos y los datos empíricos que el derecho necesita para la transformación positiva de su propia estructura y la intervención real, limitada y justa en la sociedad colombiana, a través de la función que ejercen las instituciones políticas y las normas jurídicas.

Esta necesidad del derecho de operar con los conocimientos de la psicología jurídica implica la creación y/o fortalecimiento de la relación entre el derecho y la psicología jurídica en dos sentidos, el primero de ellos hace referencia a la relación epistemológica en la que ocurre el intercambio de la información entre ambas disciplinas o ciencias, a partir del diálogo interdisciplinario y transdisciplinario entre ellas; para lograrlo este trabajo ofrece el camino posible, es decir, prescribir desde un Ley Orgánica a la psicología jurídica y a las demás ciencias como fuentes interdisciplinarias del derecho en Colombia.

El segundo sentido de la relación entre el derecho y la psicología jurídica se refiere a la relación que se establece entre los seres humanos que trabajan, investigan, estudian, practican y ejercen estas ciencias o disciplinas, es decir, entre los juristas, los psicólogos 


\section{LA PSICOLOGÍA JURÍDICA COMO UNA FUENTE DEL DERECHO}

jurídicos, demás profesionales de las ciencias sociales y humanas, los neurocientíficos, los integrantes de las fuerzas militares y policiales, y los estudiantes de derecho, psicología, sociología, antropología, medicina, etc., ya que para lograr consolidar el trabajo interdisciplinario y transdisciplinario entre estas áreas del conocimiento humano, se requiere del entendimiento entre ambos profesionales, lo cual implica la apertura mental y la flexibilidad epistemológica de estas personas.

Otro aporte significativo de este trabajo a las ciencias jurídicas, se visualiza en la aplicación del método Iusfilosófico de indagación tripartita (epistemológica, fenomenológica y deontológica) propuesto por Vanni (2008) a la psicología jurídica, ya que se comprobó que a través de este método se pueden encontrar los aportes para el fomento de la vida que la ciencia o disciplina objeto de indagación, puede ofrecerle a la humanidad.

Finalmente, se puede afirmar que si el derecho colombiano escucha y abre las puertas a la psicología jurídica y a las demás ciencias y disciplinas para que éstas intervenga en los momentos de creación, aplicación y recepción del derecho, los beneficios para nuestra sociedad podrían contribuir al progreso real de los individuos, a través del abordaje interdisciplinario del funcionamiento actual de las instituciones sociales tales como la familia, la escuela, la iglesia y el estado, que son los contextos en los cuales nos formamos los colombianos y sobre los que el derecho puede influir de cierta manera, a partir de las normas jurídicas. 


\section{Referencias}

Berscheid, E. (1999). The Greening of Relationship Science. American Psychologist, 54, 260-266.

Bull, R. (2004). Legal Psychology in the twenty first century. Criminal Behavior and Mental Health 14, 167-181.

Carnelutti, F. (1962) Metodología del Derecho. México: Unión Tipográfica Editorial Hispano Americana

Carson, D. (2011). Investigative Psychology and Law: Towards Collaboration by Focusing on Evidence and Inferential Reasoning. Journal of Investigative Psychology and Offender Profiling 8: 74-89

Clemente, M. (2012). Papel de las Ciencias Sociales y del Comportamiento en la Ley. Una definición de Psicología Jurídica. Psicología Política. 44, 87-107

Constitución Política de Colombia (1991)

Díaz (2008). Entrevista a Fernando Díaz Colorado. Psicología Jurídica. Revista Psicología Científica.com. Tomado de: http://www.psicologiacientifica.com/fernando-diaz-colorado$\underline{\text { entrevista/ }}$

Díaz (2009). Psicología y Ley. Bogotá: Priscom. Tomado de : http://aapjyf1.tizaypc.com/contenidos/contenidos/1/PSICOLOGIA\%20JURIDICA\%20\%20DIAZ\%20COLORADO.pdf 


\section{LA PSICOLOGÍA JURÍDICA COMO UNA FUENTE DEL DERECHO}

Díaz, F (2013). Conflicto, Mediación y Conciliación desde una Mirada Restaurativa y Psicojurídica: Bogotá: Ibañez.

Erişen, E. (2012). An Introduction to Political Psychology for International Relations Scholars. PERCEPTIONS, Vol. XVIII, 3, 9-28.

Estatuto Orgánico. (2010). Universidad Santo Tomás. Colombia. http://www.usta.edu.co/images/stories/documents/generales/estatuto_organico/

Ferrater, J. (2004). Diccionario de filosofía. Tomo I. Barcelona: Editorial Ariel

Gutiérrez, C. (2010). Revisión sobre la definición de Psicología Jurídica. Revista Diversitas. Perspectiva en Psicología. Vol 6, 2, 221-235.

Haney, C (2002). Making Law Modern. Toward a contextual model of Justice. Psychology, Public Policy and Law, Vol. 8, 1, 3-63.

Hare, R. y Neumann, C. (2009). Psychopathy: Assessment and Forensic Implications. The Canadian Journal of Psychiatry, Vol. 54. N0. 12, 791-802.

Hessen, J. (1981).Teoría del Conocimiento. Madrid:Espasa-Calpe

Houghton, D. (2009). Political Psychology. Situations, Individuals, and Cases. Routledge. New York.

Hoyos, C. (1999). Manual de Psicología Jurídica. Señal Editora: Medellín.

Hoyos, C. (2013).Dilemas psicojurídicos en materia de derecho penal juvenil. Medellín: Ediciones UNAULA.

Instituto Nacional de Medicina Legal y Ciencias Forenses. (2010). Guía para la realización de pericias psiquiátricas y psicológicas forenses con fines de reglamentación de visitas y 


\section{LA PSICOLOGÍA JURÍDICA COMO UNA FUENTE DEL DERECHO}

regulación de alimentos. $\quad$ Recuperado de http://www.medicinalegal.gov.co/documents/48758/78081/G8.pdf/acb423ae-bf38-4295$\underline{9 \mathrm{e} 0 \mathrm{~d}-012382 \mathrm{~d} 55433}$

Instituto Nacional de Medicina Legal y Ciencias Forenses. (2013). Guía para la realización de pericias psiquiátricas y psicológicas forenses en adultos víctimas de delitos sexuales. Recuperado de http://www.medicinalegal.gov.co/documents/10180/241931/dg-m-guia220+\%282\%29.pdf/1fc11c74-03b7-498a-9376-48a5661e56e3

Instituto Nacional de Medicina Legal y Ciencias Forenses. (2010). Guía para la realización de pericias psiquiátricas y psicológicas forenses en niños, niñas y adolescentes presuntas $\begin{array}{llll}\text { víctimas de delitos } & \text { sexuales. }\end{array}$ http://www.medicinalegal.gov.co/documents/48758/78081/G4.pdf/bc2dd6af-202b-46ad$\underline{81 \mathrm{a} 9-\mathrm{a} 4 \mathrm{ad} 75210 \mathrm{c} 8 \mathrm{~d}}$

Instituto Nacional de Medicina Legal y Ciencias Forenses. (2010). Guía para la realización de pericias psiquiátricas y psicológicas forenses mediante autopsia psicológica en la determinación de la manera de muerte (suicida, homicida o accidental). Recuperado de http://www.medicinalegal.gov.co/documents/48758/78081/G9.pdf/bcb8ce7f-c271-420a$\underline{\text { a282-33471c99ebc9 }}$

Instituto Nacional de Medicina Legal y Ciencias Forenses. (2009). Guía para la realización de pericias psiquiátricas sobre adicción a sustancias. Recuperado de http://www.medicinalegal.gov.co/documents/48758/78081/G2.pdf/d9254b7d-fc6a-499d9577-54cc13b4d685 


\section{LA PSICOLOGÍA JURÍDICA COMO UNA FUENTE DEL DERECHO}

Instituto Nacional de Medicina Legal y Ciencias Forenses. (2009). Guía para la realización de pericias psiquiátricas sobre capacidad de comprensión y autodeterminación. http://www.medicinalegal.gov.co/documents/48758/78081/G5.pdf/866e82a6-ec8e-490f-

$\underline{94 \mathrm{~b} 3-e b a 2856 \mathrm{~b} 575 \mathrm{~d}}$

Instituto Nacional de Medicina Legal y Ciencias Forenses. (2011). Guía para la realización de pericias psiquiátricas sobre daño psíquico, con fines de indemnización, conciliación o $\begin{array}{lll}\text { reparación. } & \text { Recuperado }\end{array}$ http://www.medicinalegal.gov.co/documents/48758/78081/G14.pdf/895f332e-39a2-48c0$\underline{8 \text { bde-bb4144e } 3483 \mathrm{~b}}$

Instituto Nacional de Medicina Legal y Ciencias Forenses. (2011). Guía para la realización de pericias psiquiátricas sobre estado de salud mental del privado de la libertad-estado grave por enfermedad o enfermedad muy grave incompatible con la vida en reclusión

formal-.

Recuperado

de

http://www.medicinalegal.gov.co/documents/48758/78081/G6.pdf/36f5416b-3094-4b97-

\section{$\underline{8 \mathrm{cf} 6-12776862 \mathrm{~b} 058}$}

Instituto Nacional de Medicina Legal y Ciencias Forenses. (2010). Guía para la realización de pericias psiquiátricas sobre mantenimiento, cambio o levantamiento de medida de

seguridad en inimputables. $\quad$ Recuperado de http://www.medicinalegal.gov.co/documents/48758/78081/G3.pdf/a65a2ad2-f3ef-4873$\underline{98 \mathrm{a} 9-4615 \mathrm{f} 9 \mathrm{e} 050 \mathrm{bb}}$

Instituto Nacional de Medicina Legal y Ciencias Forenses. (2010). Guía para la realización de pericias psiquiátricas sobre patria potestad (o potestad parental) y custodia. 


\section{LA PSICOLOGÍA JURÍDICA COMO UNA FUENTE DEL DERECHO}

Recuperado $d e$

http://www.medicinalegal.gov.co/documents/48758/78081/G7.pdf/24a8ec32-0479-49e4$\underline{8 f 65-632 d f 8 a a 5 c 92}$

Instituto Nacional de Medicina Legal y Ciencias Forenses. (2011). Guía para la realización de pericias psiquiátricas sobre perturbación psíquica en presuntas víctimas de lesiones $\begin{array}{llll}\text { personales } & y & \text { otros. } & \text { Recuperado }\end{array}$ http://www.medicinalegal.gov.co/documents/48758/78081/G15.pdf/f10c3823-bb0a-4c63$\underline{\text { 9c9f-19a490393e2e }}$

Kapardis, A. (2010). Psychology and Law. Critical Introduction. Cambridge University Press, New York.

Liss, M. (1992). Psychology and Law Courses: Content and Materials. Law and Human Behavior, 16: 4. Pp. 463-471.

Lloyd, S. (1988). The Benefits of legal psychology. Possibilities, practice and dilemmas. British Journal of Psychology. 79, 419-440.

Lobato, A. (2003). Santo Tomás, arquitecto de la vida universitaria. El profesor ideal en la paideia tomista. E-aquinas (1-1), 2-26.

Maestripieri, D. (2014). Editorial: The Evolution of Interdisciplinary Research on Human Behavior, Brain and Body. Adaptative Human Behavior and Psychology 1:1-3.

Martínez, E. (2003). Educar en la virtud. Principios pedagógicos de Santo Tomás. Eaquinas (1-1), 27-72. 


\section{LA PSICOLOGÍA JURÍDICA COMO UNA FUENTE DEL DERECHO}

Melton, G (1990). Law, Science, and Humanity: The Normative Foundation of Social

Science in Law. Law and Human Behavior, Vol. 14, No. 4, 315-332.

Memon, A., Vrij, A \& Bull, R. (2003). Psychology and Law. Truthfulness, Accuracy and Credibility. England: Wiley.

Mira y López, E. (1961). Manual de Psicología Jurídica. Librería “El Ateneo” Editorial: Buenos Aires. Quinta Edición.

Modelo Pedagógico Institucional. (2010). Universidad Santo Tomás. Colombia. http://www.usta.edu.co/images/stories/documents/generales/mod_educ_pedagogico/

Morales y García (2010). Psicología Jurídica: quehacer y desarrollo. Revista Diversitas. Perspectiva en Psicología. Vol. 6, 2, 237-256.

Muñoz, J., González, J. Manzanero, A., Pérez, M., Alcázar, M., Yela, M. (2011). Psicología Jurídica en España: Delimitación conceptual, Campos de Investigación e Intervención y Propuesta Formativa dentro de la enseñanza oficial. Anuario de Psicología Jurídica. Vol. 21, pp. 3-14.

Ochoa, C. (2011). La Jusrisprudencia como técnica. Revista Jurídica: Boletín Mexicano de Derecho Comparado. Extraído el 16 de Abril de: http://www.juridicas.unam.mx/publica/rev/boletin/cont/95/art/art4.htm

Palonen,K. (2003). Four Times of Politics: Policy, Polity, Politicking, and Politicization. Alternatives: Global, Local, Political. 28, (2), 171-186 


\section{LA PSICOLOGÍA JURÍDICA COMO UNA FUENTE DEL DERECHO}

Pérez, H. (2007). Manual de Técnica Legislativa. Buenos Aires : Konrad Adenauer Stiftung.

Plan General de Desarrollo 2012-2015. USTA Excelencia que transforma el País. $\begin{array}{lll}\text { Universidad Santo } & \text { Tomás. Colombia. }\end{array}$ http://www.usta.edu.co/images/stories/documents/generales/pgdesarrollo2012-2015/

Política Curricular. (2004). Universidad Santo Tomás. Colombia. http://www.usta.edu.co/images/stories/documents/generales/p_curricular/

Proyecto Educativo Institucional-PEI-. (2004). Universidad Santo Tomás. Colombia. http://www.usta.edu.co/images/stories/documents/generales/pei/

Proyecto Investigativo Institucional-PROIN- (2005). Universidad Santo Tomás. Colombia. http://www.usta.edu.co/images/stories/documents/generales/proin/

Rodríguez, C. (2007). Crítica epistemológica a los sistemas cerrados y jerárquicos de la Modernidad. Análisis del espacio virtual organizacional e institucional desde el pensar complejo. Utopía y Praxis Latinoamericana. Año 12. No. 38, 83-98.

Roth. A. (2002) Políticas públicas formulación, implementación y evaluación. Bogotá: Ediciones aurora

Salinas, I. (2009). Teoría y Práctica Psicológica en el Ámbito Jurídico. Hacia una definición del concepto de psicología jurídica. Editorial EOS, Madrid.

Schneider, F., Gruman, J., \& Coutts, L (2012). Applied Social Psychology: Understanding and Addresing Social and Practical Problems. Segunda edición. SAGE Publications. California. 


\section{LA PSICOLOGÍA JURÍDICA COMO UNA FUENTE DEL DERECHO}

Sullivan, K. (2002). Foreword: Interdisciplinarity. Michigan Law Riview. Vol 100, pp. 1217-1226.

Tapias, A., Gutiérrez C. Saade, Y., De la Torre, A., Masip, J., LaCalle, J., Henriquez

Bilbao, G., Valencia, I., Amichetti, G. y García López, E., (sf). Perfil profesional del psicólogo jurídico y forense. Consultado en septiembre de 2015 en

http://psicologiajuridica.org/psj50.html

Tapp, J. (1976). Psychology and the law: An Overture. Annual Review of Psychology. Pp. 258-404.

Thomas, F. (2000) Psicología Jurídica en Alemania. Anuario de Psicología Jurídica. Pp. $157-171$

Urra, J (2010). Criterios Éticos para los Psicólogos Jurídicos. Anuario de Psicología Jurídica, 20, 93-104.

Vanni, I. (2008) Filosofía del Derecho. Bogotá: Leyer 